Florida International University FIU Digital Commons

$7-1-2015$

\title{
Complementary and Alternative Medicine and Japanese Chronic Disease Patients' Quality of Life and Perceived Stress
}

Hideaki Tanaka

Florida International University, htana003@fiu.edu

DOI: $10.25148 /$ etd.FIDC000079

Follow this and additional works at: https:// digitalcommons.fiu.edu/etd

Part of the Alternative and Complementary Medicine Commons, and the Other Public Health Commons

\section{Recommended Citation}

Tanaka, Hideaki, "Complementary and Alternative Medicine and Japanese Chronic Disease Patients' Quality of Life and Perceived Stress" (2015). FIU Electronic Theses and Dissertations. 2220.

https://digitalcommons.fiu.edu/etd/2220 


\section{FLORIDA INTERNATIONAL UNIVERSITY}

Miami, Florida

\section{COMPLEMENTARY AND ALTERNATIVE MEDICINE AND JAPANESE \\ CHRONIC DISEASE PATIENTS' QUALITY OF LIFE AND PERCEIVED STRESS}

A dissertation submitted in partial fulfillment of

the requirements for the degree of

DOCTOR OF PHILOSOPHY

in

PUBLIC HEALTH

by

Hideaki Tanaka

2015 
To: Interim Dean Mark L. Williams

R.Stempel College of Public Health and Social Work

This dissertation, written by Hideaki Tanaka, and entitled Complementary and Alternative Medicine and Japanese Chronic Disease Patients' Quality of Life and Perceived Stress, having been approved in respect to style and intellectual content, is referred to you for judgment.

We have read this dissertation and recommend that it be approved.

$\begin{array}{r}\text { Tan Li } \\ \hline \text { Consuelo Beck-Sague } \\ \hline \text { H. Virginia McCoy, Major Professor }\end{array}$

Date of Defense: July 1, 2015

The dissertation of Hideaki Tanaka is approved.

\author{
Interim Dean Mark L. Williams \\ R.Stempel College of Public Health and Social Work
}

Dean Lakshmi N. Reddi University Graduate School

Florida International University, 2015 


\section{ACKNOWLEDGMENTS}

I would like to sincerely thank my dissertation committee members Dr. Elena

Bastida, Dr. Consuelo Beck-Sague, Dr. Tan Li, for their constructive feedback, time and support in organizing this dissertation.

I would like to extend my sincere appreciation towards my committee chair Dr. Virginia McCoy, thank you for your patience, encouragement, and support. I am deeply grateful to have had you as my major professor.

I would also like to thank Dr. Tomoaki Kimura of the MOA Health Science Foundation, thank you for allowing me to analyze your collected data. Staff and physicians of MOA Tokyo Ryoin, I thank you for your help in the collection of the qualitative interview data. I would like to acknowledge MOA International for funding me and allowing me the opportunity to study at FIU.

Participants of the qualitative interview, I would like to thank you for generously accepting to participate in my study. Finally I would like to thank my family for their consistent support throughout the years at FIU. 


\begin{abstract}
OF THE DISSERTATION
COMPLEMENTARY AND ALTERNATIVE MEDICINE AND JAPANESE

CHRONIC DISEASE PATIENTS' QUALITY OF LIFE AND PERCEIVED STRESS
\end{abstract}

\author{
by
}

Hideaki Tanaka

Florida International University, 2015

Miami, Florida

\title{
Professor H. Virginia McCoy, Major Professor
}

This mixed methods study examined the association between the frequency of five lifestyle-related complementary and alternative medicine (CAM) practices and perceived quality of life (QOL) and stress among patients in Japan diagnosed with chronic disease, and also examined why patients decided to receive Okada purifying therapy [(OPT) biofield therapy]. Data from 1,190 patients were analyzed using bivariate and multiple regression analysis, followed by analysis of one-on-one in-depth interviews conducted among 25 patients on reasons why patients decided to practice OPT. Grounded theory methodology was used to analyze transcribed interview data.

Results of multiple regression analysis indicated that engaging in arts and cultural activities and exercise was associated with a decrease in perceived stress, while arts and cultural activities, exercise, consumption of organic (additive-free) food, and practice of OPT were associated with increased QOL. Gender weakly moderated the effects of arts and cultural activities on stress but not on QOL, and gender did not have any moderating effects on the association of OPT with either stress or QOL. 
One theme, five clusters, and 13 categories emerged from the qualitative analysis. Feelings of desperation due to unrelieved symptoms of disease seemed to be the principal reason for most patients' practice of OPT. Other reasons were perception of the limits of conventional medicine in being able to treat patients' disease, dissatisfaction with conventional medicine, positive relationship with staff and doctors of the integrative medicine clinic providing OPT, and benefits of OPT, among others.

Although many patients expressed feeling doubts towards the practice of OPT at first, many seemed satisfied with the results of the practice, mainly because they were able to manage their symptoms and gain a sense of control. This may have led to an increase in QOL. The mixed methods design was able to inform the interpretation of the association of OPT with reported increase in QOL in the quantitative phase of the research. 


\section{TABLE OF CONTENTS}

CHAPTER

PAGE

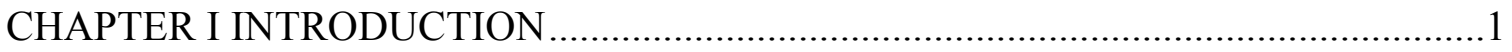

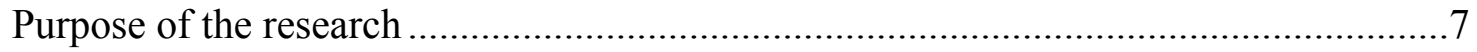

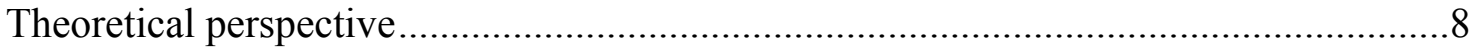

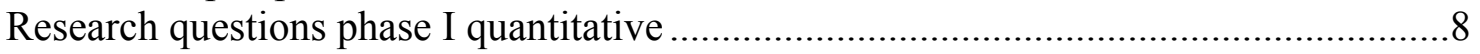

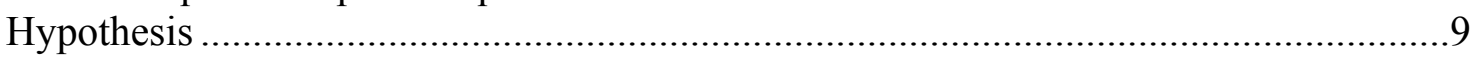

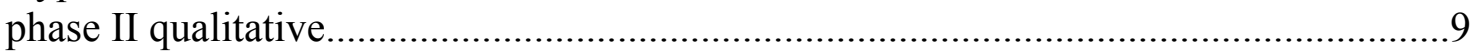

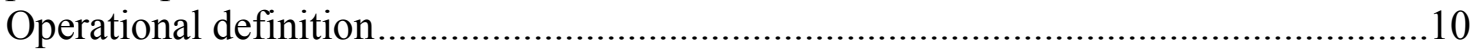

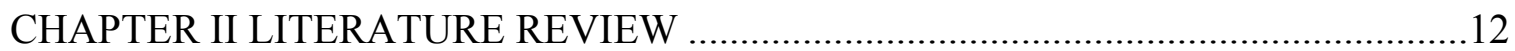

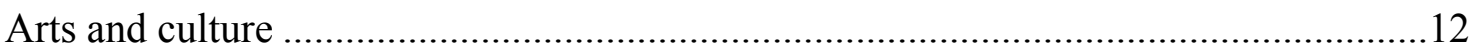

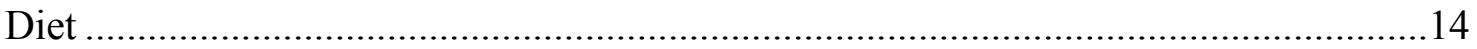

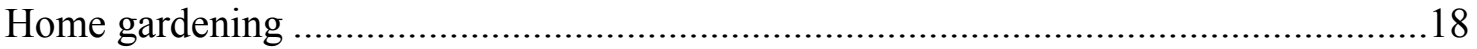

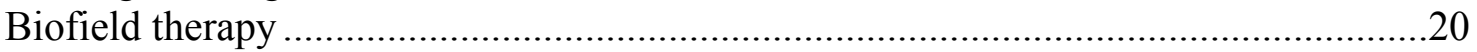

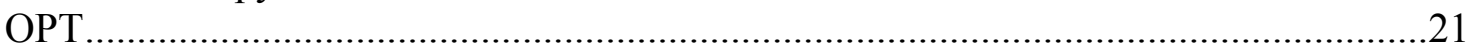

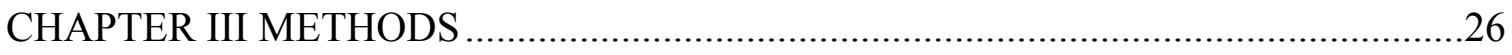

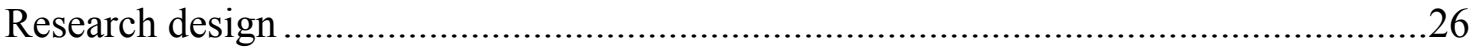

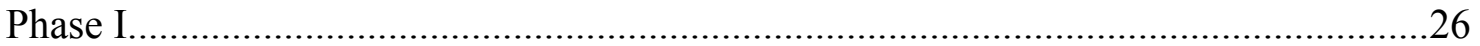

Inclusion and exclusion criteria from the parent study..............................................28

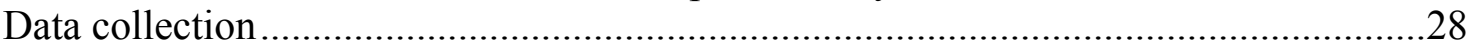

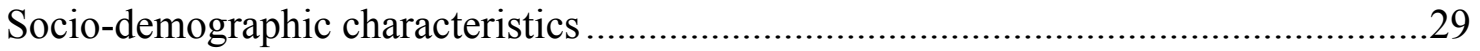

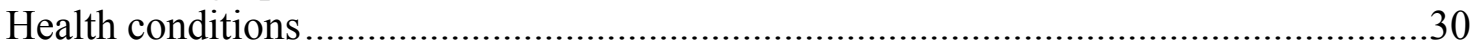

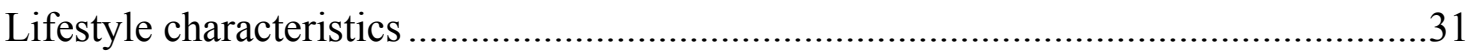

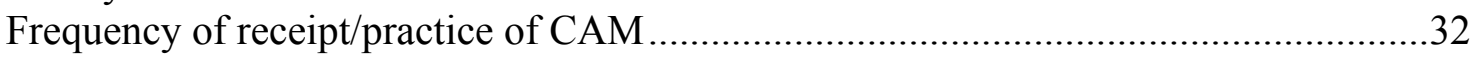

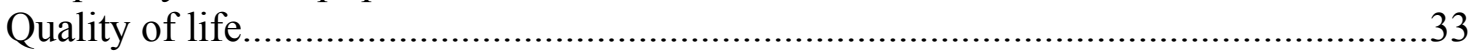

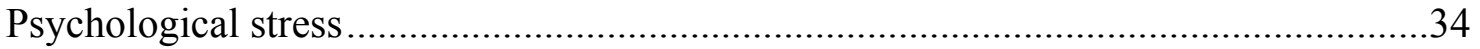

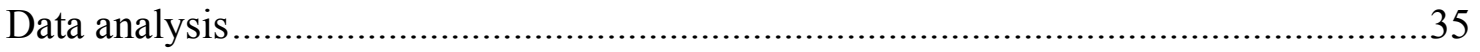

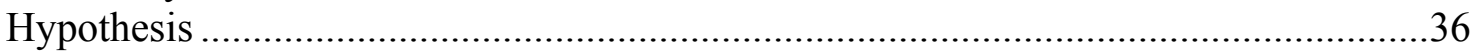

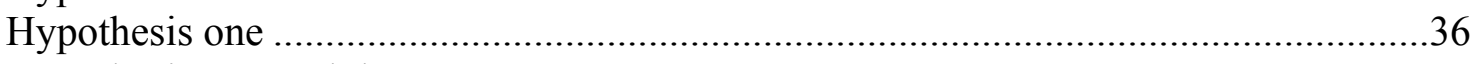

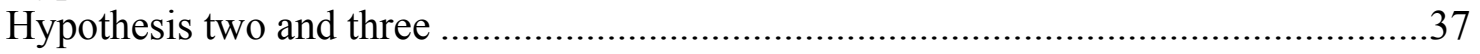

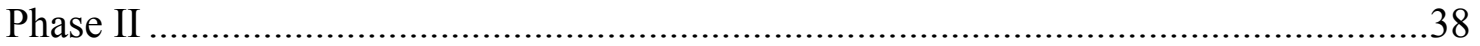

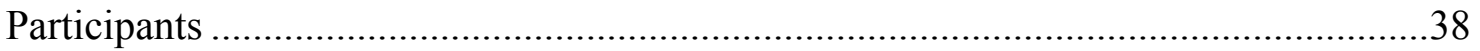

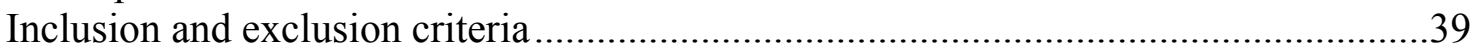

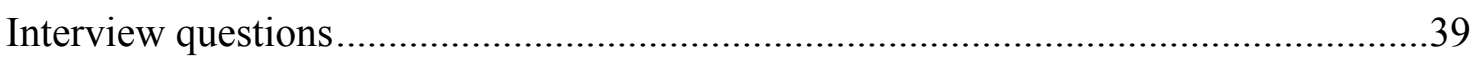

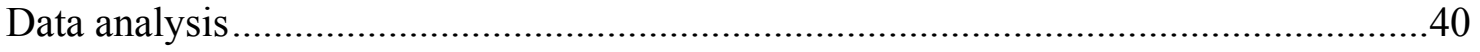

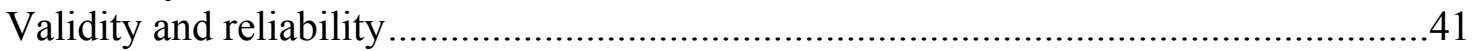

Human subject considerations .................................................................................

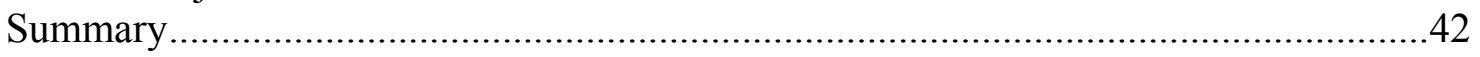

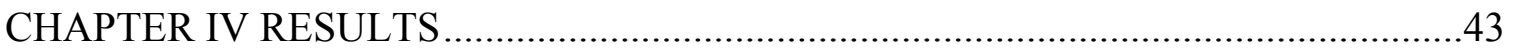

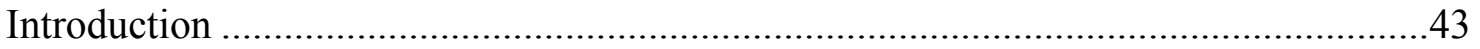




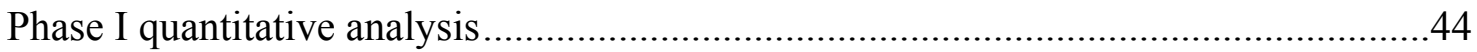

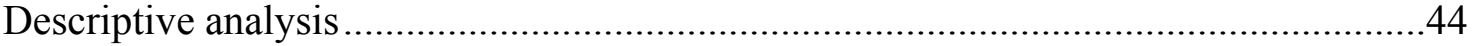

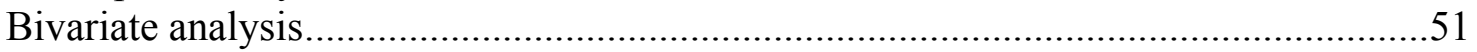

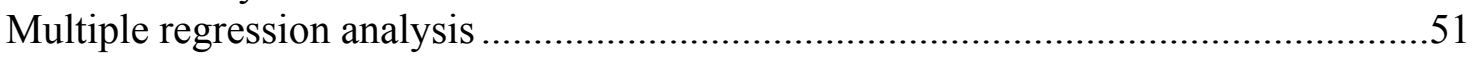

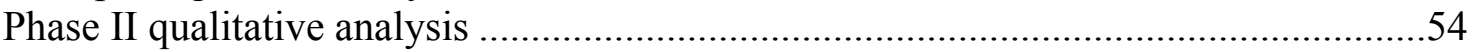

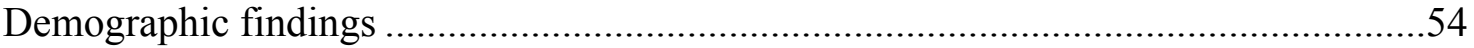

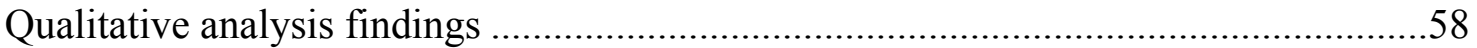

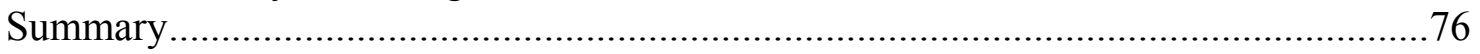

CHAPTER V DISCUSSION

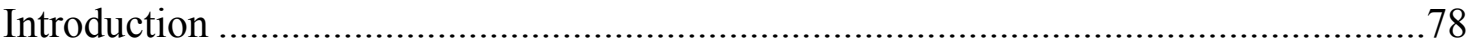

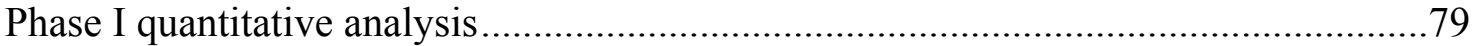

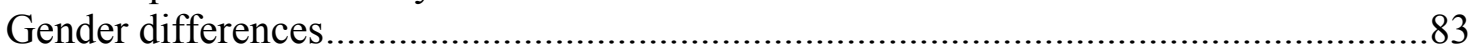

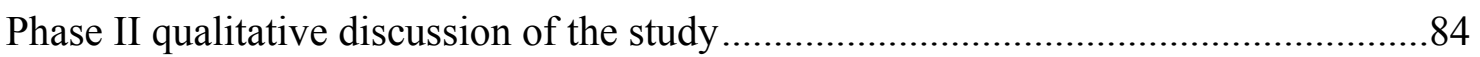

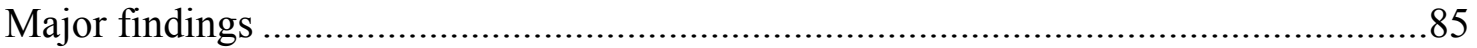

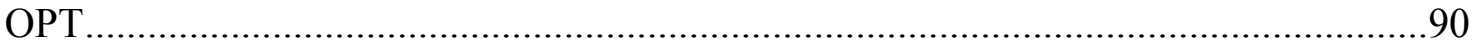

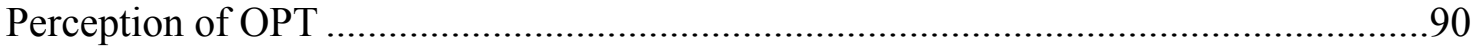

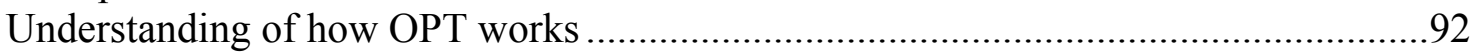

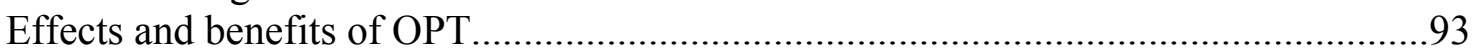

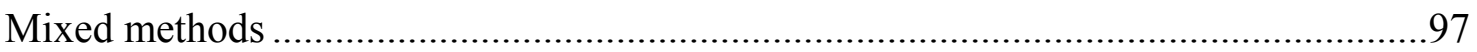

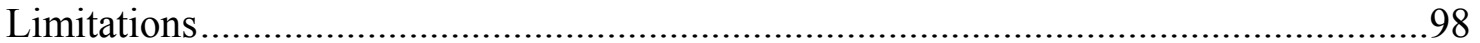

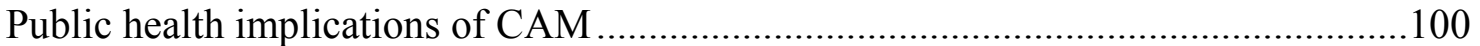

Recommendation for future research ................................................................ 102

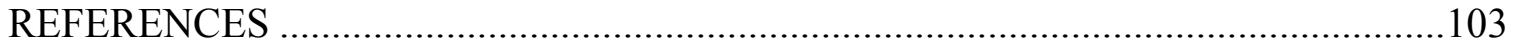

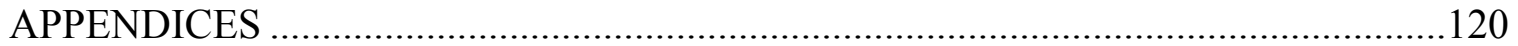




\section{LIST OF TABLES}

TABLE

PAGE

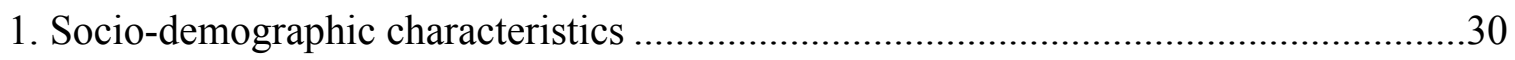

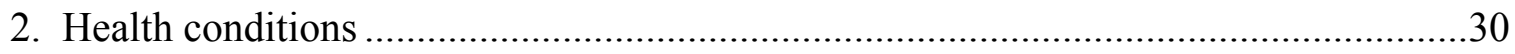

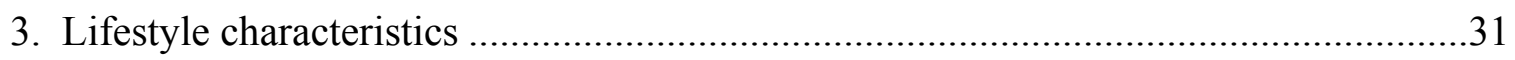

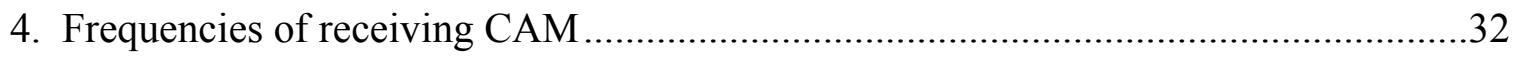

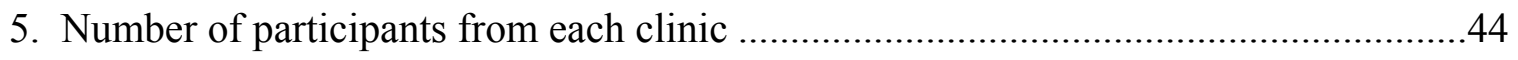

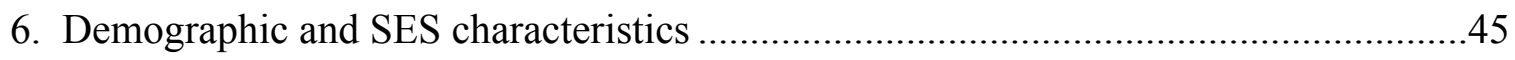

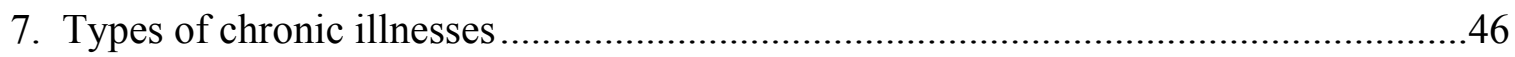

8. Characteristics of health conditions, lifestyle behaviors, and CAM practice ................47

9. Results of simple linear regression of CAM practices and QOL and perceived stress 51

10. Results of multiple regression models with adjustment factors...................................52

11. Results of multiple regression testing for interaction between gender and arts and

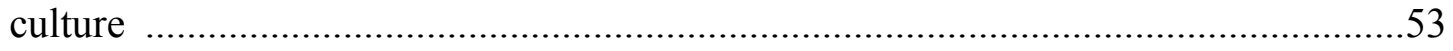

12. Results of multiple regression testing for interaction between gender and OPT ........54

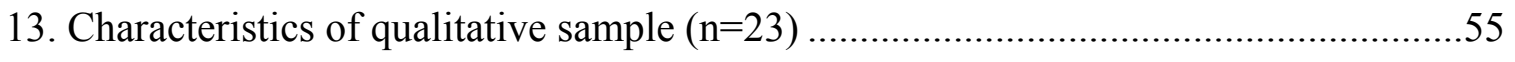

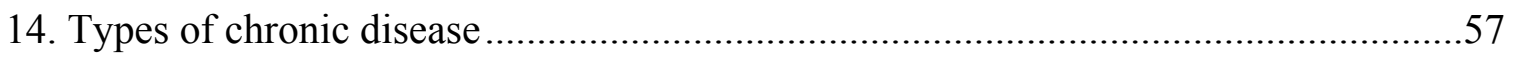

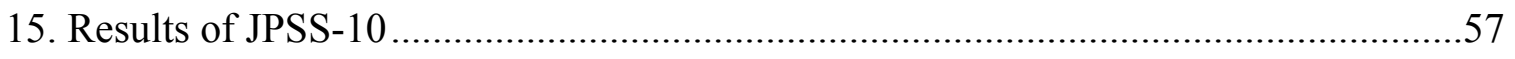

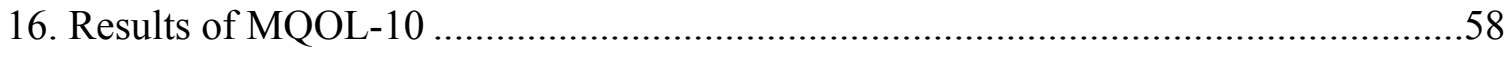

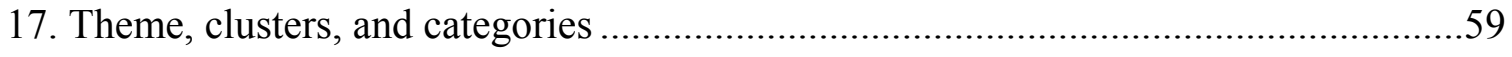

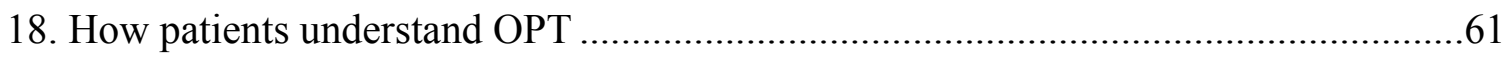

19. What prompted individuals to receive OPT............................................................65

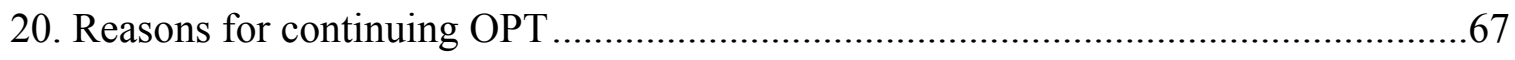


21. Thoughts on conventional medicine

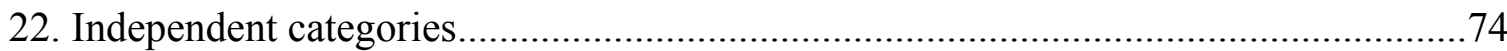




\section{ABBREVIATIONS AND ACRONYMS}

ADHD

$\mathrm{BN}$

CAM

DDT

GDP

HIV/AIDS

IARC

JPSS

JPSS-10

LDP

$\mathrm{MN}$

MOA

MQL-10

$\mathrm{NCCIH}$

NHANES

NHIS

$\mathrm{NIH}$

OECD

OPT

PSS

QOL
Attention deficit hyperactivity disorder

Benign neoplasm

Complementary and Alternative Medicine

Dichloro-diphenyl-trichloroethane

Gross domestic product

Human immunodeficiency virus infection and acquired immune deficiency syndrome

International Agency for Research on Cancer

Japanese Perceived Stress Scale

Japanese Perceived Stress Scale 10 items

Liberal Democratic Party of Japan

Malignant Neoplasm

Mokichi Okada Association

MOA Quality of Life Questionnaire 10 items

National Center for Complementary and Integrative Health

National Health and Nutrition Examination Survey

National Health Interview Survey

National Institutes of Health

Organization for Economic Co-operation and Development

Okada Purifying Therapy

Perceived Stress Scale

Quality of Life 
SF-36

WHO

WHOQOL-BREF
Short Form health survey 36

World Health Organization

World Health Organization Quality of Life Instruments Short version 


\section{CHAPTER I INTRODUCTION}

Because of advances in medical knowledge and technology, health care practice has become increasingly specialized and medical costs have soared (McKinlay, 2008). Worldwide, aging populations and the rising prevalence of chronic illnesses related to an increasingly sedentary lifestyle and higher body weight have led to increasing health care costs. Soaring government health care budgets in Japan, the United States, and most industrialized countries have required an exploration of health paradigms more focused on prevention and health promotion than on increasingly costlier medical treatments. For example, the United States government, which spends almost twice the average annual health expenditure of other Organization for Economic Co-operation and Development (OECD) countries, spent 13.7 percent of its gross domestic product (GDP) on health care in 1997 (World Health Organization, 2000), which increased to 17.4 percent in 2009 and is expected to grow to 20 percent in 2022. National health expenditure, including private and government-sponsored health insurance costs, reached $\$ 2.5$ trillion in 2009 and is estimated to grow to $\$ 5$ trillion by 2022 (Centers for Medicare and Medicaid Services, 2012). In the United States, more than 70 percent of deaths and 75 percent of health care costs are attributable to chronic diseases (Centers for Disease Control and Prevention, 2009). A study based on the National Health Interview Survey (NHIS) confirmed that the prevalence of lifestyle-related chronic conditions increased consistently among adults over the age of 25 years in the period from 2002 to 2009 (Ford, Croft, Posner, Goodman, \& Giles, 2013).

In contrast to the United States, the least cost-efficient health care system in the world (highest cost for life expectancy), Japan has one of the most efficient health care 
systems among the OECD countries. Japan, however, still spent 7.1 percent of its GDP on health care in 1997 (World Health Organization, 2000) and 9.5 percent in 2009, and this is expected to grow to about 13.5 percent by the year 2035 (Henke, Kadonaga, \& Kanzler, 2009; R. S. Jones, 2009). The national health expenditure of Japan in 2009 was estimated to be about 45 trillion yen, which increased to about 48 trillion yen in 2012 (World Health Organization, 2014). The Japanese government estimates that lifestylerelated diseases, such as those resulting from poor diet, smoking, alcohol consumption, lack of physical exercise, and excessive stress, account for almost one-third of all health spending and about 60 percent of deaths in Japan (R. S. Jones, 2009). Healthy aging has become a priority for both countries' governments to reduce health spending because health expenditures for persons over 65 years old are four to five times higher than for those under this age, as chronic diseases affect older persons more than the young. Population-based actions to improve lifestyle behavior and other evidence-based approaches to build healthier communities and lifestyles are urgently needed in the United States and Japan.

To approach the problem of lifestyle-related diseases, health promotion programs need to target efforts to reduce the causes of these diseases. A common understanding is that chronic diseases are outcomes of an accumulation of daily lifestyle factors, habits, and environmental effects (Willett et al., 2006). Poorly managed stress is a factor that may contribute to the effects of unhealthy lifestyles, promoting disease occurrence and progression. Avoiding or altering lifestyles that create excessive, poorly managed stress is essential because psychological functioning affects health and well-being (Anita, 1982). Being exposed to chronic stress can result in changes in emotional, psychological, 
and behavioral responses that influence susceptibility to and course of disease. For example, one may be exposed to stress severe enough to create changes in behaviors such as coping responses and adaptations to stressors. Increase in smoking, decreased exercise and sleep, and poor diet are behaviors that can provide pathways in which stressors influence disease risk (Cohen, Janicki-Deverts, \& Miller, 2007). Toxic stress also affects health and well-being by its effects on physiological systems that mediate host defenses, inflammatory processes, or disease progression (Baum, Herberman, \& Cohen, 1995). Toxic stress and depression exert well-researched influences on immunity. Stress disrupts normal physiology in the production of adrenaline, noradrenaline, and glucocorticoids (Yang \& Glaser, 2003). Associations have been established between pathological stress and disease progression, particularly for depression, cardiovascular disease, and human immunodeficiency virus and acquired immune deficiency syndrome (HIV/AIDS) (Hammen, 2005; Leserman et al., 1999; Rozanski, Blumenthal, \& Kaplan, 1999). Other areas in which evidence for the role of stress is beginning to emerge include asthma exacerbations, herpes simplex recurrences, occurrence of viral infections, autoimmune disease progression, and delayed wound healing (Cohen et al., 2007). Pathologic stress may influence the progression and recurrence of some cancers; although, more research needs to be conducted in this area. Health practices that can reduce stress and reduce the likelihood and/or severity of disease will ultimately result in enhanced Quality of Life (QOL) and less overall disease and/or slower disease progression. Hence disease prevention has an important component of lifestyle change, including activities that can reduce stress and enhance QOL. 
Complementary and alternative medicine (CAM) is defined as any type of health care system, practice, and products that are not considered part of conventional medicine (NCCIH, 2015). "Complementary medicine" refers to use of CAM in combination with conventional medicine, and "alternative medicine" refers to use of CAM in place of conventional medicine (NCCIH, 2015). The use of CAM has gained popularity as a strategy for health promotion and disease prevention. Utilization of CAM is found to be especially high in patients who are suffering from chronic illness and chronic pain, especially if these processes are poorly controlled by conventional medical interventions (Astin, Marie, Pelletier, Hansen, \& Haskell, 1998). A study conducted to measure the use of CAM in 1990 showed that 33.8 percent of the U.S. adult population used at least one type of CAM; this proportion rose to about 42.1 percent in 1997 (Eisenberg et al., 1998). The percentage remained stable at approximately 40 percent from 2002 to 2007 (Barnes, Bloom, \& Nahin, 2008). Among people using CAM, 40 percent used CAM to treat existing illness and the remainder for prevention of disease and/or maintenance of health and vitality. Other reasons for use of CAM include concerns about the cost of conventional care that may tend to delay presentation for care; dissatisfaction with the ability of conventional medicine to adequately treat chronic illnesses; dislike of the reductionist, mechanical model of a medicine and/or preference for a holistic, integrative model of medicine; a desire to avoid treatments with adverse effects and to reduce iatrogenic conditions; and greater appreciation of how nutritional, emotional, and lifestyle factors may affect health (Astin et al., 1998). Furthermore, patients who believed stress has a negative impact towards their disease were more likely to use CAM; in other words, CAM was often used to either reduce or avoid stress. For example, the level of perceived 
stress was shown to be a significant predictor of CAM use among patients diagnosed with inflammatory bowel disease (Langhorst et al., 2007). Common symptoms in which CAM is used include care for stress-related symptoms such as fatigue, insomnia, chronic pain, anxiety, and depression (Astin et al., 1998; Eisenberg et al., 1993).

CAM practices commonly used to relieve and/or avoid stress should ultimately lead patients to improved QOL. However, results from studies of patients' CAM use and their self-assessment of QOL have reported conflicting results. For example, a study compared breast cancer patients in an anthroposophic (a branch of medicine that recognizes the scientific basis of conventional medicine while maintaining a holistic, human-focused approach to care) hospital using CAM with patients in another hospital receiving only conventional care; this study reported improved QOL in patients treated with CAM (Carlsson et al., 2006). Another study conducted among patients with gynecological cancer reported that patients using CAM experienced overall deterioration of their health status less frequently than nonusers; CAM users also reported more improvement in some aspects of QOL (Fasching et al., 2007). However, other studies have concluded the opposite; one study concluded that the use of CAM predicted greater psychosocial distress and poorer QOL three months after the diagnosis of breast cancer (Burstein, Gelber, Guadagnoli, \& Weeks, 1999).

Despite its widespread practice, most CAM lacks a research data evidence base. The lack of proven effectiveness of CAM practices suggests a need for accurate information on CAM practices and clinical trials. 
In a study conducted among oncologists practicing in Japan, the majority (82 percent) believed that CAM practices were ineffective against cancer; the main concern was lack of reliable information regarding CAM efficacy (N. Suzuki, 2004).

This study was conducted to evaluate the five lifestyle-related CAM practices provided and promoted in an integrative medicine clinic in Japan, and also to explain the reasons why patients decided to practice Okada Purifying Therapy [OPT (biofield therapy)]. The practice of OPT is provided and promoted as a lifestyle practice at the integrative medical clinic. The original practice and idea were developed by Mokichi Okada during the 1930s. This was during the time when Japan was still relatively isolated from the influence of western culture. The philosophy underlying the practice can be traced back to Shinto, both a religion and a way of life originating in Japan. Shinto is worship of nature. Animism (the belief that natural objects have souls that may exist apart from their material bodies) and Immanentism (a belief that god or an abstract spirit pervades the world) are central notions of Shinto (Clammer, 2010). Before the rapid economic development and the modernization that took place during the mid-20th century, Japan was dominated by the ideology of nature. This affected politics, culture, values, and the people's way of thinking (Daston \& Vidal, 2010). Following the laws of nature and living in harmony with nature was a virtue. This is why Japanese culture is characterized by its close connection with nature and deep appreciation of it. This has influenced the traditional Japanese aesthetics, food, fashion, architecture, and literature (Clammer, 2010). Examples can be seen in paintings, Japanese gardens, seasonality of Japan's food and fashion, and in its passion for cherry-blossom and autumn foliage viewing. OPT is based on the concept of following the principles of nature. Okada 
emphasized the importance of humans' self-healing ability, and he believed that this selfhealing ability could be invigorated to a significant degree through the use of subtle energy. He believed that the universe is permeated with certain energy that allows all living things to exist and that this universal energy can be used to remove accumulated toxins within the body in order to facilitate physical, mental, and spiritual health (K. Suzuki et al., 2012). This therapy is practiced mainly in Japan but also in other parts of the world where many Japanese immigrants reside.

\section{Purpose of the research}

The purpose of this study was to lay the groundwork for more rigorous studies of five lifestyle-related CAM practices explored. The study focused on determining whether lifestyle-related CAM practices including OPT, art and cultural activities, natural and organic foods, home gardening, and exercise have a significant association with QOL and perceived stress among patients diagnosed with chronic diseases. No studies have directly measured the relationship between the frequency of these health practices and QOL and perceived stress among patients with chronic disease. Secondary data were used from a parent study, "Associations between perceived stress, quality of life and complementary health practices in Japanese outpatients: A multicenter observational study." The first phase of the study assessed the relationship of the five lifestyle-related CAM practices to QOL and perceived stress, controlling for various socioeconomic status and lifestyle factors among patients diagnosed with chronic disease. In addition, this study explored why patients decided to receive OPT.

Evidence of the effectiveness of OPT is limited. The design of previous studies was not rigorous enough or the studies lacked generalizability due to their small sample 
size. Despite the lack of research on its effectiveness, many people practice and receive OPT. The research utilized a sequential explanatory mixed methods design, intended to provide greater insight and understanding, gathering qualitative data based on the results of quantitative data (Creswell, 2013).

\section{Theoretical perspective}

The emerging themes and categories of the qualitative portion of the study were compared and contrasted using the Diffusion of Innovation's five stages of innovationdecision process in order to gain more insight on how participants in the interview decided to receive OPT. The innovation-decision is the process through which an individual passes from gaining initial knowledge of an innovation, to forming an attitude toward the innovation, making a decision to adopt or reject, implementation of the new idea, and confirmation of this decision. This consists of dealing with the uncertainty that is involved in deciding about a new alternative to an idea previously in existence. The

perceived newness of an innovation, and the uncertainty associated with this newness, is a distinctive aspect of innovation decision-making (Rogers, 2003).

\section{Research questions}

\section{phase I quantitative}

Frequency of practice of the five lifestyle-related CAM practices and its association to QOL and perceived stress were examined. The first research question was: What are the effects of the five CAM practices as related to perceived QOL and stress? 


\section{Hypothesis}

Three hypotheses were formed in relation to the research question.

Hypothesis \#1: All five lifestyle-related CAM practices will be positively associated with improved QOL and negatively associated with perceived stress

Hypothesis \#2: The association between practice of arts and cultural activities and QOL/perceived stress will differ significantly by sex

Hypothesis \#3: The association between practice of OPT and QOL/perceived stress will differ significantly by sex

\section{phase II qualitative}

The qualitative study explored the reasons why patients decided to receive OPT utilizing a grounded theory methodology (Corbin \& Strauss, 2008). Four questions were asked of participants in open-ended interviews in an effort to capture a comprehensive understanding of their reasons in deciding to receive OPT. The following questions were asked.

1. Please reflect back the time you first received OPT and tell me about your experience, and how you came about knowing OPT.

2. Why did you decide to continue receiving OPT

3. Before getting to know OPT, what did you do to maintain health?

4. Would you let others know about OPT?

The second research question was: Why do people choose to receive OPT? This was studied through open-ended interviews conducted with patients diagnosed with chronic diseases that explored why they chose to receive OPT. The qualitative portion of the study was able to complement the results of the quantitative portion of the study. 


\section{Operational definition}

The following operational definitions are employed throughout the study:

- Quality of life is the measure of individuals' perceptions of their position in life in the context of the culture and value systems in which they live and in relation to their goals, expectations, standards, and concerns (WHOQoL Group, 1998).

- Perceived stress is the measure of degree to which situations in one's life are appraised as stressful (Cohen, Kamarck, \& Mermelstein, 1983).

- Arts and culture are the lifestyle-related practice of enjoying arts, music, traditional culture, and natural beauty, among other things.

- OPT is a type of biofield therapy called Okada Purifying Therapy that was originally developed by Mokichi Okada. Its purpose is to maintain health and improve symptoms related to daily life. This can be practiced only by licensed practitioners who have completed a training program.

- Optimal diet is the practice of eating fresh/seasonal additive-free products such as organic vegetables.

- Biofield therapy is a healing method that utilizes biofield energy to manipulate the receiver's energy. The therapy is based on the concept that human beings are infused with subtle forms of energy although no scientific evidence documents the existence of such energy.

- CAM is a term for complementary and alternative medicine. Complementary medicine is a non-mainstream practice used together with conventional medicine, and a non-mainstream practice used in place of conventional medicine is considered alternative medicine (NCCIH, 2015). 
- Grounded Theory is a systematic inductive method for conducting qualitative research aimed towards theory development (Corbin \& Strauss, 2008).

- Mixed methods sequential explanatory design is a research design that manifests the collection and analysis of quantitative data then qualitative data in sequential phases (Creswell, 2013). 


\section{CHAPTER II LITERATURE REVIEW}

Few studies have examined the efficacy of the five lifestyle-related CAM practices. However, several studies suggest possible effectiveness of these practices in health. The five CAM practices are promoted as lifestyle modifications that should be adopted as a long-term practice rather than a one-time treatment or single intervention. It has been widely understood for decades that lifestyle affects health and mortality (Belloc, 1973; Breslow \& Enstrom, 1980). Lifestyle practices, such as smoking, alcohol use, insufficient sleep, meals in which highly-processed high-calorie foods predominate, and lack of physical activity have been shown to be strongly associated with mortality. A longitudinal prospective study conducted in Alameda County, California, supported the hypothesis that good health practices result in increased number of years of healthy life. Lifestyle improvements have resulted in improved longevity and health, and further improvements can be expected to further prolong healthy life, prevent disease, and improve QOL. Below, studies that suggest the effectiveness of the five lifestyle-related CAM practices in relation to general health, QOL, and stress will be reviewed.

\section{Arts and culture}

In Spontaneous Happiness, a book directed towards people suffering from depressive symptoms, author Dr. Andrew Weil introduces appreciation of art and beauty as one of many ways to maintain secular spirituality and emotional well-being (Weil, 2011). He recommends appreciating art through visits to museums or going to art fairs to discover aesthetically pleasing works of art. There are few studies that document effects of viewing art work and appreciating beauty on emotional well-being and reduction of stress. One study showed that viewing aesthetically pleasing nature scenes was 
significantly associated with improved postoperative recovery (Ulrich, 1984). Patients randomly assigned to a hospital room with a pleasant outdoor view of a tree had shorter postoperative stays and fewer negative evaluative comments from nurses, and required fewer analgesic doses compared to patients randomly assigned to rooms with a view of a building wall. The findings of this study suggest that pleasing natural scenes may exert a therapeutic influence. In a study conducted among undergraduate students, views of nature had a significantly faster and a complete recuperation from stress in comparison to a control treatment of views of various daily urban environments. The results also suggested a possibility of effects of restoration and increased attention through exposure to nature, in comparison to urban environments. Results of self-rating scales showed a significant increase in positive effects after views of nature. This study suggests that exposure to views of nature may facilitate recovery from stressors such as daily hassles and annoyances (Ulrich et al., 1991). In another study among patients under-going stem cell transplantation, randomly selected participants received an art intervention consisting of images from collection of art works by well-known artists and images of nature transmitted to each patient's room on a wide screen, resulted in significantly reduced levels of anxiety and negative expectations of the transplant in comparison to the control group (McCabe, Roche, Hegarty, \& McCann, 2013). Results from a study conducted among patients with breast cancer showed that art therapy was beneficial in reducing symptoms of anxiety and depression, decreasing levels of stress, and improving selfesteem and self-assessment of global health. 
Women who participated in the individual art therapy sessions significantly improved their overall QOL and general health compared with a control group (Svensk et al., 2009). Art is beginning to be viewed as an important component of holistic care for people enduring chronic symptoms.

In a cross-sectional study assessing the relationship between lifestyle and QOL, interest in art was shown to be associated with general vitality and physical and mental health (Kimura, Ogushi, Haruki, \& Okada, 2000). Art therapies such as painting, playing music, and making ceramics have been found to be associated with improved mental health (Bailey, 1997). These studies, however, were limited by their cross-sectional design, and results are compatible both with the possibility that mental health tends to be associated with enjoyment of art as well as enjoyment of art promoting mental health. A prospective study with this type of CAM intervention is needed to assess whether there is a causal relationship between nurturing an interest in art and health status, QOL, and perceived stress. These research results suggest that art activities as part of lifestyle or a form of therapy can contribute to the improvement of health, although further studies need to be conducted with a greater sample size to adequately test the hypothesis that engaging in art can improve QOL and health status.

\section{Diet}

Consumption of organic food has increased rapidly in recent decades. U.S. sales of organic products were estimated to be somewhere between $\$ 13$ billion and $\$ 14$ billion in 2005, rising to an estimated $\$ 35$ billion during 2014. Currently, organic sales account for up to 4 percent of total U.S. food sales (Greene, 2014). The rise in organic food sales reflects increased interest in the possible health benefits of organic food and the health 
consciousness of the people in the U.S. This can be supported by numerous studies on consumers' intentions in their choice of organic food purchases. Studies indicate that common reasons for the consumption of organic foods were concerns for health (Lockie, Lyons, Lawrence, \& Mummery, 2002; Magnusson, Arvola, Hursti, Åberg, \& Sjödén, 2003), food safety, environment, and ethical motives such as animal welfare (Michaelidou \& Hassan, 2008).

Some studies suggest that organic food may be safer and healthier than conventional food because they may have higher amounts of nutritional value (Lairon, 2010; Rembialkowska, 2007) and safety is assured from the absence of additives, pesticides, and other chemicals (Crinnion, 2010; Lairon, 2010). However, other studies contend that despite the evidence of higher quantities of certain nutrients in organic food compared to conventional food, there is no evidence that eating organically grown food has meaningful nutritional benefits compared to conventionally grown food products. Chronic pesticide exposure and pesticide metabolite concentrations are considered to be potentially unhealthy. However, there are no studies that have experimentally examined the causal relationship between exposure to pesticides directly from conventionally grown foods and adverse health outcomes (Forman, Silverstein, Committee on Nutrition, Council on Environmental Health, \& American Academy of Pediatrics, 2012). Presently, evidence of the health benefits of organic food in comparison to conventional food appears to be scarce. Studies which prove possible advantages of organic foods in comparison to conventional food products have yet to be conducted.

Conventional produce and foods rely on pesticides, additives, and other chemicals during the process of cultivation and preparation for consumption. Although the detection 
of pesticide residues in conventional produce is rare and the health risk from consuming foods containing pesticide residues is considered minimal (Nasreddine \& Parent-Massin, 2002), limiting the amount of exposure to pesticides may reduce potential human health risks. For example, in developing countries pesticides that may be associated with an increase in the occurrence of cancer - such as older pesticides including organochlorines, lead arsenate, creosote, and sulfate - are still in use (Alavanja, 2004; Repetto \& Baliga, 1996). Although farmers tend to have lower risk for overall mortality, heart disease, and all cancers in contrast to people from other occupational groups of the same age, risks for special types of cancers including the lip, melanoma, brain prostate, stomach, connective tissue, and lymphatic hematopoietic system were found to be relatively high compared to the general population, suggesting a possible association between pesticides and the above malignancies (Blair, Zahm, Pearce, Heineman, \& Fraumeni Jr, 1992; Cantor et al., 1992). In research related to food and nutrition practices, some studies have suggested that dichloro-diphenyl-trichloroethane (DDT), which is no longer used in Japan or the U.S., and related chemicals may be associated with increased risk of some congenital defects and reduced lactation (Rogan \& Chen, 2005).

The top 10 most used pesticides in the U.S. during 2001 were herbicides glyphosate, atrazine, metolachlor-s, acetochlor, dichlorophenoxyacetic acid (2,4-D), and pendimethalin, and the fumigants metam sodium, dichloropropene, methyl bromide, and chloropicrin (U.S. Environmental Protection Agency, 2011). Herbicide glyphosate, the most commonly used herbicide worldwide, was classified as probably carcinogenic by the International Agency for Research on Cancer (IARC), an intergovernmental agency forming part of the World Health Organization (WHO); however due to the limited 
amount of evidence based on human research there are opposing claims regarding this classification. However, suggestive evidence is obtained from animal experiments (Guyton et al., 2015). Furthermore, in a study based on the National Health and Nutrition Examination Survey (NHANES), it was evident that the majority of the American population is exposed to dichloropropene, a major metabolite of dichlorobenzene, also a suspected carcinogen for humans, widely used as a chemical intermediate for the production of pesticides, deodorants, dyes, and pharmaceutical drugs (Ye, Wong, Zhou, \& Calafat, 2014). The use of organophosphates is declining, but these compounds are still commonly used for agricultural purposes. Studies have shown associations between long term exposure to diazinon, a type of organophosphate, and increased risk for lung cancer (R. R. Jones et al., 2015). The results of this study were consistent with previous studies conducted among pest control workers who used diazinon, and their elevated risks of lung cancer for whom used diazinon (Pesatori, Sontag, Lubin, Consonni, \& Blair, 1994). In a systematic review, numerous studies showed a significant association between increased maternal prenatal exposure to organophosphate and associations with neurodevelopmental, behavioral, and cognitive abnormalities in infants and children (González-Alzaga et al., 2014).

Consuming organically grown foods can reduce the exposure to these healthdamaging substances (Curl, Fenske, \& Elgethun, 2003; Lu et al., 2006) and may increase the intake of health-promoting micronutrients (Lairon, 2010). However, research conducted for the purpose of comparing the nutritional quality in organically grown food and conventionally grown food is limited; few data exist to demonstrate meaningful differences in the nutritional quality of organically versus conventionally grown food, 
although it is possible that such differences exist. A literature review on the nutritional quality of organic food in comparison to conventional food products concluded that organic plant products tended to have more dry matter, some minerals (including iron and magnesium), and anti-oxidant micronutrients (phenols, resveratrol), while animal organic products have more polyunsaturated fatty acids (Lairon, 2010). In another study, the analysis suggested better quality and higher content of nutritionally significant minerals in organic produce, but weaknesses in the design of these studies limit their interpretability (Worthington, 2001). No studies have directly measured associations between organic versus conventional food consumption and QOL.

\section{Home gardening}

According to the National Gardening Association, 80 percent of U.S. households had gardens a 60 percent increase from the year 1996. Gardening was most popular in the 55- to 64-year-old age group in terms of money spent on products and services related to gardening (Wright \& Wadsworth, 2014). This trend is expected to continue as aging populations increase in the U.S.

Gardening is considered both a physical exercise and contact with nature, and gardens and gardening activity are expected to provide opportunities for an individuals' mental, physical, and spiritual recovery and improvement (DiPietro, 2001; Grabbe, Ball, \& Goldstein, 2013). In a population-based case-control study, individuals who performed only gardening activities had a 66 percent less chance of having primary cardiac arrest compared with individuals who were physically inactive. The results of gardening activity were equivalent to those of high-intensity activities, and walking and exercising with regard to its protective factor against primary cardiac arrest (Lemaitre RN, Siscovick 
DS, Raghunathan TE, Weinmann S, Arbogast P,Lin D., 1999). In another study, results showed that people living in "green" living environments had lower morbidity and mortality, in particular from stress-related diseases such as anxiety disorder and depression. Children and people with lower socioeconomic status were more likely to experience positive effects of "green" environments (Maas et al., 2009). Among studies related to children, gardens appeared to lower children's symptoms of attention deficit hyperactivity disorder (ADHD) (Kuo \& Taylor, 2004). Gardening activities facilitated the ability to cope with stress (Evans, 2003). In a study in Japan assessing the effects of integrative medicine, horticultural therapy and other therapies were conducted with patients suffering from cancer. The horticultural therapy consisted of 60-minute weekly sessions of growing vegetables. This and various other complementary therapies were shown to significantly improve QOL measures, especially measures related to physical functioning, general health perception, vitality, emotions, and mental health (Nakau et al., 2013). In a systematic review of 31 studies that dealt with gardening activities and their effects on mental or physical health among the adult population, the majority of studies found some evidence that gardening is enjoyable for older adults and increases overall quality of life, physical ability, and activeness (Wang \& MacMillan, 2013).

In addition to promoting improvements in physical and mental well-being, gardening, as a therapeutic activity, is considered to provide opportunities for empowerment and increased competence, building bridges to naturally occurring supports and resources within the broader community (Milligan, Gatrell, \& Bingley, 2004). For instance, community garden projects may improve individual health as well as strengthen neighborhood bonds through activities that incorporate volunteerism, 
leadership, neighborhood activities, and recruitment. The neighborhood bond is expected to strengthen through social processes of social connections, reciprocity, mutual trust, collective decision-making civic engagement, and community building (Teig, 2009). These community gardens have the potential to impact public health through increased social engagement and improved mental health, and increased physical activity and improved nutrition. Gardens represent one example of a community-based health promotion program that cuts across differences in age, ethnicity, race, income, and education, and is a good example of a location-based strategy that can strengthen and sustain neighborhoods and improve the health of the residents (Teig, 2009).

\section{Biofield therapy}

Biofield therapy is a healing modality that uses subtle energy forms or "nonphysical energy" which is believed to affect the body and mind. Some of the common biofield therapies include Reiki, Therapeutic Touch, laying on of hands, and Johrei. These practices claim to use subtle energies for the process of healing others. A healer transmits or guides energy to a recipient who is physically present, or in a different location to which the healer sends the energy by distant healing and intercessory prayer (Jain \& Mills, 2010).

According to the National Center of Health Statistics, the percentage use of biofield therapy has been 5 percent during the years of 2002, 2007, and 2012 among respondents of the national survey on CAM use (Clarke, Black, Stussman, Barnes, \& Nahin, 2015). Despite the increase in other types of CAM modalities such as the use of non-mineral, non-vitamin dietary supplements, deep breathing exercises, yoga, and taichi, biofield therapy use has remained stable over the past decade. 


\section{OPT}

OPT is a healing method created by Mokichi Okada, founder of Mokichi Okada Association International (MOA), during the 1930s in Japan. OPT is based on principles of a unique understanding of the human body, illness, and health. OPT is a type of biofield therapy that assists the self-healing process through the use of subtle energy. Practitioners of OPT consider stiff and/or warm spots on the body to represent accumulated toxins, and therefore, these are the key areas on which practitioners focus the therapy. Okada believes that the universe is permeated with certain energy that allows all living things to exist. The practitioner purports to absorb this universal energy and radiate it from his or her palm towards the key areas on the recipient's body. The distance between the palm and the recipient's body is usually 1 to 2 feet. The administration of OPT typically lasts from 30 to 60 minutes in one session. From the perspective of Okada, OPT invigorates the self-healing ability to remove the accumulated toxins, which facilitates physical, mental, and spiritual health (K. Suzuki, Uchida, Kimura, \& Katamura, 2012).

There are only a few studies published on OPT to date. One is the parent study of this proposed research. The second study is a randomized clinical trial that assessed the effectiveness of OPT by comparing the effects of OPT on brain waves with those of a placebo. Results indicated that OPT was more effective in increasing alpha waves in the frontal and central cortex than a placebo treatment (Uchida, Iha, Yamaoka, Nitta, \& Sugano, 2012). The randomized clinical trial was greatly limited by the fact that it had only 19 participants and was a single-blind trial. Participants were randomized to either the control or OPT group on different days at the same hour of the day and were not 
informed as to the type of experimental session they would be receiving. The study also included survey measurement of Profile of Mood States (POMS) to assess whether there was any change in six emotional states (anxiety-tension, depression, anger-hostility, vitality, fatigue, and confusion). Both the OPT session and the placebo session showed significant decreases in scores for tension-anxiety, depression, anger-hostility, and confusion. Scores for vitality also increased significantly for both sessions. None of the emotional states measured by POMS were significantly different between the OPT and the placebo session, which implied that the participants were not able to distinguish between the two treatments in their self-report data, that the participants were truly blinded to the two procedures and that presumably, the statistically significant differences in alpha waves reflected some effect independent of something participants would detect. The third study was a large cross-sectional study that measured a self-reported symptom change after an OPT therapy session of 30 minutes or more. Results indicated improvement in the severity of physical pain, palpitation/dizziness, and anxiety/depression (K. Suzuki et al., 2012). The main limitation of this study was that the survey was quasi-experimental, a convenience sample without a control or comparison group. The severity of symptoms before and after the therapy introduced bias in favor of the intervention primarily through placebo effect. Moreover, revealing honest assessments may have been difficult for the participants because the setting of the study exposed the recipient's responses to the practitioners who administered the practice, resulting in social desirability bias. 
Finally, the study sample included a high proportion of elderly and/or female patients who participated with an initial positive attitude towards OPT, which may have resulted in further bias and contaminated the generalizability of results.

The study by Uchida et al. is relatively strong in being able to conclude and infer a valid causal relationship between the treatment and its results. However, the generalizability of results is limited due to the small sample size. Moreover, the therapeutic value of increasing alpha waves per se for improving QOL or reducing stress has not been established with any certainty. The study conducted by Suzuki et al. suggested that OPT is likely to be harmless. However, any enthusiasm over effectiveness claims is tempered by the multiple biases in the study design. This study that we conducted may have addressed some of these limitations by utilizing a validated scale instrument that is self-administered, allowing the participants to give honest evaluations of efficacy of the practices.

There are also several studies (Bennett, Laidlaw, Dwivedi, Naito, \& Gruzelier, 2006; Brooks, Schwartz, Reece, \& Nangle, 2006; Buzzetti et al., 2013; T. Laidlaw, Bennett, Dwivedi, Naito, \& Gruzelier, 2005; T. M. Laidlaw et al., 2003; T. M. Laidlaw et al., 2004; T. M. Laidlaw et al., 2006; Reece, Schwartz, Brooks, \& Nangle, 2005; Taft, Moore, \& Yount, 2005) on Johrei, considered a form of OPT, as the underlying philosophy and the technical procedures are considered to be the same. Johrei is a Japanese non-touch healing method aimed at spiritual purification of body and mind and described as a type of self-hypnosis (Hammerschlag, Marx, \& Aickin, 2014). A systematic review of published randomized clinical trials of Johrei reported that all identified nonphysical contact biofield therapy trials were pilots characterized by small 
sample sizes, precluding robust conclusions, but that two-thirds of the higher-scoring trials demonstrated at least partial effectiveness. In a qualitative study conducted among breast cancer patients, the practice of Johrei may have helped participants to better cope with the disease, creating a sense of control and empowerment (Bennett et al., 2006). In a quantitative study involving the same subject participants, Johrei showed evidence of improving mood states such as decreasing anxiety and other debilitating emotional states and increasing perceived energy levels (T. Laidlaw et al., 2005). However, both the qualitative and quantitative studies were pilot studies and limited in sample size; thus, the results of the analyses can only be used as indications that encourage further research in this area. In a study conducted with university medical students prior to examinations, Johrei was able to reduce self-rated stress indicators related to depression, confusion, and loss of vigor in comparison to a control group. Self-rated anxiety, depression, and anger were relieved through the practice of Johrei, compared to both the control and another group receiving hypnosis (T. M. Laidlaw et al., 2003). Within the same extended study, the practice of Johrei showed psychological and immunological benefits in students facing the stress of examinations. Participants of Johrei showed increases in percentages of CD56+ NK cells (Naito et al., 2003). However, these studies consisted of a very small sample size: 16 participants in each of the three groups at baseline. Only 26 of 48 participants were available for the second post-assessment, suggesting the possibility of bias. The beneficial effects measured from Johrei may have occurred due to chance alone or from the effect of an education session in the Johrei group from a trained practitioner, which could possibly have induced a stronger placebo effect than the control group receiving only mock neurofeedback with no components of education. 
In another study conducted with both the givers and receivers of Johrei, receiving Johrei was associated with relief of distress and improvement of emotional state as measured before and after the session. However, the study design did not include a control group or a comparison group, hence the possibility of a placebo effect or bias could not be excluded (Reece et al., 2005). In a pilot study conducted among substance abusers, Johrei intervention resulted in decrease in measures related to negative emotional states and increase in positive emotional states. However, the study had a very small sample size, and a waitlist control design was used with no form of sham healing condition as a control to measure the effect of Johrei nor to control for placebo effect; thus, no valid conclusions on the effectiveness of Johrei can be made from this study (Brooks et al., 2006). 


\section{CHAPTER III METHODS}

\section{Research design}

This study explored the association of the five CAM practices introduced in this study as related to QOL and perceived stress among chronically ill patients in Japan and why patients chose to practice OPT by interviewing patients to elicit their reasons for doing so. The research utilized a sequential explanatory mixed methods design intended to provide more insight and understanding by gathering qualitative data based on the results of quantitative data (Creswell, 2013).

\section{Phase I}

The quantitative phase of the research to explore the association of the five CAM practices as related to QOL and perceived stress among chronically ill patients was conducted as a secondary analysis of a cross-sectional dataset from the parent study, "Associations between perceived stress, QOL and complementary health practices in Japanese outpatients: A multicenter observational study," conducted between April 2009 and June 2012. The data from the parent study were collected at MOA, a health promotion institution that provides service and promotes health through programs aimed at achieving healthy communities and individuals. The programs introduced in the current research were administered through the MOA Health and Wellness Center, a facility dedicated to the promotion of health and integrative medicine based on concepts and ideas conceived by Mokichi Okada, the founder of MOA International, and by members of the "Healthy Life Network." The MOA Health and Wellness Center operates under the guidance of certified physicians, and the key goal is to help individuals and families achieve health through multiple approaches of CAM provided by the centers. At 
present there are 11 MOA Health and Wellness Centers in Japan and seven outside of Japan. Outpatients visit the centers for the purpose of receiving one or more of the CAM health practices.

The possible benefits of consumption of natural and organic foods (Crinnion, 2010), home-gardening (Teig, 2009), and exercise (Wilson, Ellison, \& Cable, 2015) in maintaining or creating positive influence towards good health have been studied extensively. In comparison, the benefits of OPT and art and cultural activities in health maintenance have not been as extensively studied. However, OPT and arts and cultural activities fit in the domains of CAM provided by the National Center for Complementary and Integrative Health (NCCIH), National Institutes of Health, which classifies CAM into three categories: (1) natural products, (2) mind and body practices, and (3) other complementary health approaches (NCCIH, 2015).

Biofield therapies such as Reiki, healing touch and Qi Qong are categorized among the mind and body practices. Therefore, OPT is most likely to also be categorized as a mind and body practice. Biofield therapies are intended to affect energy fields that purportedly surround and penetrate the human body. The existence of such fields has not been scientifically proven (National Cancer Institute, 2012).

Art and cultural activities are also most relevant to the classification of mind and body practices. Mind-body interventions are techniques intended to stimulate the mind's capacity to affect the bodily function and symptoms such as meditation, prayer, mental healing, and art, music, and dance therapy (National Cancer Institute, 2012).

These CAM practices are particularly attractive in circumstances where it is believed that there is not more that conventional medical care and treatment can do for 
these patients (Thorne, Paterson, Russell, \& Schultz, 2002). These CAM practices are consistent with the belief of most alternative medicine in which humans have "built-in" recuperative powers analogous to the healing of a cut through scarring. Most CAM adherents believe that this self-healing process can be accelerated, sometimes to a significant degree, with specific stimuli. Thus, CAM practitioners typically focus on the therapies designed to stimulate patients' own resources to fight on their own behalf, based on the assumption that this emphasis on enhancing the "natural healing process" is the most appropriate foundation of any medical therapy. The five CAM practices share a similar philosophy that human beings have an innate powerful self-healing ability.

\section{Inclusion and exclusion criteria from the parent study}

This study used a portion of the data from the primary study with permission from the principal investigator. The primary study was conducted among participants in 10 clinics throughout Japan. Criteria for participation in the study were the following: 18 years of age or older and experience in receiving CAM programs at least once at one of the 10 clinics. Individuals were invited to participate in a study about CAM. Those who agreed and signed consent forms were asked to participate in various computer-assisted short questionnaire Japanese Perceived Stress Scale-10 (JPSS-10)(Kimura et al., 2008) and MOA Quality of Life Scale-10 (MQL-10)(Kimura et al., 2009) at the 10 clinics.

\section{Data collection}

The parent study collected the frequency of practice of OPT, arts and cultural activities, organic and natural foods, home gardening, and exercise as a lifestyle practice. The frequency of practice that each patient reported reflected not only the amount of CAM practice that they received at the wellness center but also the frequency of practice 
outside the wellness center. The frequency of OPT was measured through the question, "How often have you received OPT in the last three months?" Frequency of participation in arts and cultural activities was measured through the question, "How often have you engaged in arts and cultural activities other than music?" The frequency of organic and natural food was measured through the question, "What proportion of your daily diet consisted of natural, organic, and preservative/additive free food?" The frequency of home gardening was measured through with the question, "How often did you participate in home-gardening activities?" The frequency of exercise was measured through the question, "How often have you exercised, including activities such as taking a walk?"

The present study focused only on patients diagnosed with chronic disease, and the analytic model included QOL indicators and perceived stress as the dependent variables, and one of the five CAM practices as the independent variable. A computerassisted data collection method was used for this study in which participants were asked to enter survey questionnaire responses in a personal computer tablet. The survey measured the following variables:

\section{Socio-demographic characteristics}

The socio-demographic characteristics included age, gender, annual income, occupation, educational status, marital status, and number of people in household. The following shown in table 1 were the answer choices to each of the questions. 
Table 1. Socio-demographic characteristics

\begin{tabular}{|c|c|c|c|c|c|c|}
\hline Title & Question & $\begin{array}{c}\text { Answer } \\
\text { choice \#1 }\end{array}$ & $\begin{array}{c}\text { Answer } \\
\text { choice \#2 }\end{array}$ & $\begin{array}{c}\text { Answer } \\
\text { Choice \#3 }\end{array}$ & $\begin{array}{c}\text { Answer } \\
\text { Choice \#4 }\end{array}$ & $\begin{array}{c}\text { Answer } \\
\text { Choice \#5 }\end{array}$ \\
\hline Gender & & Male & Female & & & \\
\hline Occupation & $\begin{array}{c}\text { Are you } \\
\text { currently } \\
\text { Employed? }\end{array}$ & Employed & $\begin{array}{c}\text { Self- } \\
\text { Employed }\end{array}$ & Housewife & Student & Unemployed \\
\hline $\begin{array}{l}\text { Annual } \\
\text { Income }\end{array}$ & $\begin{array}{l}\text { How much is } \\
\text { your annual } \\
\text { income? }\end{array}$ & $\begin{array}{l}\text { Less than } \\
\$ 20,000\end{array}$ & $\begin{array}{c}\text { More than } \\
\$ 20,000 \\
\text { but less } \\
\text { than } \\
\$ 50,000\end{array}$ & $\begin{array}{c}\text { More than } \\
\$ 50,000 \\
\text { but less } \\
\text { than } \\
\$ 70,000\end{array}$ & $\begin{array}{c}\text { More than } \\
\$ 70,000 \\
\text { but less } \\
\text { than } \\
\$ 100,000\end{array}$ & $\begin{array}{l}\text { More than } \\
\$ 100,000\end{array}$ \\
\hline $\begin{array}{l}\text { Educational } \\
\text { Status }\end{array}$ & $\begin{array}{c}\text { What is your } \\
\text { educational } \\
\text { status? }\end{array}$ & $\begin{array}{l}\text { Graduated } \\
\text { junior } \\
\text { high } \\
\text { school }\end{array}$ & $\begin{array}{l}\text { Graduated } \\
\text { high } \\
\text { school }\end{array}$ & $\begin{array}{l}\text { Graduated } \\
\text { junior } \\
\text { college }\end{array}$ & $\begin{array}{l}\text { Graduated } \\
\text { vocational } \\
\text { school }\end{array}$ & $\begin{array}{c}\text { Graduated } 4 \\
\text { year college/ } \\
\text { graduate } \\
\text { school }\end{array}$ \\
\hline $\begin{array}{l}\text { Marital } \\
\text { Status }\end{array}$ & $\begin{array}{l}\text { Are you } \\
\text { currently } \\
\text { married? }\end{array}$ & $\begin{array}{l}\text { Currently } \\
\text { married }\end{array}$ & $\begin{array}{c}\text { Widow/ } \\
\text { widower }\end{array}$ & Divorced & $\begin{array}{l}\text { Never } \\
\text { married }\end{array}$ & \\
\hline $\begin{array}{l}\text { \# of people } \\
\text { in household }\end{array}$ & $\begin{array}{l}\text { How many } \\
\text { people are } \\
\text { staying at } \\
\text { your } \\
\text { residence } \\
\text { (including } \\
\text { you)? }\end{array}$ & $\begin{array}{l}\text { One } \\
\text { person }\end{array}$ & $\begin{array}{c}\text { Two } \\
\text { people }\end{array}$ & $\begin{array}{l}\text { Three } \\
\text { people }\end{array}$ & $\begin{array}{c}\text { Four } \\
\text { people }\end{array}$ & $\begin{array}{c}\text { Five people } \\
\text { or more }\end{array}$ \\
\hline
\end{tabular}

\section{Health conditions}

Health conditions included measures of the amount of stiffness in shoulders, backache, headache, pain in the hands and feet, appetite, excretory functions, allergies, and asthma. Answer choices to each question were the following:

Table 2. Health Conditions

\begin{tabular}{lllllll}
\hline \multicolumn{1}{c}{ Title } & \multicolumn{1}{c}{ Question } & $\begin{array}{c}\text { Answer } \\
\text { choice \#1 }\end{array}$ & $\begin{array}{c}\text { Answer } \\
\text { choice \#2 }\end{array}$ & $\begin{array}{c}\text { Answer } \\
\text { choice \#3 }\end{array}$ & $\begin{array}{c}\text { Answer } \\
\text { choice \#4 }\end{array}$ & $\begin{array}{c}\text { Answer } \\
\text { choice \#5 }\end{array}$ \\
\hline $\begin{array}{l}\text { Stiffness in } \\
\text { shoulders }\end{array}$ & $\begin{array}{l}\text { Do you feel stiffness } \\
\text { in your shoulders } \\
\text { now? }\end{array}$ & Very stiff & Stiff & $\begin{array}{l}\text { Slightly } \\
\text { stiff }\end{array}$ & Normal & Not stiff \\
& $\begin{array}{l}\text { Do you feel that your } \\
\text { shoulders get stiff } \\
\text { easily from daily } \\
\text { activities and work } \\
\text { related activities? }\end{array}$ & $\begin{array}{l}\text { Gets very } \\
\text { stiff }\end{array}$ & Gets stiff & $\begin{array}{l}\text { Gets } \\
\text { slightly stiff }\end{array}$ & $\begin{array}{l}\text { Does not } \\
\text { easily get } \\
\text { stiff }\end{array}$ & $\begin{array}{l}\text { Does not get } \\
\text { stiff at all }\end{array}$ \\
& $\begin{array}{l}\text { Do you feel any } \\
\text { backache? }\end{array}$ & $\begin{array}{l}\text { Very } \\
\text { painful }\end{array}$ & Painful & $\begin{array}{l}\text { Slightly or } \\
\text { sometimes } \\
\text { painful } \\
\text { Backache }\end{array}$ & $\begin{array}{l}\text { Not so } \\
\text { painful }\end{array}$ & $\begin{array}{l}\text { Not painful } \\
\text { at all }\end{array}$ \\
& Do you feel any & Very & Painful & Slightly or & Not so & Not painful
\end{tabular}




\begin{tabular}{|c|c|c|c|c|c|c|}
\hline & headache? & painful & & $\begin{array}{l}\text { sometimes } \\
\text { painful }\end{array}$ & painful & at all \\
\hline $\begin{array}{l}\text { Pains in the } \\
\text { hand and feet }\end{array}$ & $\begin{array}{l}\text { Do you feel pain in } \\
\text { the hands/feet and/or } \\
\text { joints? }\end{array}$ & $\begin{array}{l}\text { Very } \\
\text { painful }\end{array}$ & Painful & $\begin{array}{l}\text { Slightly or } \\
\text { sometimes } \\
\text { painful }\end{array}$ & $\begin{array}{l}\text { Not so } \\
\text { painful }\end{array}$ & $\begin{array}{l}\text { Not painful } \\
\text { at all }\end{array}$ \\
\hline Appetite & $\begin{array}{l}\text { Do you have a good } \\
\text { appetite? }\end{array}$ & $\begin{array}{l}\text { Very good } \\
\text { appetite }\end{array}$ & $\begin{array}{l}\text { Good } \\
\text { appetite }\end{array}$ & $\begin{array}{l}\text { Fair } \\
\text { appetite }\end{array}$ & $\begin{array}{l}\text { Bad } \\
\text { appetite }\end{array}$ & $\begin{array}{l}\text { Very bad } \\
\text { appetite }\end{array}$ \\
\hline Discharge & $\begin{array}{l}\text { Are your excretory } \\
\text { functions (bowel } \\
\text { movements, } \\
\text { urination) normal? }\end{array}$ & Very good & Good & Fair & Bad & Very bad \\
\hline Menstrual cycle & $\begin{array}{l}\text { Is you menstrual } \\
\text { cycle regular? }\end{array}$ & Very good & Good & $\begin{array}{l}\text { Sometimes } \\
\text { irregular }\end{array}$ & $\begin{array}{l}\text { Very } \\
\text { irregular }\end{array}$ & $\begin{array}{l}\text { N/A Male or } \\
\text { s/p } \\
\text { hysterectomy } \\
\text { or s/p } \\
\text { Menopause }\end{array}$ \\
\hline Allergy & $\begin{array}{l}\text { Are you predisposed } \\
\text { to any allergy? }\end{array}$ & $\begin{array}{l}\text { Predisposed } \\
\text { to be } \\
\text { allergic }\end{array}$ & $\begin{array}{l}\text { Somewhat } \\
\text { allergic }\end{array}$ & $\begin{array}{l}\text { Allergic in } \\
\text { the past }\end{array}$ & Not allergic & Do not know \\
\hline Food allergy & $\begin{array}{l}\text { Are you allergic to } \\
\text { any food? }\end{array}$ & $\begin{array}{l}\text { Currently } \\
\text { allergic }\end{array}$ & $\begin{array}{l}\text { Allergic in } \\
\text { the past }\end{array}$ & Not allergic & $\begin{array}{l}\text { Do not } \\
\text { know }\end{array}$ & \\
\hline $\begin{array}{l}\text { Chemical } \\
\text { allergy }\end{array}$ & $\begin{array}{l}\text { Are you allergic to } \\
\text { any chemical } \\
\text { substance? }\end{array}$ & $\begin{array}{l}\text { Currently } \\
\text { allergic }\end{array}$ & $\begin{array}{l}\text { Allergic in } \\
\text { the past }\end{array}$ & Not allergic & $\begin{array}{l}\text { Do not } \\
\text { know }\end{array}$ & \\
\hline $\begin{array}{l}\text { Nasal } \\
\text { inflammation }\end{array}$ & $\begin{array}{l}\text { Do you suffer from } \\
\text { nasal inflammation? }\end{array}$ & $\begin{array}{l}\text { Currently } \\
\text { with } \\
\text { symptoms }\end{array}$ & $\begin{array}{l}\text { Had } \\
\text { symptoms } \\
\text { in the past }\end{array}$ & $\begin{array}{l}\text { No } \\
\text { symptoms }\end{array}$ & $\begin{array}{l}\text { Do not } \\
\text { know }\end{array}$ & \\
\hline Dermatitis & $\begin{array}{l}\text { Do you have } \\
\text { symptoms of } \\
\text { dermatitis? }\end{array}$ & $\begin{array}{l}\text { Currently } \\
\text { with } \\
\text { symptoms }\end{array}$ & $\begin{array}{l}\text { Had } \\
\text { symptoms } \\
\text { in the past }\end{array}$ & $\begin{array}{l}\text { No } \\
\text { symptoms }\end{array}$ & $\begin{array}{l}\text { Do not } \\
\text { know }\end{array}$ & \\
\hline Asthma & $\begin{array}{l}\text { Do you have } \\
\text { symptoms of asthma? }\end{array}$ & $\begin{array}{l}\text { Currently } \\
\text { with } \\
\text { symptoms }\end{array}$ & $\begin{array}{l}\text { Had } \\
\text { symptoms } \\
\text { in the past }\end{array}$ & $\begin{array}{l}\text { No } \\
\text { symptoms }\end{array}$ & $\begin{array}{l}\text { Do not } \\
\text { know }\end{array}$ & \\
\hline Alcohol & $\begin{array}{l}\text { Do you drink } \\
\text { alcohol? }\end{array}$ & $\begin{array}{l}\text { Drink every } \\
\text { day }\end{array}$ & $\begin{array}{l}\text { Drink } \\
\text { mostly } \\
\text { every day }\end{array}$ & Sometimes & Rarely & None \\
\hline
\end{tabular}

\section{Lifestyle characteristics}

The lifestyle characteristics included measures of amount of sleep, smoking, secondhand smoking, and alcohol consumption.

Table 3. Lifestyle characteristics

\begin{tabular}{|c|c|c|c|c|c|c|}
\hline Title & Question & $\begin{array}{l}\text { Answer choice } \\
\# 1\end{array}$ & $\begin{array}{l}\text { Answer } \\
\text { choice \#2 }\end{array}$ & $\begin{array}{l}\text { Answer } \\
\text { choice \#3 }\end{array}$ & $\begin{array}{l}\text { Answer } \\
\text { choice\# } 4\end{array}$ & $\begin{array}{l}\text { Answer } \\
\text { choice } \# 5\end{array}$ \\
\hline $\begin{array}{l}\text { Amount of } \\
\text { sleep }\end{array}$ & $\begin{array}{l}\text { Do you sleep } \\
\text { well? }\end{array}$ & Sleep very well & Sleep well & $\begin{array}{l}\text { Sleep is } \\
\text { fair }\end{array}$ & $\begin{array}{l}\text { Sleep is } \\
\text { bad }\end{array}$ & $\begin{array}{l}\text { Sleep is } \\
\text { very bad }\end{array}$ \\
\hline Smoking & $\begin{array}{l}\text { Do you } \\
\text { currently } \\
\text { smoke? }\end{array}$ & $\begin{array}{l}\text { Smoke } \\
\text { regularly every } \\
\text { day }\end{array}$ & $\begin{array}{l}\text { Smoke } \\
\text { sometimes }\end{array}$ & $\begin{array}{l}\text { Used to } \\
\text { smoke in } \\
\text { the past }\end{array}$ & $\begin{array}{l}\text { Have } \\
\text { never } \\
\text { smoked }\end{array}$ & \\
\hline $\begin{array}{l}\text { Passive } \\
\text { smoking/ } \\
\text { Smoke } \\
\text { exposure }\end{array}$ & $\begin{array}{l}\text { Does anyone of } \\
\text { your family } \\
\text { member smoke? }\end{array}$ & $\begin{array}{l}\text { Smoke } \\
\text { regularly every } \\
\text { day }\end{array}$ & $\begin{array}{l}\text { Smoke } \\
\text { sometimes }\end{array}$ & $\begin{array}{l}\text { Used to } \\
\text { smoke in } \\
\text { the past }\end{array}$ & $\begin{array}{l}\text { Have } \\
\text { never } \\
\text { smoked }\end{array}$ & \\
\hline
\end{tabular}


Alcohol

Do you drink alcohol?

Drink every day

Drink

Sometimes Rarely

None

mostly

every day

\section{Frequency of receipt/practice of CAM}

The frequency of receipt and/or practice of each CAM practice was measured by asking the participants how often they received each of the practices based on a five-point scale. There were seven measures related to OPT. The remaining were questions asking about the frequency of the other CAM practices. All answers were chosen from a fivepoint scale.

Table 4. Frequencies of receiving CAM

\begin{tabular}{|c|c|c|c|c|c|c|}
\hline Question & $\begin{array}{c}\text { Answer } \\
\text { Choice \#1 }\end{array}$ & $\begin{array}{c}\text { Answer } \\
\text { Choice \#2 }\end{array}$ & $\begin{array}{c}\text { Answer } \\
\text { Choice\#3 }\end{array}$ & $\begin{array}{c}\text { Answer } \\
\text { Choice \#4 }\end{array}$ & $\begin{array}{c}\text { Answer } \\
\text { Choice \#5 }\end{array}$ & $\begin{array}{c}\text { Answer } \\
\text { Choice \#6 }\end{array}$ \\
\hline $\begin{array}{l}\text { Have you received OPT in } \\
\text { the recent three months? }\end{array}$ & Yes & No & & & & \\
\hline $\begin{array}{l}\text { How often have you } \\
\text { received OPT in the last } \\
\text { three months? }\end{array}$ & Every day & $\begin{array}{l}\text { Five to six } \\
\text { times a } \\
\text { week }\end{array}$ & $\begin{array}{l}\text { Three to } \\
\text { four times } \\
\text { a week }\end{array}$ & $\begin{array}{l}\text { Once or } \\
\text { twice a } \\
\text { week }\end{array}$ & $\begin{array}{l}\text { Once in } \\
\text { several } \\
\text { weeks }\end{array}$ & $\begin{array}{l}\text { Do not } \\
\text { practice }\end{array}$ \\
\hline How long was the average & Less than & $15-30$ & $30-60$ & $1-2$ hours & More than & \\
\hline $\begin{array}{l}\text { duration of each OPT } \\
\text { session? }\end{array}$ & 15 minutes & minutes & minutes & & 2 hours & \\
\hline $\begin{array}{l}\text { How often did you } \\
\text { practice or administer the } \\
\text { OPT to others? }\end{array}$ & Every day & $\begin{array}{l}\text { Five to six } \\
\text { times a } \\
\text { week }\end{array}$ & $\begin{array}{l}\text { Three to } \\
\text { four times } \\
\text { a week }\end{array}$ & $\begin{array}{l}\text { Once in } \\
\text { several } \\
\text { weeks }\end{array}$ & $\begin{array}{l}\text { Do not } \\
\text { practice }\end{array}$ & \\
\hline $\begin{array}{l}\text { How long was the average } \\
\text { duration of each OPT that } \\
\text { you administered to } \\
\text { others? }\end{array}$ & $\begin{array}{l}\text { Less than } \\
15 \text { minutes }\end{array}$ & $\begin{array}{l}15-30 \\
\text { minutes }\end{array}$ & $\begin{array}{l}30-60 \\
\text { minutes }\end{array}$ & 1-2 hours & $\begin{array}{l}\text { More than } \\
2 \text { hours }\end{array}$ & \\
\hline $\begin{array}{l}\text { Do you feel that your } \\
\text { psychological health was } \\
\text { benefitting from the } \\
\text { practice of OPT? }\end{array}$ & $\begin{array}{l}\text { Very } \\
\text { much }\end{array}$ & Mostly & Somewhat & Little bit & None & \\
\hline $\begin{array}{l}\text { Do you feel that your } \\
\text { physical health was } \\
\text { benefitting from the } \\
\text { practices of OPT? }\end{array}$ & Very much & Mostly & Somewhat & Little bit & None & \\
\hline $\begin{array}{l}\text { How often have you } \\
\text { participated in arts and } \\
\text { cultural activities other } \\
\text { than music? }\end{array}$ & Every day & $\begin{array}{l}\text { Mostly } \\
\text { every day }\end{array}$ & Frequently & $\begin{array}{l}\text { Occasion- } \\
\text { ally }\end{array}$ & None & \\
\hline $\begin{array}{l}\text { What proportion of your } \\
\text { daily diet consisted of } \\
\text { natural, organic, and } \\
\text { preservative/additive-free }\end{array}$ & $\begin{array}{l}\text { More than } \\
80 \%\end{array}$ & $60-80 \%$ & $40-60 \%$ & $20-40 \%$ & $\begin{array}{l}\text { Below } \\
20 \%\end{array}$ & \\
\hline
\end{tabular}


food?

How often do you practice home gardening and other gardening practices?

How often do you exercise, including activities such as taking a

$\begin{array}{lllll}\text { Every day } & \begin{array}{l}\text { Mostly } \\ \text { every day }\end{array} & \text { Frequently } & \text { Sometimes } & \text { None } \\ \text { Every day } & \begin{array}{l}\text { Mostly } \\ \text { every day }\end{array} & \text { Frequently } & \text { Sometimes } & \text { None } \\ & & & & \end{array}$
walk?

\section{Quality of life}

QOL was measured using the 10-item MOA QOL Questionnaire (see appendix). The MQL-10 has been developed to assess QOL and determine the effects of health practices in large-scale health surveys. The questions were answered utilizing a five-point scale. The scale was designed to assess physical, mental, and social well-being. Each item was scored from 0 to 4 , with higher scores indicating better QOL. The validity of this scale has been established through comparison with the short version of the World Health Organization Quality of Life instrument (WHOQOL-BREF, 26 items) and the 36Item Short Form Health Survey (SF-36) that is used globally. Originally the MQL-10 was developed as a health survey instrument to assess the effects of health practices on QOL, using generally worded questions. Although this instrument's name comes from the developer's organization (MOA), it is not a measure used specifically for the assessment of MOA's health programs. The validation study for this measure demonstrated that correlation coefficient between the total score of the MQL-10 and the average score of the WHOQOL-BREF was $0.81(\mathrm{P}<0.001, \mathrm{n}=195)$; and the correlations with the general health perception, vitality, and mental health domains of the SF-36 were $0.58,0.62$, and 0.64 , respectively $(\mathrm{P}<0.001, \mathrm{n}=260)$. During the development of this scale, three tests were conducted. The mean score for the first test was 27.4 with a standard deviation of 
5.24; the mean score for the second test was 28.1 with a standard deviation of 4.80; and the mean score for the third test was 26.7 with a standard deviation of 5.77 (Kimura et al., 2009).

\section{Psychological stress}

Perceived psychological stress was measured using the 10-Item JPSS-10 (see appendix) (Kimura et al., 2008). JPSS-10 is a shortened version of JPSS created by Iwahashi et al. (Iwahashi, Tanaka, Fukushi, \& Hongo, 2002), which is a translated version of the Perceived Stress Scale (PSS) created by Cohen et al. (Cohen et al., 1983). PSS is one of the few instruments that intends to measure global levels of perceived stress objectively, assessing the degree to which situations in one's life are appraised as stressful. This scale assesses perceived stressful experience or stress responses over the previous month. PSS has been proven to have substantial reliability and validity, and has also shown correlations with a range of self-reports and behavioral criteria. The PSS was translated into JPSS, and in order to examine the extent to which all the items in the PSS and JPSS represented the same phenomena, Cronbach's alpha coefficient was calculated, which resulted in 0.88 for PSS and 0.81 for JPSS. Kimura et al. created a shortened version of the JPSS - JPSS-10 - in response to the suggestions made by Cohen et al. for the creation of a shortened version of the PSS. The concordance rate of the determination between the JPSS and the JPSS-10 was high (77.3 percent); therefore, the JPSS-10 was assumed to be acceptable as a scale for the assessment of perceived stress including individual assessments. Scores of 0-13 are considered low stress, 14-18 normal, 19-24 high, and anything above 25 is considered very high stress (Kimura et al., 2008). 


\section{Data analysis}

Prior to conducting analysis, nominal variables - including gender, marital status, occupation, and education - were recoded to dichotomous variables. Marital status was recoded into: 1) married, or 2) not married, including divorced and widowed. Occupation was recoded into two categories: 1) employed and self-employed, or 2) unemployed, including housewife and student. Educational attainment was also recoded into two categories: 1) high school graduate or less, or 2) post-high school education, including junior college, technical school, and college graduate or post-college education. The frequency of practice of CAM variables and the remaining variables of annual income, sleep, appetite, and excretory functions were collected as categorical variables. Bivariate analyses were conducted. However, the variables were also analyzed as continuous variables. The differences in the categories of the scales were treated as equal. Previous research has justified treating ordinal scales as an interval scale for the purpose of conducting parametric tests (Baker, 1966).

Data were checked for missing values and outliers. There were 190 missing values in the variable "annual income." The overall mean value of annual income was entered for participants who had missing values in annual income. Initial analyses were conducted including the mean annual income for participants with missing data in this field, and excluding the participants with missing values in the variable "annual income." The results were similar; thus, the variable of annual income was included with the overall mean income value entered for participants with missing data in these variables (Mertler \& Vannatta, 2005). Assumptions of linearity, normality, homoscedasticity, and multicollinearity were met. 
In the parent study, the control factors used were gender, age, occupation, education, and marital status. In addition to these control factors, the present study used reported annual income, appetite, excretory functions, and sleep as control factors. By controlling for these variables, a more refined correlation was predicted between QOL and stress and the five CAM practices.

\section{Hypothesis}

Chronic stress may be associated with both excess eating or anorexia (Adam \& Epel, 2007), as most people either increase or decrease their food intake as a response to stress (Epel et al., 2004), (Stone \& Brownell, 1994). Hence dissatisfaction with appetite may be associated with lower scores on QOL and higher scores on the perceived stress scale. The quality of sleep is also affected by stress, and furthermore, QOL is affected by the amount and quality of sleep (Reimer \& Flemons, 2003). The state of excretory functions (e.g., reports of constipation, diarrhea) may be associated with stress and quality of life since these control factors all reflect individual organ systems;

dissatisfaction in these aspects of health may come from stress or be aggravated by stress, or conversely, may lead to stress ultimately reducing QOL. Controlling for these factors was important to control for confounding effects and observe correlations between each CAM practice with QOL and stress.

\section{Hypothesis one}

Hypothesis\#1: All five lifestyle-related CAM practices will be associated with improved QOL and reduced perceived stress 
A backward multiple regression analysis, a type of stepwise multiple regression, was conducted to test hypothesis number one and determine which if any of the five practices were significantly associated with improved QOL and decreased perceived stress $(\mathrm{p}<0.05)$. Twelve models were created for this analysis. The first 10 assessed the association of each of the five lifestyle-related CAM practices with QOL and perceived stress through multivariate regression analysis. The remaining two models were an overall model with QOL as the dependent variable and another model with perceived stress as the dependent variable, including all of the control factors and CAM practices as independent variables.

\section{Hypothesis two and three}

Hypothesis \#2: The association between practice of arts and cultural activities and QOL/perceived stress will differ significantly by sex

Hypothesis \#3: The association between practice of OPT and QOL/perceived stress will differ significantly by sex

To test for hypotheses number two and three, six models were created for each hypothesis and tested using multiple regression analysis. The first model consisted of gender, arts and cultural activities, and an interaction variable of the two variables as the independent variables, and perceived stress as the dependent variable. The second model consisted of gender, arts and cultural activities, and an interaction variable of those two variables, with all the remaining control variables as the independent variables, and perceived stress as the dependent variable. The third model consisted of gender, arts and cultural activities, an interaction variable of those two variables, all the remaining control variables, and all other CAM practices as the independent variables, and perceived stress 
as the dependent variable. This was repeated for the three remaining models with QOL as the dependent variable. The same procedures were used to test the third hypothesis, substituting OPT for arts and cultural activities.

To address concerns regarding multicollinearity, a statistical technique (centering towards the variable arts and culture) was employed (Leona S. Aiken, Stephen G. West, \& Raymond R. Reno, 1991; Robinson \& Schumacker, 2009). The mean score of arts and culture was subtracted from each score of the variable "arts and culture" to form a centered variable of arts and culture. Next, an interaction variable of gender and centered arts and culture was created. The three variables were entered into the first model as independent variables and perceived stress was used as the dependent variable. The same procedures were followed for the third hypothesis with OPT.

\section{Phase II}

The purpose of the qualitative study was to determine why people choose to practice OPT. An in-depth interview was employed at the second phase of the sequential explanatory mixed methods design. Grounded theory was utilized as the research methodology. This approach is a general methodology for developing theory that is grounded in data systematically gathered and analyzed. Theory is developed during actual research by continuously going back and forth between analysis and data collection (Creswell, 2012; Denzin \& Lincoln, 2003) .

\section{Participants}

For the qualitative portion of the study, one-on-one interviews were conducted with 25 patients diagnosed with chronic illness. Patients were convenience-sampled based on the patient's availability and voluntary consent to participate in the interview. 
The interview took place at Tokyo Ryoin, one of the 10 clinics chosen within Japan where data for the parent study were collected. Tokyo Ryoin was chosen by the researcher based on the clinic's availability and approval for conducting research. The indepth interviews followed a semi-structured interview guide with questions concerning the process of how the patients decided to practice OPT.

\section{Inclusion and exclusion criteria}

Eligibility for participation in the qualitative portion of the study were: age 18 years or older, some prior knowledge and at least one experience of receiving OPT, and being diagnosed with a chronic disease.

\section{Interview questions}

The interview was conducted based on four basic questions to capture the multiple elements of reasons why participants decided to receive and continue OPT. The following questions were asked:

1. Please reflect back on the time you first received OPT, and tell me about your experience and how you came about knowing OPT.

2. Why did you decide to continue receiving OPT?

3. Before getting to know OPT, what did you do to maintain health?

4. Would you let others know about OPT?

Other questions were also asked that were intended to facilitate the interview and to probe reasons why participants decided to receive OPT. Interviewer followed the flow of each interview. 


\section{Data analysis}

The coding was conducted after all of the data from the interviews were transcribed into text. Analyses consisted of three phases of coding: open coding, axial coding, and selective coding. During open coding, data conceptualization was conducted by the researcher, scrutinizing the data in an attempt to understand the essence of what was being expressed in the data. Then each of the concepts was given a conceptual name or a label to describe that understanding. Concepts are the smallest unit of qualitative data that represent a complete thought or idea. Concepts can range in size from a single word in context to several sentences. Coding requires the right word or two that best describe conceptually what the researcher believes is indicated in the data. After conceptualization of data, categories were created from systematically evaluating and channeling codes into related groupings. Categories were formed from grouped codes that were saturated, using the constant comparative approach. Next, axial coding was conducted by relating concepts/categories to each other. Similar concepts that were generated during open coding were gathered together and related to each other during this phase. Qualitatively different concepts were separated. Higher-order axial categories were created by connecting similar categories, and clusters were formed.

The information gathered from axial coding was then organized into a coding paradigm that presents a theoretical model of the process of why patients practice OPT. Finally, during selective coding, themes or broad patterns that describe the overall storyline that emerges for the data were chosen. A label was given to the central phenomenon that fits the story. How well each participant's story fit the chosen overarching theme was tested by comparing each story with the overarching theme and 
applying each story to the central phenomenon and each of the categories that are based on the theme (Corbin \& Strauss, 2008; Creswell, 2012; Denzin \& Lincoln, 2003).

\section{Validity and reliability}

The researcher became fully immersed within the clinics and the people visiting the clinics for the purpose of collecting more accurate and valid findings from the participants. In general, the more experience a researcher has with participants and the settings, the more accurate or valid the findings will be. To determine the accuracy of the qualitative findings, member checking was also conducted. This procedure involved taking the coded descriptions and final reports that were created through interview back to the participants to determine whether they feel that the descriptions are accurate. Major findings, themes, and theory that were analyzed through the qualitative phase were taken back to the participants to check for accuracy. Specifically, a follow-up conversation was conducted over the telephone with three non-randomly chosen participants to obtain additional feedback on the findings.

To ensure reliability of findings, transcripts and notes were checked to make sure that no mistakes were made during transcription. Codes were compared with data constantly so that there was no false shift in the meaning of the codes during the process of coding.

\section{Human subject considerations}

The study plan for this research was approved by the Institutional Review Board at Florida International University. The study status was deemed expedited due to the characteristics of the study, such as the collection of data from voice made for research purposes during interviews with participants. 


\section{Summary}

This study utilized a sequential explanatory mixed methods design combining both quantitative research and qualitative research. The first phase of the study used a quantitative approach to examine the effects of the five CAM practices on QOL and perceived stress among patients 18 years or older who were diagnosed with chronic illness and living in Japan. This was a secondary cross-sectional data analysis using data from research that was conducted in Japan. Permission to use secondary data was granted by the principal investigator of the primary research at the MOA Health Science Foundation. The secondary data consisted of 1,190 participants (894 [75.1 percent] women; mean age 60.54). A multiple linear regression analysis was conducted to determine the association between the practice of five CAM practices and QOL and perceived stress controlling for age, gender, marital status, occupation, education, annual income, appetite, sleep, and excretory functions. Interaction effects between gender and arts and culture, and interaction effects between gender and OPT were also assessed using multiple regression analysis.

The second phase of the study explored the reasons why patients decided to receive OPT using grounded theory as the method of qualitative inquiry. This approach is a general methodology for developing theory that is grounded in data systematically gathered and analyzed. Data collection and analysis were conducted simultaneously back and forth several times for the purpose of strengthening the fit between data and analysis. In-depth interviews were conducted among 25 patients diagnosed with chronic illness. Patients were conveniently sampled at a clinic in Tokyo that was one of the 10 clinics in Japan where the quantitative data was collected. 


\section{CHAPTER IV RESULTS}

\section{Introduction}

This study assessed the association of the five lifestyle-related CAM practices with QOL and perceived stress in chronically ill patients, and attempted to explain why participants decided to receive OPT. The study consisted of a two-phase explanatory sequential mixed-methods approach intended to provide more insight and understanding by gathering qualitative data based on the results of quantitative data. The qualitative phase utilized grounded theory as its method of inquiry.

This chapter is divided into two sections. In phase I, secondary data analysis was conducted utilizing data from parent study "Associations between perceived stress, quality of life and complementary health practices in Japanese outpatients: a multicenter observational study," for which the data were collected throughout Japan in 10 clinics between 2010 and 2012. First, demographic characteristics and frequency of CAM practices, health conditions, and lifestyle factors are described for 1,190 chronically ill participants who were available. Second, the association between each of the five CAM practices and QOL and perceived stress measures is addressed. Third, whether there exist differences in the association between OPT and arts and culture with QOL and perceived stress between males and females is examined. Finally, in phase II, the qualitative analysis, emergent themes and codes are presented from 25 chronically ill participants who have received OPT in one of the clinics in Tokyo. 


\section{Phase I quantitative analysis}

This dissertation study addressed the following research question: What are the effects of the five CAM practices on QOL and perceived stress? Three hypotheses examine this research question.

Hypothesis \#1: Arts and culture, exercise, diet, home gardening and OPT will have positive association with QOL and negative association with perceived stress.

Hypothesis \#2: The association between practice of arts and cultural activities and QOL/perceived stress is significantly different between males and females.

Hypothesis \#3: The association between practice of OPT and QOL/perceived stress is significantly different between males and females.

\section{Descriptive analysis}

For this part of the study, data from 1,190 participants collected from 10 medical clinics throughout Japan were analyzed. Table 5 lists the prefectures of the clinics and the numbers of participants from each clinic. The sample was drawn by convenience in these 10 clinics. Almost one-fourth (23.4 percent) of the data were collected from participants in Hokkaido.

Table 5. Number of participants from each clinic

\begin{tabular}{lll}
\hline Prefecture & Frequency (n) & Percent (\%) \\
\hline Aichi & 109 & 9.2 \\
Hiroshima & 189 & 15.9 \\
Hokkaido & 279 & 23.4 \\
Ishikawa & 40 & 3.4 \\
Kagoshima & 115 & 9.7 \\
Kochi & 75 & 6.3 \\
Okinawa & 103 & 8.7
\end{tabular}




\begin{tabular}{lll} 
Osaka & 165 & 13.9 \\
Shizuoka & 28 & 2.4 \\
Tokyo & 87 & 7.3 \\
Total & 1190 & 100.0 \\
\hline
\end{tabular}

Table 6 describes the 1,190 participants chosen for this study. The mean age of the participants was 60.54 years old $(\mathrm{SD}=14.192)$ and they ranged in age from 20 to 91 years. Over three-fourths of the participants were female $(n=894,75.1 \%), 58$ percent of the participants reported being unemployed ( $\mathrm{n}=690,58$ percent), about 70 percent of the participants were high school graduates or below ( $\mathrm{n}=834,70.1$ percent), and almost threefourths were married ( $\mathrm{n}=877,73.7$ percent).

Table 6. Demographic and SES characteristics

\begin{tabular}{|c|c|c|}
\hline Demographic and SES variables & $\begin{array}{l}\text { Frequency } \\
\text { (n) }\end{array}$ & $\begin{array}{l}\text { Percent } \\
(\%)\end{array}$ \\
\hline \multicolumn{3}{|l|}{ Age } \\
\hline 20 to 29 & 31 & 2.6 \\
\hline 30 to 39 & 86 & 7.2 \\
\hline 40 to 49 & 138 & 11.6 \\
\hline 50 to 59 & 230 & 19.3 \\
\hline 60 to 69 & 377 & 31.7 \\
\hline 70 to 79 & 242 & 20.3 \\
\hline 80 and over & 86 & 7.2 \\
\hline \multicolumn{3}{|l|}{ Sex } \\
\hline Male & 296 & 24.9 \\
\hline Female & 894 & 75.1 \\
\hline \multicolumn{3}{|l|}{ Occupation } \\
\hline Employed & 496 & 41.7 \\
\hline Unemployed & 690 & 58 \\
\hline Missing & 4 & 0.3 \\
\hline \multicolumn{3}{|l|}{ Annual Income* } \\
\hline Above 7 million yen (US $\$ 58,800$ ) & 80 & 6.7 \\
\hline 5 million to 7 million yen (US $\$ 58,800$ ) & 123 & 10.3 \\
\hline 2 million to 5 million yen (US $\$ 42,000$ ) & 653 & 54.9 \\
\hline
\end{tabular}


Below 2 million yen (US \$16,800) $\quad 334$

\section{Education}

Above high school graduate $\quad 351$

$\begin{array}{lll}\text { High school graduate and below } & 834 & 70.1\end{array}$

$\begin{array}{lll}\text { Missing } & 5 & 0.4\end{array}$

\begin{tabular}{lcc} 
Marital status & & \\
Married & 310 & 73.7 \\
Unmarried & 3 & 26.1 \\
Missing & *currency rate $\$ 1=120$ yen \\
\hline & & \\
2014 Median household income in Japan 5 & .370 million yen (US $\$ 43,518)$ \\
Poverty threshold 1.27 million yen /one person household (US $\$ 15,113)$
\end{tabular}

Table 7 shows the participants' chronic illness diagnoses. Hypertension ( $\mathrm{n}=287$, 24.7 percent), dyslipidemia ( $\mathrm{n}=262,22$ percent), other ( $\mathrm{n}=120,10.1$ percent), diabetes $(\mathrm{n}=104,8.7$ percent), and liver/pancreatic disease $(\mathrm{n}=79,6.6$ percent) were the five most common diseases that were reported.

Table 7. Types of Chronic illnesses

\begin{tabular}{lll}
\hline Chronic condition & Frequency (n) & Percent (\%) \\
\hline Malignant Neoplasm & 30 & 2.5 \\
Malignant Neoplasm Post Surgery & 51 & 4.3 \\
Benign Neoplasm & 21 & 1.8 \\
Benign Neoplasm Post Surgery & 8 & 0.7 \\
Anemia & 74 & 6.2 \\
Endocrinal Disorder & 40 & 3.4 \\
Diabetes & 104 & 8.7 \\
Obesity & 42 & 3.5 \\
Dyslipidemia & 262 & 22 \\
Mental Disorder & 7 & 0.6 \\
Neurotic Disorder & 38 & 3.2 \\
Cranial Nerve Disorder & 15 & 1.3 \\
Allergic Disease & 54 & 4.5 \\
Heart Disease & 70 & 5.9 \\
Hypertension & 287 & 24.1 \\
Cerebrovascular Disease & 35 & 2.9
\end{tabular}




\begin{tabular}{lll} 
Respiratory Disease & 45 & 3.8 \\
Gastrointestinal Disease & 43 & 3.6 \\
Liver/Pancreatic Disease & 79 & 6.6 \\
Joint pain/gout & 67 & 5.6 \\
Rheumatism/Collagenosis & 34 & 2.9 \\
Kidney Disease & 31 & 2.6 \\
Others & 120 & 10.1 \\
\hline
\end{tabular}

Table 8 shows the frequency of health conditions, lifestyle behaviors, and CAM practices reported based on questions with Likert scale-type responses. These variables were included as control and independent variables for analysis. Over half of the participants reported having a very good appetite ( $\mathrm{n}=688,57.8$ percent), and almost half reported sleeping well ( $\mathrm{n}=559,47.0$ percent) and having satisfactory excretory functions ( $\mathrm{n}=542,45.5$ percent). One-fourth of the participants reported that they received OPT everyday ( $\mathrm{n}=308,25.9$ percent); 40 percent reported that they participated in arts and cultural activities frequently ( $\mathrm{n}=478,40.2$ percent); and almost one-third reported that more than 80 percent of their food consisted of additive-free, natural and organic food products. More than one-fourth reported engaging in home gardening activities frequently ( $\mathrm{n}=335,28.2$ percent) and almost one-third reported exercising frequently $(\mathrm{n}=$ $381,32.0$ percent).

Table 8. Characteristics of health conditions, lifestyle behaviors, and CAM practice

\begin{tabular}{lll}
\hline Lifestyle variables & Frequency (n) & Percent (\%) \\
\hline Appetite & & \\
Very good appetite & 688 & 57.8 \\
Normal appetite & 434 & 36.5 \\
Unsure & 42 & 3.5 \\
Poor appetite & 26 & 2.2 \\
Very poor appetite & 0 & 0 \\
Sleep & &
\end{tabular}




$\begin{array}{lll}\text { Very well } & 371 & 31.2 \\ \text { Well } & 559 & 47.0 \\ \text { Unsure } & 135 & 11.3 \\ \text { Poor } & 125 & 10.5 \\ \text { Very poor } & 0 & 0\end{array}$

\section{Excretory functions}

Very good

Well

Unsure

Poor

\section{Frequency of receiving OPT}

Every day

Five to six times a week

Three to four times a week

Once or twice a week

Once in several weeks

Do not practice

Missing

\section{Arts and culture}

Every day

Almost every day

Frequently

Occasionally

None

Missing

Frequency of Eating AdditiveFree "Organic" Food

More than $80 \%$

$60-80 \%$

$40-60 \%$

$20-40 \%$

Below 20\%

Missing

\section{Home gardening}

Every day

Almost every day
1

176

247

281

152

17

9

25.9

14.8

20.8

23.6

12.8

1.4

0.2

14.7

24.0

40.2

17.7

3.3

0.1 


\begin{tabular}{lll} 
Frequently & 335 & 28.2 \\
Sometimes & 299 & 25.1 \\
None & 326 & 27.4 \\
Exercise & & \\
Every day & 128 & 10.8 \\
Almost every day & 201 & 16.9 \\
Frequently & 381 & 32.0 \\
Sometimes & 313 & 26.3 \\
None & 167 & 14.0 \\
\hline
\end{tabular}

The outcome variables were measures of QOL and perceived stress, measured by the use of two scales, MQOL-10 and JPSS-10. Reliability analysis was conducted to test the internal consistencies of both scales. Cronbach's alpha for six items on JPSS-10 was 0.828, and 0.732 for the remaining four items, and the Cronbach's alpha for MQOL-10 was 0.859 . Both scales were above the cutoff point of 0.8 that was deemed appropriate for basic research (Lance, Butts, \& Michels, 2006). The mean score for the outcomes of the JPSS-10 was $15.25(\mathrm{SD}=5.772)$, which was in the range of normal stress, and the mean score for MQOL-10 was $26.98(\mathrm{SD}=5.327)$. With a maximum score of 40 points, a higher score on the MQOL-10 indicates a higher QOL and a lower score indicates a lower QOL based on the scale instrument. Conversely, with a maximum score of 40 points, higher scores indicate a higher perceived stress level and a lower score indicates a lower perceived stress level for the JPSS-10. Figure 1 is a histogram of the distribution of the JPSS-10 score, and Figure 2 is a histogram of the distribution of the MQOL-10 score. The histograms depict a normally distributed bell-shaped curve for JPSS-10 (mean score 15.25, median 15) and a slightly positively skewed bell-shaped curve for MQOL-10 score (mean score 26.98, median 28). 
Chart 1 Distributions of score of JPSS-10

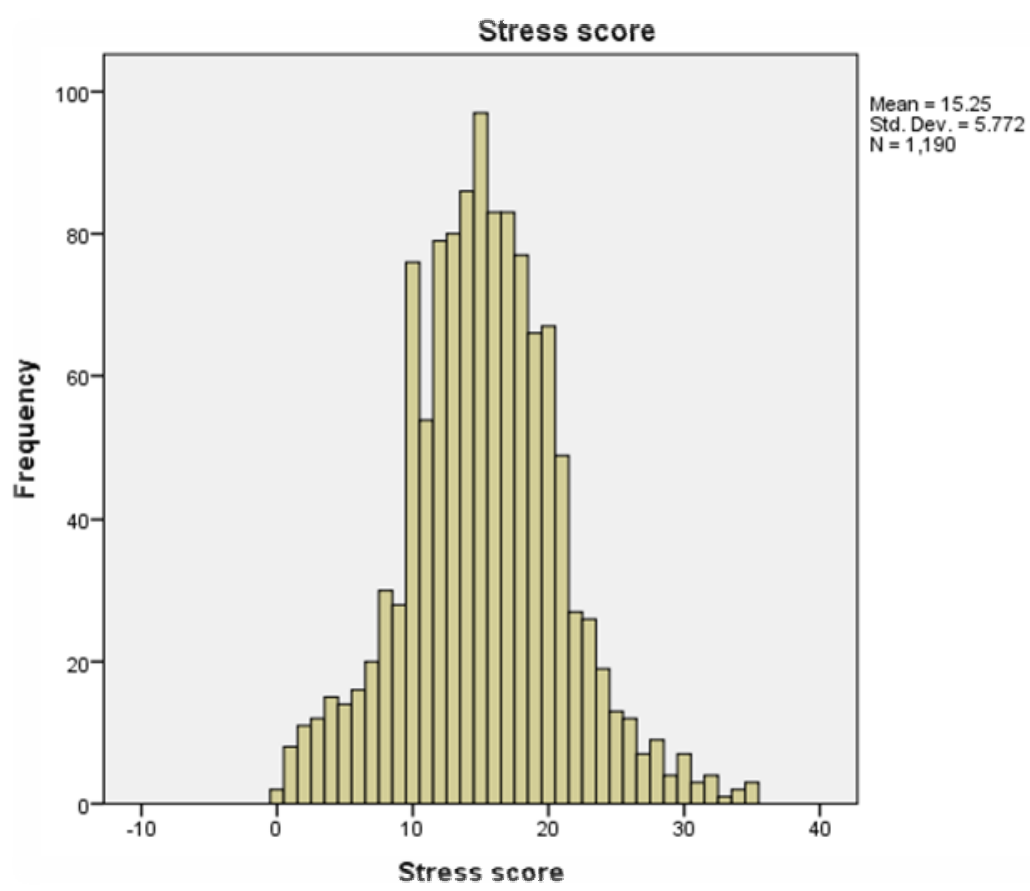

Chart 2. Distribution of scores of MQOL-10

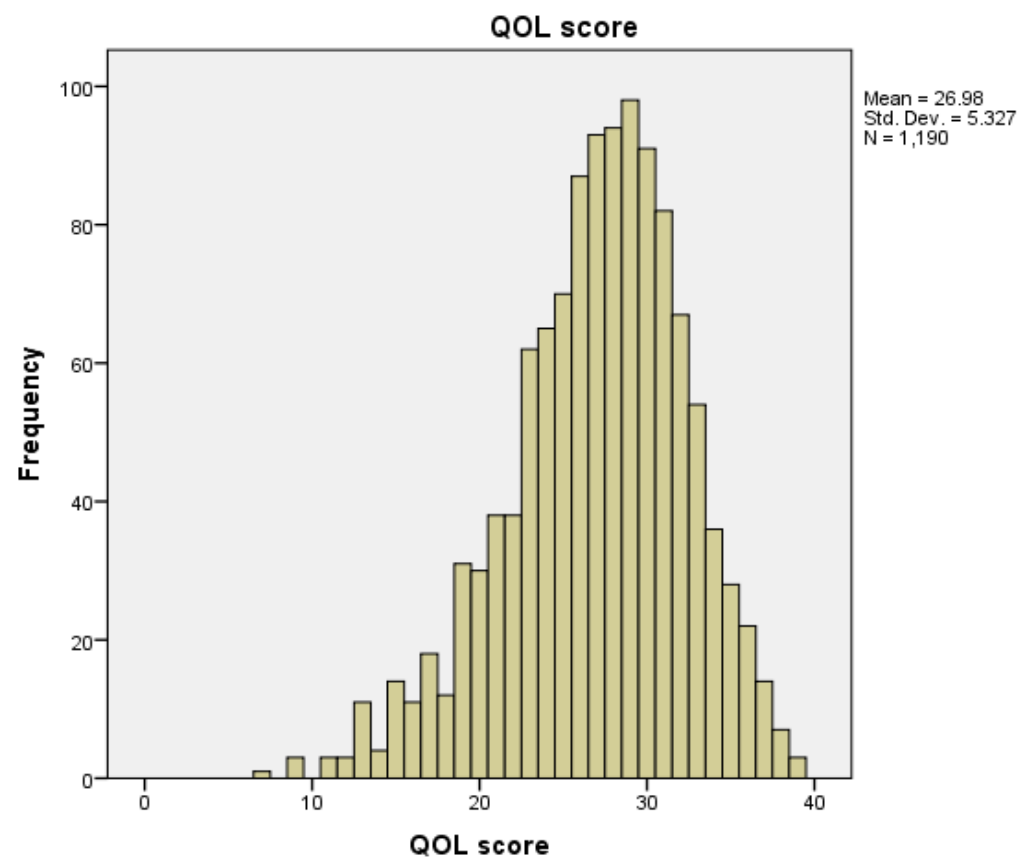




\section{Bivariate analysis}

To test the first hypothesis, a bivariate analysis was performed in order to determine if the five lifestyle-related CAM practices and the outcome measures of perceived stress and QOL were related to one another. A simple linear regression analysis was performed between each of the five lifestyle-related CAM practices and the two outcome measures of perceived stress and QOL to examine their unadjusted relationships. All of the five CAM practices showed significant negative associations with perceived stress and significant positive association with QOL (Table 9).

Table 9. Results of simple linear regression of CAM practices and QOL and perceived stress

\begin{tabular}{|c|c|c|}
\hline & Perceived Stress & QOL \\
\hline CAM practices & $\beta(\mathrm{SE})$ & $\beta(\mathrm{SE})$ \\
\hline Exercise & $-0.213(0.138) * * *$ & $0.247(0.127)^{* * *}$ \\
\hline Home gardening & $-0.19(0.134)^{* * *}$ & $0.171(0.124)^{* * *}$ \\
\hline Arts and Culture & $-0.226(0.159)^{* * *}$ & $0.265(0.145)^{* * *}$ \\
\hline Additive-Free "Organic " Food & $-0.153(0.144)^{* * *}$ & $0.266(0.129)^{* * *}$ \\
\hline OPT & $-0.062(0.117)^{*}$ & $0.148(0.107)^{* * *}$ \\
\hline
\end{tabular}

\section{Multiple regression analysis}

Table 10 shows the results of the regression model predicting participants' perceived stress and QOL based on control variables and the five CAM practices. Results for the model of each CAM and control variables indicated exercise (adjusted $\beta=-0.103$, $\mathrm{p}<0.001$ ), arts and culture (adjusted $\beta=-0.135, \mathrm{p}<0.001$ ), and additive-free organic food (adjusted $\beta=-0.070, \mathrm{p}<0.01$ ) to have a significant negative association with perceived stress controlling for variables of age, sex, education level, annual income, sleep, 
appetite, and excretory functions. In addition, exercise (adjusted $\beta=0.173, p<0.001$ ), arts and culture (adjusted $\beta=0.204, p<0.001$ ), diet (adjusted $\beta=0.182, p<0.001$ ), home gardening (adjusted $\beta=0.084, \mathrm{p}<0.01$ ), and OPT (adjusted $\beta=0.125, \mathrm{p}<0.001$ ) all had a significant positive association with QOL. Results for the model containing all of the CAM and control variables are also included in Table 10. Results reported that exercise (adjusted $\beta=-0.086, p<0.01$ ) and participation in arts and culture activities (adjusted $\beta=-$ $0.121, \mathrm{p}<0.01)$ had a significantly negative association with higher perceived stress. Exercise (adjusted $\beta=-0.137, p<0.001$ ), arts and culture activities (adjusted $\beta=-0.143$, $\mathrm{p}<0.001$ ), additive-free "organic" diet (adjusted $\beta=-0.111, \mathrm{p}<0.001$ ), and OPT (adjusted $\beta=0.058, \mathrm{p}<0.05)$ all had significant positive associations with better QOL.

Table 10. Results of multiple regression models with adjustment factors

\begin{tabular}{|c|c|c|c|c|}
\hline \multirow[b]{3}{*}{ CAM practice } & \multicolumn{2}{|c|}{ Perceived Stress } & \multicolumn{2}{|c|}{ Quality of Life } \\
\hline & $\begin{array}{c}\text { Each CAM + } \\
\text { Control } \\
\text { variables } \\
\end{array}$ & $\begin{array}{c}\text { All CAM + } \\
\text { Control } \\
\text { variables } \\
\end{array}$ & $\begin{array}{c}\text { Each CAM + } \\
\text { Control } \\
\text { variables } \\
\end{array}$ & $\begin{array}{c}\text { All CAM + } \\
\text { Control } \\
\text { variables } \\
\end{array}$ \\
\hline & $\beta \quad(\mathrm{SE})$ & $\beta \quad(\mathrm{SE})$ & $\beta(\mathrm{SE})$ & $\beta(\mathrm{SE})$ \\
\hline Exercise & $-0.103(0.131)^{* * *}$ & $-0.086(0.131)^{* *}$ & $0.173(0.116)^{* * *}$ & $0.137(0.114)^{* * *}$ \\
\hline $\begin{array}{l}\text { Arts and } \\
\text { Culture }\end{array}$ & $-0.135(0.153)^{* * *}$ & $-0.121(0.156)^{* *}$ & $0.204(0.137)^{* * *}$ & $0.143(0.141)^{* * *}$ \\
\hline $\begin{array}{l}\text { Additive-Free } \\
\text { "Organic" Diet }\end{array}$ & $-0.070(0.133)^{* *}$ & -0.038 & $0.182(0.117)^{* * *}$ & $0.111(0.127)^{* * *}$ \\
\hline $\begin{array}{l}\text { Home } \\
\text { Gardening }\end{array}$ & $-0.051(0.130)$ & 0.002 & $0.084(0.117)^{* *}$ & -0.016 \\
\hline OPT & -0.038 & -0.015 & $0.125(0.094)^{* * *}$ & $0.058(0.97)^{*}$ \\
\hline
\end{tabular}

When adjusted for all control variables, perceived stress did not vary significantly by organic additive-free diet, home gardening, and OPT. When adjusted for all control variables, QOL did not vary significantly by home gardening and very modestly by OPT. 
Table 11 shows the results of the regression model testing the hypothesis that the association of practice of arts and culture activities and QOL and perceived stress vary significantly by sex. Results indicated that the interaction variable of gender and arts and culture was significantly associated with perceived stress (adjusted $\beta=0.077, \mathrm{p}<0.05$ ) in the first model (Table 11) containing gender, arts and culture, and the interaction variable of gender and arts and culture as the independent variable, and perceived stress as the dependent variable. However, in the other models, the variation by gender was not statistically significant.

Table 11. Results of multiple regression testing for interaction between gender and arts and culture

\begin{tabular}{|c|c|c|c|c|c|c|}
\hline & \multicolumn{3}{|c|}{ Perceived Stress } & \multicolumn{3}{|c|}{ QOL } \\
\hline & Model 1 & Model 2 & Model 3 & Model 4 & Model 5 & Model 6 \\
\hline & $\beta$ (SE) & $\beta(\mathrm{SE})$ & $\beta(\mathrm{SE})$ & $\beta(\mathrm{SE})$ & $\beta$ (SE) & $\beta$ (SE) \\
\hline $\begin{array}{l}\text { Gender } \\
\text { Arts and }\end{array}$ & $0.061^{*}$ & $0.098^{* * *}$ & $0.073^{*}$ & $0.135^{* * *}$ & $-0.119^{* * *}$ & $-0.092^{* *}$ \\
\hline Culture & $-0.280^{* * *}$ & $-0.183^{* * *}$ & $-0.175^{* * *}$ & $0.297^{* * *}$ & $0.278^{* * *}$ & $0.197^{* * *}$ \\
\hline Interaction & $0.077^{*}(0.385)$ & 0.044 & 0.057 & 0.003 & 0.009 & 0.004 \\
\hline \multicolumn{7}{|c|}{$\begin{array}{l}\text { Models } 1 \text { and } 4 \text { consist of variables of gender, arts and culture, and interaction of the two as independent } \\
\text { variables; Models } 2 \text { and } 5 \text { consist of arts and culture, control variables, and interaction as the independent } \\
\text { variables; and Models } 3 \text { and } 6 \text { consist of all five CAM variables, control variables, and interaction as the } \\
\text { independent variables }\end{array}$} \\
\hline \multicolumn{7}{|c|}{$\begin{array}{r}\beta \text { is the measure of adjusted beta } \\
\mathrm{SE} \text { is the measure of standard error } \\
* * * \mathrm{p}<0.001, * * \mathrm{p}<0.01,{ }^{*} \mathrm{p}<0.05\end{array}$} \\
\hline
\end{tabular}

Table 12 shows the results of the regression model testing the hypothesis of whether there is a significant difference in the association of practice of OPT and QOL/perceived stress between males and females. Results indicated that the interaction variable of gender and OPT did not significantly change the relationship of CAM variables to perceived stress or QOL in all three models. 
Table.12 Results of multiple regression testing for interaction between gender and OPT

\begin{tabular}{|c|c|c|c|c|c|c|}
\hline & \multicolumn{3}{|c|}{ Perceived Stress } & \multicolumn{3}{|c|}{ QOL } \\
\hline & Model 1 & Model 2 & Model 3 & Model 4 & Model 5 & Model 6 \\
\hline & $\beta(\mathrm{SE})$ & $\beta(\mathrm{SE})$ & $\beta(\mathrm{SE})$ & $\beta(\mathrm{SE})$ & $\beta(\mathrm{SE})$ & $\beta(\mathrm{SE})$ \\
\hline Gender & 0.014 & 0.039 & $0.062^{*}$ & -0.048 & -0.03 & $-0.064^{*}$ \\
\hline OPT & $-0.062^{*}$ & -0.038 & -0.015 & $0.144^{* * *}$ & $0.125^{* * *}$ & $0.058^{*}$ \\
\hline Interaction & -0.033 & -0.031 & -0.01 & 0.043 & 0.045 & 0.004 \\
\hline
\end{tabular}

Models 1 and 4 consist of variables of gender, OPT, and interaction of the two as independent variables; Models 2 and 5 consist of OPT, control variables, and interaction as the independent variables; and Models 3 and 6 consist of all five CAM variables, control variables, and interaction as the independent variables

$$
\begin{aligned}
& \beta \text { is the measure of adjusted beta } \\
& \mathrm{SE} \text { is the measure of standard error } \\
& * * * \mathrm{p}<0.001,{ }^{* *} \mathrm{p}<0.01,{ }^{*} \mathrm{p}<0.05
\end{aligned}
$$

\section{Phase II qualitative analysis}

The purpose of the exploration of the second research question was to determine why people choose to practice OPT. Addressing this research question required the use of qualitative methods as the second phase of the sequential explanatory mixed methods design. The intent of this design was to have the qualitative data help explain in more detail the initial quantitative results (Creswell, 2013). The qualitative phase focused on finding out why patients decided to practice OPT by using grounded theory methodology as a strategy of inquiry.

\section{Demographic findings}

Of the 25 participants who were interviewed, 19 were female and six were male. Of the 25 participants, two (one male and one female) were not able to complete the selfadministered questionnaire prior to conducting the interview due to time constraints. The average age of the rest of the 23 participants who completed the self-administered questionnaire was 62.4 years old $(\mathrm{SD}=9.9)$. Table 13 lists further demographic characteristics such as sex, occupation, annual income, education, and marital status. 
Almost half of the participants were housewives $(\mathrm{n}=10)$. Most had a modest annual income of 2 million yen to 5 million yen $(\mathrm{n}=9)$ or below 2 million yen $(\mathrm{n}=7)$ per year (US $\$ 16,800$ to $\$ 42,000)$. Almost a third of the participants were high school graduates $(n=7)$, and another third had a college education or above $(n=7)$. Most of the participants were married $(n=16)$. About a third of the participants responded that they had received OPT at least once in the previous several weeks $(n=8)$. Only one participant reported no receipt of OPT at least once in the previous three months. Most participants reported 30 to 60 minutes per OPT session $(n=15)$, and several participants reported receipt of one to two hours per session $(\mathrm{n}=6)$.

Table 13. Characteristics of qualitative sample $(n=23)$

\begin{tabular}{lll}
\hline Characteristics of sample & Frequency (n) & Percent (\%) \\
\hline Age & & \\
30 to 39 & 1 & 4 \\
40 to 49 & 1 & 4 \\
50 to 59 & 5 & 22 \\
60 to 69 & 11 & 48 \\
70 and older & 5 & 22 \\
Sex & & \\
Male & 5 & 22 \\
Female & 18 & 78 \\
Occupation & & \\
Employed & 6 & 26 \\
Self-employed & 3 & 13 \\
Housewife & 10 & 43 \\
Unemployed & 4 & 17 \\
Annual Income* & & \\
Below 2 million yen (US \$16,800) & 7 & 30 \\
2 million yen to 5 million yen (US \$42,000) & 9 & 39 \\
5 million yen to 7 million yen (US \$58,800) & 4 & 17 \\
7 million yen to 10 million yen (US \$84,000) & 1 & 4 \\
Above 10 million yen (US \$84,000) & 1 & \\
& & \\
& & \\
& &
\end{tabular}


No response

\section{Education}

Elementary/Junior high school graduate

High school graduate

Junior college graduate

Technical school graduate

College graduate or above

\section{Marriage}

Married

Widowed

Not Married

No response

Frequency of

1

4

of receiving OPT (within the last 3 months)

ery day

Five to six times a week

Three to four times a week

Once or twice per week

Once in several weeks

Do not practice

\section{Amount of time in receiving OPT each time}

\begin{tabular}{lcc}
$\begin{array}{l}\text { Less than } 15 \text { minutes } \\
15 \text { to } 30 \text { minutes }\end{array}$ & 1 & 4 \\
30 to 60 minutes & 1 & 65 \\
1 to 2 hours & 6 & 26 \\
\hline & 2014 Median household income in Japan 5.370 million yen (US $\$ 43,518)$ \\
& Poverty threshold 1.27 million yen /one person household (US $\$ 15,113$ )
\end{tabular}

Malignant neoplasms (MNs) were the most common chronic condition, with five participants diagnosed as having the disease. Four participants had diabetes.

Hypertension, allergic disease, and benign neoplasms (BNs) were reported by three participants each. Several participants had multiple chronic conditions. In Table 14 the number and percentage of participants diagnosed for each condition are noted. 
Table 14. Type of Chronic disease

\begin{tabular}{lc}
\hline Type of Disease & Frequency (n) \\
\hline Malignant neoplasm (MN) & 1 \\
MN after surgery & 4 \\
Benign Neoplasm (BN) & 2 \\
BN after surgery & 1 \\
Diabetes mellitus & 4 \\
Psychiatric disease & 2 \\
Cranial nerve disease & 2 \\
Allergic disease & 3 \\
Heart disease & 2 \\
Hypertension & 3 \\
Cerebrovascular disease & 1 \\
Respiratory disease & 2 \\
Liver or pancreatic disease & 1 \\
Rheumatic/connective tissue disease & 1 \\
\hline
\end{tabular}

The results of the JPSS-10 questionnaire and MQOL-10 questionnaire are shown on Tables 15 and 16. The mean for MQOL-10 score was 27.04 and for JPSS-10 was 13.3, which would be categorized in between low stress and normal stress.

Table 15. Results of JPSS-10 (mean 13.30)

\begin{tabular}{lll} 
Score & Frequency (n) & Percent (\%) \\
\hline 4 & 1 & 4 \\
6 & 3 & 12 \\
8 & 1 & 4 \\
10 & 2 & 8 \\
11 & 2 & 8 \\
12 & 2 & 8 \\
14 & 1 & 4 \\
15 & 1 & 4 \\
16 & 2 & 8 \\
17 & 2 & 8 \\
18 & 3 & 12
\end{tabular}




\begin{tabular}{lll}
19 & 1 & 4 \\
21 & 2 & 8 \\
Missing & 2 & 4 \\
\hline
\end{tabular}

Table 16. Results of MQOL-10 (mean 27.04)

\begin{tabular}{lll}
\hline Score & Frequency (n) & Percent (\%) \\
\hline 18 & 1 & 4 \\
20 & 1 & 4 \\
22 & 3 & 12 \\
24 & 1 & 4 \\
25 & 1 & 4 \\
26 & 3 & 12 \\
27 & 1 & 4 \\
28 & 3 & 12 \\
29 & 1 & 4 \\
30 & 2 & 8 \\
31 & 4 & 16 \\
32 & 1 & 4 \\
35 & 1 & 4 \\
Missing & 2 & 8 \\
\hline
\end{tabular}

\section{Qualitative analysis findings}

Analysis indicated one theme, four clusters, and 13 categories. The selective coding theme was chosen from one of the 13 categories, because this was most applicable to all of the other categories and best explained the reason why interviewed patients decided to receive OPT. The theme is: Feelings of extreme desperation "clutch at a straw." Table 17 lists the clusters and categories that joined to form this theme based on analysis. 
Table 17. Theme, clusters, and categories

\begin{tabular}{lll}
\hline \multicolumn{1}{c}{ Theme } & \multicolumn{1}{c}{ Cluster } & \multicolumn{1}{c}{ Categories } \\
\hline & How patients understand & Perception towards OPT \\
& & Effects of OPT \\
& & Understanding of how OPT works \\
& What prompted & Suffering from symptoms \\
individuals to receive & To practice as a therapist towards family or friends \\
& OPT & suffering from disease \\
Feelings of extreme & Reasons for continuing & Unexpected positive results from receiving OPT for the \\
desperation & first time & Benefits of OPT \\
& & $\begin{array}{l}\text { Positive relationship and satisfaction with staff and } \\
\text { doctors of the clinic }\end{array}$ \\
& & Limits of conventional medicine \\
& Thoughts on & Dissatisfaction with western medicine \\
& conventional medicine & Feelings of extreme desperation, "clutch at a straw" \\
& Independent categories & Letting others know about OPT \\
& & Family member \\
\hline
\end{tabular}

The analysis will describe the categories within each of the four clusters. The first cluster was: How patients understand OPT. Within this cluster there were three categories: 1) Perception towards OPT, 2) Effects of OPT, and 3) Understanding of how OPT works (Table 18).

The first category, Perception towards OPT, emerged from participants' opinions of how they perceived OPT. Various descriptions of perception towards OPT emerged. The most common responses stated by participants were feelings of suspiciousness towards OPT, having doubts about whether OPT works or not, describing OPT as strange and mysterious, and also thinking that OPT was a practice by a religious organization and becoming aware that it is not. Suspiciousness towards OPT was directed towards the organization providing the service. Several participants described feeling doubtful despite noticing effects from receiving OPT; they were not determined enough to be 
enthusiastically supporting the practice. Participants described OPT as mysterious in two different aspects. One aspect of the mysteriousness came from how the therapy appeared physically. The other aspect came from the effects that were being felt without physical contact with the therapist during the therapy. "I don't know whether it is because of OPT, but it's mysterious" and "OPT is mysterious, never have been in this mysterious world" were voiced by participants.

In the second category, Effects of OPT, the effects of OPT felt by the participants emerged. Participants' responses included OPT being comfortable and relaxing, being mentally relaxing, feeling positive after receiving, and the body feeling warm and light after receiving OPT. At the same time, however, some were not sure of any effect; moreover, were in doubt about the effectiveness of the therapy. Effects described were both psychological and physical. For example, psychological effect was voiced by participant 3: "It soothes you mentally. The practitioners come to you and they are compassionate, and they will be with you. The members and the people from the network as well, and they are not forcing." Various physical effects were reported; body feeling light and body feeling hot were the most commonly voiced effects from participants. Descriptions of physical effects were many, including changes such as regained appetite, stopped weight reduction, and reduction of adverse effects from medication voiced by a participant suffering from cancer.

In the third category, Understanding of how OPT works, participants described OPT as a therapy that takes time. Participants' common understanding of how OPT worked included expectations for a gradual decrease in symptoms over time without any adverse effects. The expectations for a gradual decrease in symptoms seemed to be the 
common understanding. Participant 18 describes it nicely as the following: "According to

Dr. K, he can't guarantee that the rashes would not appear again. However, the frequency

of the rashes appearing may decrease, or even if it appears there is a chance that it would

stop from spreading at some point. He told me to think of it that way. This is how I am

now. I still have worries."

Table 18. How patients understand OPT

\begin{tabular}{ll}
\hline Category & Emergent cluster: How patients understand OPT \\
\hline Perception & Participant 1: The therapists volunteer to treat patients, right? That felt strange in the \\
towards OPT & beginning. Reiki healing and other types of healing, such as qi-qong, they do it as a \\
& business, right? But this was done without any fees paid to the volunteers. This felt \\
& strange. There is the clinic and people go there as volunteers and regular people help \\
& each other out through healing others. The idea of being able to heal the body back to \\
& normal was surprising. I didn't think it could be this easy. I didn't like it that they \\
& were practicing OPT without being paid. It's not that I didn't like it, it was strange. \\
& Healing and Reiki is pretty expensive, but why was this possible? That's what I felt. I \\
& was half in doubt.
\end{tabular}

Participant 5: I don't know as much as being able to recommend this to friends, I am still in doubt towards this.

Participant 9: I knew this therapy from long time ago. At first I thought to myself, "Would such a therapy be able to solve anything?" However, after starting to come here, the discomfort I had in my body is gradually disappearing, which is a fact. My perception towards this therapy is slowly changing. I decided to continue receiving this therapy, I think it's because the suspiciousness that I had towards OPT is gradually disappearing.

Participant 10: At first I thought it was mysterious and thought why it would do so much of this just by raising your palms like this. I think everybody feels the same way. I started to want to study this myself too, so I started. At first OPT felt mysterious. It felt very mysterious. You just sit there and you don't touch. That's why it felt mysterious in the beginning.

Participant 14: I couldn't understand this practice in the beginning I couldn't understand it for a while.

Participant 24: Two hours per session, I received two hours from three people. They asked me when I was going to the hospital next time. The results of the A1c measured a month ago would be available the present month it was because of the system of the hospital. A1c is a measurement of glucose inside your body. You know now the amount of glucose from the blood test which was drawn from the previous month. That's why you only know two months later for the outcome of the OPT received from Mrs. N. Finally when the results came back it was 6.5. I wasn't quite sure whether it was because of this. Mrs. N told me it's definitely because of this. She told me that she has a firm belief. However, I didn't really know. I am not good enough to be able to practice towards others too. It was incomprehensible to me. People were coming over and administering towards you, they were also volunteers. Then she took 
me to a clinic far away, and I was introduced to the doctors. I have my own physician in internal medicine. This doctor spoke to me from a different perspective, from the perspective of eastern medicine, however also including western medicine and spoke with me. It was a world I've never seen before, so I thought it was mysterious. Mrs. N told me I was able to do it too.

Participant 5* (wife): My sister was a member of a religious entity. My husband has never had any contact with religious organizations, but I have heard and witnessed things about them before and I disliked them. Even when my sister tried to recommend me things, I didn't respond. I have had fights with my sister about it. Then when my husband was diagnosed with lung cancer, my sister tried to convince me to go and try just once. She would explain to me how it was not a religion. She asked me many times to go, she described to me about the clinic in Shinagawa and how there were physicians working there. I would try to think of excuses so we won't have to go, I would use to tell her, "I will go once the outside temperature become warmer," or tell her how difficult it is for us to go all the way to Shinagawa because he is sick. Then she told me about a story of a person who suffered from pancreatic cancer and lost appetite, but regained appetite once after he started to receive OPT. That's why she told me to try out OPT, just for the purpose of increasing appetite. However, even then, I did not fulfill her request. That's why she made contact with some members of the MOA and asked them to visit our house.

When they first came to our house, I told them I dislike religion, and they told me that this is not a religion.

Effects of OPT Participant 3: It feels comfortable, putting aside whether it cures or not. I know I start to feel calm mentally, so it's a perplexing feeling.

It soothes you mentally. The practitioners come to you and they are compassionate, and they will be with you. The members and the people from the network as well, and they are not intrusive.

Participant 5 (self): I wasn't in much pain nor was I suffering. I received OPT for about 1 to 2 hours. During the therapy I would drift into sleep. After the therapy was finished it felt like my whole body was loosened. I still continue the regular medicine, to treat for the adverse symptoms from using Iressa (lung cancer drug). The doctor introduced me to a dermatologist, and I still continue the treatment for the rashes. I am continuing both OPT and the regular treatment and they are working together. We don't know which is being effective towards the rashes.

As I have told you earlier, we are beginners of OPT, so we are not sure how it is effecting my worsened condition to gradually become better, stopping the decline of weight, and gaining back my appetite, etc.

Participant 7: OPT fits me, it feels like it is working. Mentally you feel elevated, and become positive. You feel like you want to do something for others, you want to be of help to other people. It creates kind feelings.

Participant 8: Your body feels light after receiving it and you feel refreshed. The environment is good here. While you receive OPT you can relax, the place is near my house. I can easily come here. There is no pain involved. Pain is usually involved in many other treatments, right? That's why if I can receive treatment like this, it is such a comfortable treatment. You feel calm, and I feel that OPT is good in these aspects.

Particiant15: It's effective mentally. If you take a look at the physical aspects I have appetite, I can sleep well, I am enjoying life, and I feel that my body is recovering well. I think that these results were achieved from coming here. If I only went to the city hospital I don't think I would be able to be where I am now. 
Participant 16: I have never felt any effect. I don't feel anything now either.

Participant 19: It feels like lightning is striking inside your body. While I am receiving a specific spot on my body, other body parts start to feel pain, when I receive some specific part of the body other key spots related to where I am receiving feels struck. It feels like light is striking within my body like a snake moving around. It's really painful. People around me looked surprised because my body twists.

Participant 20: I don't understand it well, but it feels good. I haven't studied well yet. Half of my eye is disabled, so even if I bought books I wouldn't be able to study. If your pain starts to decrease I think you would feel better, that's what it is.

Participant 21: It doesn't really have to do with effects towards the disease, but I feel that the irritation starts to decrease whenever I receive OPT. I am happy about this.

Participant 24: I was saying to her I wish we were able to see this. I am not able to see this. Whenever I receive from Mrs. N, I feel warm. I think that's what it is. I feel that the blood flow inside the body is getting better, because my body would feel lighter.

Understanding of Participant 5 (self): I listened and also read about the philosophy of Okada. This does How OPT works not create adverse effects, rather it brings better conditions. I think this is enough for me to believe in this. It does not cause adverse effects.

Participant 6: I think it is creating a really good synergistic effect. Physically I don't think there is much you can observe right away as to the change or effects from practicing OPT.

This therapy does not use any artificial objects. It's natural. Biofield energy is something that exists in the universe. I think it's the best. It's a natural therapy. From long ago we say "treatment" (in Japanese characters written as putting your hands on the wound) right? It really does start to feel better when you put your hands on aching parts of your body. It's the same as when a mother strokes her child's stomach. This is the simplest way but it also is the most effective, and there are no adverse effects. I think it is the safest treatment method. I think it works especially towards your mental aspect.

It feels so comfortable for me. Every week I feel grateful for being able to have time to maintain my mind and body. It's not expensive. I don't feel any barriers towards receiving it, I feel very grateful.

Participant 12: After the second time coming here, depending on the person who I receive from, I started to feel something bounce off on my head. It's similar to a wave movement, something strange. That was after the second session. I don't feel any big changes, I am able to sleep and relax, it feels good. However I don't feel any changes that I can grasp, so I think this therapy is something you take your time on.

Participant 13: This is something you take your time on. This is not something you focus on for a short period of time, there are no adverse effects.

Participant 14: For a long time I was doing great, but when I stopped receiving OPT for a while the intraocular pressure started to rise again. It felt like the pressure which was stopping from rising has expired. I became aware that this is something I need to continue and cannot stop.

Participant 18: According to Dr. M, he can't guarantee that the rashes would not appear again. However the frequency of the rashes appearing may decrease, or even if 
it appears there is a chance that it would stop from spreading at some point. He told me to think of it that way. This is how I am now. I still have worries.

Participant 24: I don't feel anything because my sensitivities are dull. The doctors at the clinic told me that people who are in a bad condition wouldn't be able to feel. You start to feel this after receiving for several times. I want to be like that, but the place is far from where I live.

* Wife of participant 5 has participated in the interview

The second cluster is What prompted individuals to receive OPT. Within this cluster exist two categories: 1) Suffering from symptoms and 2) to practice as a therapist towards family or friends suffering from disease (Table 19).

The first category, Suffering from symptoms, emerged from participants' descriptions of how they were struggling through symptoms of various diseases and started to receive OPT with the hope of being able to alleviate the suffering from the disease. Participants were often introduced to OPT by friends and family members after revealing the situation of their disease. Others found the clinic on their own. Some participants gained knowledge about OPT through word of mouth from a friend's friend.

The second category, to practice as a therapist towards family or friends suffering from disease, emerged from participants who stated that they initially started OPT to support friends or family who were suffering from disease. Several participants discussed how they have requested that their family members learn how to administer OPT so that they can receive OPT at home. This was how family members started to practice as therapists towards family or friends suffering from disease. Participants' desires were to be able to receive OPT on a daily basis without having to come to the clinic each time, and their family members were willing to learn how to administer for their family members or friends suffering from the disease. The response from Participant 22 describes the process well: 
"So my son went to receive OPT during the spring break, and then spring break was almost getting to be over so he asked me to become a member so that I can learn how to practice OPT towards him. So I joined, and administered OPT to my son every day. I received a manual on how to administer so I think it is written inside. My son has dermatitis so I don't want to touch his body so much. There are places where he looks hurt, and you can't really tell over his clothes. He has so many scabs around his body, that's why I used to do it with my eyes closed. My son would tell me to open my eyes and do it, but closing my eyes became my habit. So I was practicing OPT on my son for about two to three years, after that I became certified as a third level practitioner, but I am still not confident."

Table 19. What prompted individuals to receive OPT

Category Emergent cluster: What prompted individuals to receive OPT

Suffering from Participant 3: I had started to feel difficulty walking. I realized this was not normal. I symptoms went to the doctor, but the doctor told me he was not able to figure out what was going on inside me yet. The doctors were not able to identify what was going on. When the doctors told me this, I felt that there would be nothing further conventional medicine can do for me. I had a friend that I see daily. She asked me if I was interested in receiving OPT. My friend didn't really know much about this healing technique at this time, but she asked me if I wanted to go with her. It seemed to be ok, so I went.

Participant 5 (self): That's when we first started to try a chemotherapy called Iressa, which is used to treat lung cancer. That was on December 15, two years ago. Then after using Iressa, due to the adverse drug effects rashes started to appear all over my body. These are some of the scars that you can see. They itch and when I scratch them I get really irritated.

I knew MOA through my wife's sister. She lives in Sapporo, and she has been a member of the Toho-no-Hikari. She told me about an existence of a therapy, and she recommended passionately to me to go for a check-up. Then the clinic introduced me to Mr. N who took us here today. I have been receiving OPT from Mr. N since last November and also have been making reservations to come here to receive OPT. I received a medical check-up here, and since then I am receiving OPT. Mr. N comes to our place once a week. That is the process of how I got to know about OPT.

Participant 7: The reason why I started coming to this clinic was because my husband died. My husband died from cancer. After my husband was diagnosed with cancer it became very tough for me psychologically. I think my physical body was also struggling. After he died, there were issues I needed to take care of, such as inheritance of the house and taxes etc, and it was really hard for me. Both my mind and body were 
starting to go wrong. Suddenly, it was hard for me to breathe, sometimes it was so difficult for me to breathe that I had to crouch down. My heart was beating loud and fast. My body was in an abnormal condition.

Participant 9: I was diagnosed with a disease and when I spoke about it to my mother she introduced me here with the hope of somehow finding a solution to the problem.

Participant 12: About seven years ago, I had a vertigo which caused me to lay on bed for half of the day. I couldn't walk without closing my eyes and I had to go to the restroom crawling down. I went to Touhou Medical University Hospital and had a check-up on my brain and my vertigo. The doctors told me not to worry about it, there is nothing that is especially worrisome. However, I was not feeling well, my head would feel dizzy. So I discussed this with my friend who used to be one of my classmates during high school her name was Mrs. H. She introduced me to the clinic.

To practice as a therapist towards family or friends suffering from disease
Participant 1: I have studied for the certification of the third level practitioner, to teach my friends about this. I knew from before that energy from the universe is good for you. My friend became ill and the doctor couldn't do much about it. She told me about this and I decided to join along. I thought it would be good if I can do this to my friends, because this can be practiced by anybody.

Participant 16: My friend became a member first. She started this because her daughters were suffering from atopic dermatitis. I didn't choose to become a member then. My sister's husband died and my friend's sister died from a disease that was why I started to practice OPT with the hope of being able to comfort them and making them feel better. I was very healthy back then and I didn't have any medical problems.

The third cluster is Reasons for continuing OPT. There were three categories within this cluster. They are: 1) Unexpected positive results from receiving OPT for the first time, 2) Benefits of OPT, and 3) Positive relationship and satisfaction with staff and doctors of the clinic (Table 20).

In the first category, Unexpected positive results from receiving OPT for the first time, descriptions of how the participants experienced OPT emerged. Participants stated that they were surprised at the unexpected physical effects they felt. Common descriptions of unexpected effects were feeling warmth from receiving OPT and the body feeling loosened after the therapy. Unexpected effects motivated them to continue the therapy, as can be seen by the comments made by Participant 3: "The first time I received OPT, I was very surprised. My body became hot. I thought I was a type of person that did 
not believe in these kinds of things. However, once I actually received it, my body started to become hot. That was the beginning of my experience with OPT."

The second category, Benefits of OPT, consists of descriptions of the benefits that participants have experienced through the practice of OPT. Participants shared experienced benefits in relation to the conditions of their diseases. For instance, Participant 5 stated that anorexia related to cancer treatment stopped and appetite increased after receiving OPT. Also, other conditions, such as foot edema related to renal insufficiency, reportedly subsided, cancer progression slowed, and stabilization of chronic conditions was reported.

The third category was Positive relationship and satisfaction with staff and doctors of the clinic. Within this category, codes such as "dialogue between the doctor and patient addressed concerns," "doctor at the clinic listens to patients," and "patients continue to receive treatment because of staff's compassionate service" emerged.

Table 20. Reasons for continuing OPT

\begin{tabular}{|c|c|}
\hline Category & Emergent Cluster Reasons for continuing OPT \\
\hline \multirow[t]{4}{*}{$\begin{array}{l}\text { Unexpected positive } \\
\text { results from receiving } \\
\text { OPT for the first time }\end{array}$} & $\begin{array}{l}\text { Participant 1: The first time that I received the practice was in Kokubunji, it was } \\
\text { something that they organized for health and arts, and it felt really good. I initially } \\
\text { like alternative medicine practices, so I was able to receive it without any } \\
\text { hesitation or awkwardness. You sit in the seat and receive the treatment and I } \\
\text { remember how good it felt. }\end{array}$ \\
\hline & $\begin{array}{l}\text { Participant 3: The first time I received OPT, I was very surprised. My body } \\
\text { became hot. I thought I was a type of person that did not believe in these kinds of } \\
\text { things. However, once I actually received it, my body started to become hot. That } \\
\text { was the beginning of my experience with OPT. }\end{array}$ \\
\hline & $\begin{array}{l}\text { Participant 4: The first time I received it I was so surprised. I was curious towards } \\
\text { what this was. That was the reason I started. }\end{array}$ \\
\hline & $\begin{array}{l}\text { Participant 14: When I first heard about it I was surprised. However, I am } \\
\text { interested in many things so I decided to try it out and at first I went to my friend's } \\
\text { house to receive it. } \\
\text { My body felt so light afterwards. Every time she administered the OPT around my } \\
\text { pancreas from behind, it was hurting. The pain was relieved afterwards so I }\end{array}$ \\
\hline
\end{tabular}


thought this therapy was really great.

Participant 17: My sister took me to the clinic, I felt it right away, with my body. My condition improved surprisingly. I felt it with my whole body. That's why I was surprised. I had some psychological damage due to my son's issues. I was suffering so much that I couldn't get up from bed. My sister saw me like this and asked me if I would go to the clinic with her. That time I received OPT and right after receiving it, my body reacted right away. I felt very good. I was not feeling better mentally but physically I was feeling better. It was similar to what you would feel after going to a massage, a shiatsu-massage, or acupuncture. The same feeling of your body feeling loosened. So with this therapy there is no physical contact, you don't even touch, but why did it produce the same kind of result? I was surprised about this.

Benefits of OPT Participant 5 (self): My appetite was gone due to the adverse effect from the medicine, and I had started to lose weight. My constant weight was about $60 \mathrm{~kg}$ throughout my adult life. I have never lost more than that or gained more than that for the past 40 to 50 years of my life. However, after the cancer had spread from my lung, I am not sure whether it was because I started to take Iressa (lung cancer drug), but my weight started to change. When I found that the cancer had spread to my bones, my lower back all the way to my right leg was feeling dull and heavy, but not only that, my weight had slowly began to decrease from $60 \mathrm{~kg}$ to about $57 \mathrm{~kg}$. That was when I contacted the doctor and we were able to detect the cancer spreading out to other parts of my body. After taking Iressa, my appetite had decreased rapidly. My weight had gone down to $53 \mathrm{~kg}$, almost as low as 52 $\mathrm{kg}$. But my weight loss somehow stopped recently. My appetite had not been very good, but my wife has since been researching what is good for my body and also things like what to cook, and she would prepare food for me based on that. Now I am able to finish eating whatever is prepared before me. When I checked my weight yesterday it was returning to $54.1 \mathrm{~kg}$. I feel that my weight loss has stopped and I am gradually returning back to my normal weight.

"I had a really bad swelling on my instep. When I took the blood test they told me the level of creatinine was rising. So my feet got swollen. But when I received OPT the swelling subsided drastically. Something like that had happened, and also as I have told you earlier, my appetite is back to normal, I am able to finish whatever has been prepared as a meal. What my doctor who has been treating my cancer says is that, if you continue taking Iressa for this long, the chemotherapy's effectiveness towards fighting cancer gradually decreases. It has been more than one and a half years, almost about one year and eight months, since I started Iressa. So usually at this time we are supposed to advance to the next type of chemotherapy, or exploring another treatment. We are supposed to be at that kind of stage by now. However, the cancer seems to not be advancing, the cancer that spread to the right lung has not disappeared but it is not advancing. When the doctors checked through the MRI and CT scan, it was not advancing to other parts of the bones nor starting to get hurt. We just had a checkup on the brain about 10 days ago through the MRI. The cancer had not spread to the brain at all. The doctors say that the progression of the cancer can slow for a prolonged period. When strangers see me, they won't even notice that I am a cancer patient. I look pretty good. (Before) they would ask me what could be wrong with you? Also, when I see friends that I haven't seen in a few years, who knew beforehand that I have cancer, they always question what is wrong with me. I don't look at all like I have cancer. My condition has been stable like this. When I experience stuff like the swollen instep subsiding so rapidly, I start to think that OPT might have some effectiveness, and that it is working well together with western medicine. 
Participant 9: In the beginning I was skeptical about whether this kind of practice would solve anything. Once I started to come here, the discomfort I had and the body aches faded away a little bit, which is a fact. The image that I had towards this practice is slowly changing. I have a feeling of heaviness and pain right now. When I receive OPT the heaviness and pain fades away for a while.

Participant 15: OPT has effects on your spirit and mind rather than on aspects targeted by western medicine. So I moved on and stepped up mentally and spiritually. Right now being able to live is so important to me.

Just three or four days ago I received the second results of the medical examination at the hospital in Kawasaki. Doctor told me like this. He didn't say that I was cured, but he told me this time I was fine. That's when I felt that the 10 months coming here was not useless. That's how I am feeling right now. Only three or four days have passed since I received the results of the examination. The examination consists of checking with the endoscope, and then you wait for one week, then you take the computerized tomography and wait another week, then after three weeks you receive your results. While I wait for the results I feel so worried, each time.

I am not sensitive to many things, but even then, when it is one day before the results I am so worried about what the doctor will say. I was hospitalized on the second year and had an operation. This time was the third time; it has been two years since I had the operation.

When the doctor told me that this time was ok, and he didn't see any spread of the disease, I was so relieved. That's what my condition is right now. That's what my story is about.

Positive relationship and satisfaction with staff and doctors of the clinic
Participant 7: The first doctor who saw me was Dr. O. Just by talking with Dr. O I was feeling comforted. He told me how normal it was to be like how I was mentally and physically after going through so much of what I have experienced. He told me that my degree of stress is over 120 percent. He understood me so well. I started to receive OPT.

Participant 8: Actually, the reason why I come here is because I like Dr. M. I am not receiving OPT from him. I listen to what he has to say and for example, he tells me to administer OPT to this part of the body, and I do it. I do places of my body based on what he says. My wife administers it to me too. I am 69 years old right now, and I am able to live somehow. I feel that this is what my circumstance is right now.

Participant 9: That time when I came here there was nothing that changed dramatically. However, after talking to the doctor a little bit I felt a sense of comfort. I was able to become mentally calm.

Participant 13: In this place the interaction between the patient and staff and doctors are obviously different from regular hospitals. It may be because the volunteers take the core responsibilities, the atmosphere is like home. You are somewhat relaxed. You can receive treatment in a natural environment. Also, the doctors are good too. I have a disease which advances and I talk to them, and they give me appropriate advices. They provide to you service in a way in which just by seeing their faces you get relaxed. When I have to go to the hospital, I tell them that I don't want to take these kinds of medical examinations and ask for their opinion. They tell me I understand how you feel, but taking medical examination will give you many advantages. The exam itself lasts only for a short period, so you should receive the medical examination. Everybody treats you very well here, I can say that. 
The fourth cluster is Thoughts on conventional medicine. Within this cluster exist two categories: 1) Limits of conventional medicine and 2) Dissatisfaction with western medicine (Table 21).

The first category under Thoughts on conventional medicine is Limits of conventional medicine. Many participants felt that there was a limit to what conventional medicine could do for their conditions. There were two participants diagnosed with a complex cranial nerve disease for which there was no available treatment. Another participant described his experience of suffering from a dermatological condition in which he felt the limits of conventional medicine from going through years of repeated symptoms and treatments that were ineffective.

The second category, Dissatisfaction with western medicine, was constructed from codes that emerged from participants describing how they disliked the way the doctors attended to their needs. Other dissatisfactions were related to the development of mistrust of western medicine due to adverse effects on organs that initially did not have problems and medical procedures that resulted in worsened symptoms.

Table 21. Thoughts on conventional medicine

\begin{tabular}{ll}
\hline Category & Emergent Cluster: Thoughts on conventional medicine \\
\hline Limits of & Participant 3: I have started to feel difficulty in walking. I realized that this was not \\
conventional & normal. I went to the doctor, but the doctor told me he could not figure out for sure \\
medicine & going on. When the doctors told me this, I felt that there would be nothing further \\
& conventional medicine could do for me. \\
& Interviewer: What is the greatest reason that makes you continue practicing OPT? \\
& Participant 3: It's because I want to recover from my disease. Doctors tell me that it \\
& is difficult with conventional western medicine. That's why I want to take this \\
& challenge using eastern medicine. \\
& Participant 18: About six years ago when I was still working, something I had never \\
& experienced happened suddenly. I started to have rashes all around my arms and legs, \\
& which eventually spread throughout my whole body. It was all red and I couldn't do \\
\hline
\end{tabular}


anything about it. So I went to my primary health care clinic, dermatologist, and received a pretty strong medicine, and it was under control. After it was over, the rashes came back over and over again. So I decided to go to a clinic with greater and different level of dermatologists. However it was all the same procedures. I received medicine, which were steroids. They made me put them on. Everything was the same procedure over and over again, experiencing the same painful condition. The next thing I considered was going to an even greater hospital, so I went to the Juntendo University hospital. They immediately hospitalized me. They were telling me that this is a serious condition. However they did not know why this was happening. They just told me that they did not know. The fact was that I was still suffering from pain. This hospitalization occurred about four to five years ago, it was hopeless. After that, each year I would have serious symptoms of rashes appearing all over my body about two or three times each year; the severity was different each time. Then last year... no last year, August was the last time that I had the sudden rashes spreading on my body. So if this was going to continue, not only my body, but psychologically I would not be able to handle it any longer, I would get so confused and didn't know what was going on. If this was continuing and I was receiving the same kind of care each time I would not be able to stand it.

Participant 23: If I was not practicing OPT, the damage would have been bigger. It's an incurable disease and there is nothing western medicine can do to help me, that's why if I didn't know OPT I would have been in a very painful state mentally.

Dissatisfaction with western medicine
Participant 15: That was the condition as to which I received life. However, I felt that the methods of western medicine nowadays don't have feelings of compassion. They would look at the screen and not even look at the face of the patients. They would not even ask how my symptoms were. They would just look at the data, and I didn't know whether they were listening to what I had to say, and they just gave me a lot of medicine. They gave me medication for one whole year. That's when I started to feel worried. I was alive, but I was worried about whether I would be able to survive. They wouldn't even listen to me. Then I had spoken about this to my sister-in-law and she immediately recommended me to come here.

Participant 17: Regular hospitals prescribe lots of medicine. They give so many medicines implying that if the medicine is not taken the disease will not be recovered. Then I had adverse side effects from taking too much medication. I sometimes take medicine to treat my asthma. The medicine is steroids. I have continued to take this for about seven to eight years. Then my kidney began to have problems. My face got swollen, the doctors told me that my kidney has problems. That's why I stopped taking medicine. So I gradually stopped taking medicine even while having an asthma attack. It becomes painful but I try not to take medication. Symptoms eventually become better without the use of medication. I have learned abdominal breathing, and I stopped taking medication for most of the time.

Participant 18: The common things that I experienced and want to say about going to the doctors is that the doctors won't listen to what I was saying. It's not that they don't want to listen. I think they are too busy, dermatologists. There are so many kids that come for treatment with atopic dermatitis. Even when I had a very severe condition they would just prescribe me medication and say goodbye. This was the cycle which was repeated continuously.

So eventually I came to a solution that I need to look for a better place for my condition.

I was not a kind of person that would get involved with the doctors so much. I have met a lot of doctors in dermatology. Each doctor specialized in western medicine. I didn't think they were doctors. I didn't want to concede that they were. The reason is 
because they won't try to understand the suffering that the patients are going through, they would not try to listen. If I were to describe them, they are only robots making decisions based on data. Medicine is supposed to be a healing act or benevolence. They are supposed to respond to psychological and spiritual needs, being able to listen. After those needs are met the physical aspect of the body becomes better. If doctors lack those elements, then they are not, I don't know, doctors from other specializations, but I thought the doctors specializing in dermatology were the lowest. However, they are doctors. I feel that for people with problems with skin, many of the reason behind the symptoms comes from mental and psychological things. Most of the doctors were like that, they were awful. I can understand that they are busy. There were no doctors that would show me a way to try to approach my illness from that kind of aspect.

Participant 24: I have diabetes. When I had a periodic medical examination the doctor recommended surgery. After the surgery my diabetes has gotten worse. I am not sure whether it was because of the medication or because of the surgery, but before the surgery I was pretty stable. However, after having the surgery the doctor told me that I needed to take insulin in order to lower my blood sugar levels. I was taught how to do insulin while I was hospitalized. This is the story behind it. My A1c doesn't go down. My A1c levels elevated to around 8 or so. I have altered my diet and I have also exercised. The name of the disease was called tuberculoma and the medication was quite strong. I was told to take the anti-tuberculosis drug and the people from the municipal health center came to my house. My family members were also checked just because of the name tuberculosis. My diabetes wasn't so severe at first. My A1c was stable too. I was doing physical activities as well. However, during the periodic medical examinations the doctors told me that there was an image of a lesion, like a coin, which was a shape of a cross. He referred me for further examination to further explore whether this lesion was benign or malignant at a hospital. So when I went to the hospital the doctor told me they didn't know, so they recommended me to get an operation. They needed to take out a piece of the tissue and culture it in order to judge whether it was benign or malignant. If it was malignant it was suspected that it would evolve into a cancer. There were three types of diseases concerned with lung that this was suspected to be, and they weren't able to judge until a piece of it was taken out. Eventually we found out that it was tuberculoma. It was benign and it wasn't tuberculosis or anything. They gave me an anti-tuberculosis drug which was so big I wasn't able to swallow it. But I wasn't supposed to break it into pieces. Then, I had to take this medication for half a year, and my A1c also went up to 9.5 or 8.5. It became so high and wouldn't come down. After I was discharged from the hospital, my face looked pale, and my friend asked me how I was doing.

The remaining categories are independent categories that do not belong to any

cluster, including Feelings of extreme desperation, "clutching at a straw"; Letting others

know about OPT; and Family Members (Table 22).

The first category is Feelings of extreme desperation, "clutching at a straw."

Many participants, when asked why they decided to start and continue receiving OPT, 
answered that they were desperate and would try anything to relieve the symptoms and recover from the disease. This category involved participants' feelings of suffering from the pain of the symptoms and also the pain of not having any solution for removing the symptoms. The desperation led to seeking treatment at different hospitals and trying out different types of treatment. Participants were actively seeking to relieve symptoms of their disease. Participants' main focus was on relieving the pain and doing something good for the body.

The next category was Letting others know about OPT. Many participants felt that it was hard to let others know about the practice. They assumed that other people would have trouble understanding the practice. Most participants stated that they would not let others know about OPT proactively, but if they come across people who are looking for help, they would let them know. Some participants stated that they were reluctant to let others know about the practice because they had not recovered from the disease and it might not be convincing to others. However, there also were people who had already introduced the practice to others who were also suffering from chronic diseases.

The last category is Family Members. Participants mentioned how family members reacted to the practice of OPT. Most participants responded that family members understood and accepted OPT practice. This was because the participant was seen changing positively, and family members were relieved to see the participants become better. 
Table 22. Independent categories

\begin{tabular}{ll}
\hline Category & Independent Categories \\
\hline Feelings of & Participant 18: I started to have rashes all around my arms and legs, which \\
extreme & $\begin{array}{l}\text { eventually spread throughout my whole body... } \\
\text { desperation, }\end{array}$ \\
Interviewer: A lot of previous interviewees told me how desperate they were. \\
$\begin{array}{l}\text { Participant 18: You are absolutely right. Each time I went to a different place, } \\
\text { everything was the same. I thought maybe there is nothing available for me anymore } \\
\text { and I lost confidence. }\end{array}$
\end{tabular}

Participant 19: My sister told me that there is a good hospital that she can take me to, which may be good for mental wellness. I knew my sister was doing something. I disliked religion, I would avoid it, so my sister didn't tell me in advance. She invited me to go. During that time I was psychologically beaten up. I was desperate, I would have clutched at a straw. I have gone through purification ceremonies, discussion on hotlines for mental sufferers to ask for help, and have also been to psychiatric hospitals. So when I went with my sister it was unexpectedly soothing towards my body.

Participant 20: I don't think my interview fits your research. Before I was introduced to this, I used to sing a lot. I had my first recital on May 31st. After less than one week I was diagnosed with this disease. It's my eyes and I am a soprano so I can't sing out loud. I can't sing out loud. Even my teacher got ill. I introduced her here, and she is also coming. She is the instructor for my singing, so two of us are no longer able to sing. My life has changed completely. So I don't care what is good and what is not good, I'm just trying to handle my health condition. I don't think I can be helpful to your research. I don't think my experience is typical. I want to make this clear, but not being able to sing is hard for me. My previous job I had, I had to quit because of my chronic pain. Singing was my purpose in life. It wasn't just my hobby. I was trying to restart my life. For example, if I have a fight with my husband right now I won't even be able to scream. That's why I am taking care of my body cautiously right now. So I am sorry, but I don't have anything that is changing mentally due to this therapy.

Participant 9: I was advised to have surgery, but I want to avoid surgery. The doctor's words when I first came for a check-up, he told me that we can solve this problem. Those words were very reassuring. I was able to hold my hopes up, it felt like that. That's why I decided to continue.

Letting others Participant 1: I would want to let others know. If there is anybody that is suffering know about OPT and troubled I would want to let them know about this. If they are not able to believe in things that are not able to be seen, they would misunderstand this. That's why I would not let others know from myself that I am receiving this kind of practice. However, I would let them know if they are suffering and troubled, and they come to me to talk to me about it, I may introduce them to this. I may not be able to talk about this from myself.

Participant 3: It is difficult for others to understand. That's why I think I have to recover from this disease first for it to be convincing. For instance, if I were to tell my friends that I am practicing this sort of therapy, and describe to them how my current condition is like, they would respond by saying, "Oh, are you sure you want to continue practicing this therapy?" I would receive this kind of reaction from, say, about 80 percent of the people. That's why I stopped encouraging others to try it out. I plan on telling other people after I become a little better. However, my family is happier about it. For example, OPT practitioners come to visit my house and my family sees me change, so they have become more understanding about it and 
practicing OPT is going smoothly. My eldest son is away, though. Interviewer: Why do you feel that it is difficult to let others know?

Participant 3: Because it is not convincing. If I let others know while I am still not recovered, the whole discussion will end by them telling me that you are not recovered. That's why I have feelings of frustration, because it feels good. Putting aside whether it will cure my disease or not, it soothes you mentally and I know this. That's why it is a bit frustrating.

Participant 18: Well, I don't think I have ever spoken about it towards others. However, I have it set up in my mind like this. If I come to realize that there is somebody experiencing the same kind of worries that I have, or if they ask me for advice I would let them know.

It is like that usually - you don't hear people recommending things without regards to other people's condition of health. Once when I was drinking with my relatives, I would never say such thing, but my wife is really happy about it. Because she saw me how much I had been suffering. Whenever she drinks alcohol she talks about my experience towards our siblings. She describes how I was getting better through these things, but most of the time they made fun. That's why I tell my wife not to tell them. I understand their feeling because I felt the same way seven or eight years ago. I been through this and I know that others would be shocked to hear this - not shocked but they would not accept it. However, if they come to me and ask me what happened to your condition, I would let them know clearly, of course.

Family Members Participant 11: My family was also affected by my dizziness and arrhythmia. They became really worried when I lost 10 kilograms due to this condition. They have seen me gradually getting better, so they were not worried about where I was going and what I was doing. They acknowledged that this therapy fits me, and they have shown approval of what I was getting. My family members, my daughter and younger sister, had also become affiliated with MOA and received training to practice OPT on others.

My daughter had been diagnosed with a serious disease two years ago. She had ovarian cancer and she had to remove both her uterus and ovaries. When I was feeling very helpless as a mother when my daughter was suffering from the disease, the staff at the clinic suggested me to administer OPT towards her. This was the time that I felt really good about knowing OPT. When she had her surgery and when I administered OPT towards her wound, it brought relief fast. When I spoke with Dr. $\mathrm{M}$, he told me that the cancer tends to gather around the wound, so administering OPT around the wound is good. After cancer was diagnosed I have administered OPT to my daughter every single day. There were several days, about two or three days, in which I was not able to because I was home late. My daughter seems to be glad and she is the type who can feel differences after receiving OPT. That's why I have a sense of satisfaction. I feel so happy right now that I got to know this method, and that I am able to receive it myself and also able to administer towards my daughter.

Participant 21: My husband also practices OPT, so I do this every day with him. My husband became a member three months after I did, because I wanted him to practice towards me. He said yes. 


\section{Summary}

Phase I resulted in significant associations between all of the five lifestyle related CAM practices with decrease in perceived stress, and increase in QOL in the bivariate analysis. In the multiple regression analysis, arts and culture and exercise were significantly associated with decrease in perceived stress. Arts and culture, exercise, additive-free "organic" diet, and OPT was significantly associated with increased QOL, after controlling for age, sex, education level, annual income, sleep, appetite, and excretory functions. Furthermore, interaction variable of gender and arts and culture was associated weakly with perceived stress in the first model, but no significant associations were observed for interaction variable of gender and OPT towards stress and QOL.

In phase II of the research, grounded theory analysis resulted in the emergence of one theme, four clusters, and 13 categories. Feelings of extreme desperation "clutch at a straw" was chosen as the theme, because this was most applicable to all of the participants on why they practiced OPT. Perception towards OPT, Effects of OPT, and Understanding of how OPT works were categories which emerged to form a cluster How patients understand OPT. Suffering from symptoms, to practice as a therapist towards family or friends suffering from disease emerged to form a cluster What prompted individuals to receive OPT. Unexpected positive results from receiving OPT for the first time, Benefits of OPT, Positive relationship and satisfaction with staff and doctors of the clinic emerged to form a cluster Reasons for continuing OPT. Limits of conventional medicine, Dissatisfaction with western medicine emerged to form a cluster Thoughts on conventional medicine. Finally, Feelings of extreme desperation "clutch at a straw", Letting others know about OPT, and Family member emerged as independent categories. 
Although many patients expressed feeling doubts towards the practice of OPT at first, many seemed satisfied with the results of the practice mainly due to being able to manage their symptoms and having a sense of being in control. This may have led to increase in QOL. The mixed methods design was able to inform the interpretation of the association of OPT with reported increase in QOL in the quantitative phase of the research. 


\section{CHAPTER V DISCUSSION}

\section{Introduction}

This current mixed methods research was conducted to explore associations between the five lifestyle-related CAM practices with QOL and perceived stress among chronically ill patients controlling for several lifestyle factors and health conditions, and to increase knowledge of why patients decide to receive OPT. Quantitative findings showed significant associations of arts and cultural activities and exercise with decreasing perceived stress, and arts and culture, exercise, diet, and OPT with increased QOL. Gender significantly moderated the effects of arts and culture in one model with a weak association but was not significant in moderating the effects of OPT on decreasing perceived stress or increasing QOL. In addition to the quantitative results, qualitative results provided valuable insight on the reasons behind patients' decision to receive OPT. One theme, four clusters, and 13 categories were identified as emerging themes and categories from the transcribed interviews.

This chapter is divided into three sections. First the results of the quantitative analysis and implications of the findings are summarized and compared with previous studies, followed by a summary of qualitative results and implications of the findings.

Finally, the overall results of the mixed methods analysis are discussed, and limitations of the study and recommendations and implications for public health are summarized. 


\section{Phase I quantitative analysis}

The quantitative phase of research was conducted for the purpose of generating a more refined prediction of association by adding three additional control factors (appetite, excretory functions, and sleep) because these factors were predicted to have significant associations with both stress and QOL. Controlling for these factors was meaningful to control for confounding effects of the three variables, and to allow the observation of the association between each of the CAM practices with QOL and stress. In contrast to the primary study, the results of the present study showed a slightly higher level of association between each CAM practice and QOL and perceived stress in the bivariate analysis. However, lower levels of association were observed in the multivariate analysis. In the multivariate model, results indicated that the added variables of sleep, appetite, and excretory functions were all significant in predicting perceived stress and QOL.

Deterioration of sleep, appetite, and excretory functions significantly predicted increased perceived stress and decreased QOL. The added variables served as confounding factors, which is evident in the lowered associations between the five CAM practices and QOL and perceived stress.

In the multivariate model containing one CAM practice along with all the other control variables, all of the CAM practices except for home gardening and OPT were significantly associated with lower perceived stress. All the remaining CAM practices had weak associations with decreased perceived stress $(\beta=-0.070 \sim-0.135)$. All five CAM practices were significantly associated with improved QOL $(\beta=0.084 \sim 0.204)$. In the final multivariate model containing all of the five CAM practices and control variables as the independent variables, home gardening was not significant, and the four remaining CAM 
practices were significantly correlated with improved QOL $(\beta=0.058 \sim 0.143)$.

Furthermore, diet that included additive-free "organic" foods, OPT, and home gardening were not significantly associated with lower perceived stress, whereas exercise $(\beta=-$ $0.086)$ and arts and culture $(\beta=-0.121)$ were weakly associated with lower perceived stress.

Results indicated that practice of arts and cultural activities had the strongest association with both improved QOL and lower perceived stress, and exercise had the second-strongest associations. The association of exercise with improved health and QOL is consistent with many studies; physical activity has been shown to improve QOL even among patients suffering from chronic illness (Brown et al., 2003; Courneya \& Friedenreich, 1999; Motl \& Gosney, 2008). The benefits of exercise on reducing perceived stress have also been established in previous studies (Nguyen-Michel, Unger, Hamilton, \& Spruijt-Metz, 2006).

Arts and cultural activities had the strongest association with both QOL and perceived stress. The purpose of the practice of arts and culture has two elements. One is the aspect of creation of artwork. For example, the purpose of art therapy is to use the creative process to allow awareness and expression of an individual's deepest emotions (Malchiodi, 1999). Creative artwork activities enable patients to express their feelings through activities such as painting, drawing, or crafts. The second aspect of arts and culture is enjoying the beauty of art. This includes going to museums and galleries, enjoying beautiful scenery and landscapes at parks, etc. Studies have been conducted that address the effectiveness of both health benefits obtained during the process of creation of artwork and the positive health effects of enjoying the beauty of art. There have been 
several studies showing evidence of the effectiveness of art therapy on patients with mental health needs. Improvements in well-being, such as mood, self-esteem, QOL, reduction in stress, and blood pressure, have been reported in a systematic review of the effectiveness of creative activities on mental well-being (Leckey, 2011). Furthermore, studies have indicated the effectiveness of pleasant views of nature and aesthetic views towards recovering from stress and creating positive feelings (Ulrich, 1991). A study in Japan in which brain wave activity was measured after subjects viewed two types of potted plants, each with and without flowers, showed that participants were most relaxed when they watched plants with flowers and least relaxed when they looked at pots without plants (Nakamura \& Fujii, 1990).

Consumption of organic and/or additive-free food products had the thirdstrongest association with QOL but was not significantly associated with lower perceived stress. Some studies have suggested negative effects of intensification of food production and use of pesticides and other chemical products to increase the amount and speed of food production or shelf life on the environment and human health (Leckie, 1999). Other studies report no evidence of health and nutrition benefits of organic food compared to conventional foods (Honkanen, Verplanken, \& Olsen, 2006). Conventional food production relies heavily on chemical pesticides, chemical fertilizers, hormone antibiotics as "growth factors" for farm animals, genetically modified plants and seeds, and food additives and preservatives to produce and store food efficiently, leading to claims that conventional food may be less healthy than organically grown food (Saba \& Messina, 2003). Although the study findings on the negative health impacts of the use of pesticides in food production on human health and nutritional benefits of organic produces in 
comparison to conventional produces remain equivocal, the consumption of natural, organic, additive/preservative-free products seems to be increasing in popularity, as can be seen by the expanding market (Greene, 2014). The reasons why consumers of organic food are motivated to purchase organic foods vary, but studies indicate that among the most important factors motivating organic food purchases were putative health benefits (Chryssohoidis \& Krystallis, 2005; Shepherd, Magnusson, \& Sjoden, 2005).

Choosing organic food requires a strong commitment to this practice by consumers, as organic foods cost 10 percent to 40 percent more than conventional food products (Winter \& Davis, 2006). Thus, personal income may be an important predictor of organic consumption. Many patients in the present study reported consuming organic food, with 31 percent of study subjects reporting that more than 80 percent of their food was organic. The participants of the present study have a strong interest in and commitment to organic foods, because this habit requires additional expense. While there was no indication in this study of a significant association between annual income and QOL and perceived stress in the bivariate analyses (see appendix), health-related QOL and household annual income have been shown to have a strong association, especially among men (Yamazaki, Fukuhara, \& Suzukamo, 2005).

Practice of home gardening did not remain significantly associated with QOL and perceived stress in the final model. This was not consistent with the results from the primary study. The primary study reported a significant association between home gardening and both improved QOL and lower perceived stress. Since gardening is a combination of exercise and contact with nature, this activity was expected to be effective in reducing stress and increasing QOL. The result was also inconsistent with the result of 
a previous study on home gardening assessing the stress-relieving effects of gardening on acute stress (Van den Berg \& Custers, 2010). Gardening activity was effective in reducing acute stress measured by the amount of cortisol in the participants' saliva after engaging in gardening activity.

OPT was weakly associated with improved QOL but did not significantly predict decreased perceived stress. This was consistent with the primary study. Patients who suffer from chronic illnesses tend to score lower in QOL compared with people who are not suffering from any disease (Kimura, Suzuki, Uchida, \& Katamura, 2012). In addition, severity of disease and the level of QOL have been shown to have a significant relationship (Shavro, Ezhilarasu, Augustine, Bechtel, \& Christopher, 2012). Thus, patients with severe conditions may be more likely to report low QOL and be more willing to practice OPT more frequently. In comparison to the remaining four other types of CAM practices, OPT is practiced for the purpose of recovering from disease more than for the purpose of preventing disease or maintaining health. The remaining CAM practices are practiced with disease prevention and maintaining health in mind. Patients diagnosed with a severe state of chronic disease may practice OPT more frequently and will also have a lower QOL, which can be one explanation for the observed results.

\section{Gender differences}

Results from a systematic study on the demographic characteristics of the use of CAM showed females to be more likely to use CAM than males (Bishop \& Lewith, 2010). The findings were gathered from studies conducted in the United States, United Kingdom, Australia, Canada, Turkey, Italy, some Asian countries, and South Africa. Among medical doctors, female physicians were more likely than male physicians to use 
for themselves and also recommend to their patients the use of mind-body therapies, such as acupuncture, massage therapy, meditation, relaxation techniques, spinal manipulation, and yoga (Sierpina, Levine, Astin, \& Tan, 2007). The significant difference in the use of CAM among gender derives from the difference in attitudes towards the use of CAM. Females tend to have more positive attitudes towards the use of CAM and learning about the theory and practice of CAM compared to males (Greenfield et al., 2006). The present study supported the results of previous studies with three-fourths of the study participants being female. However, there were no differences in the outcome measures by gender. Therefore, differences by gender may not have an impact on creating differences in the perception of the effects of CAM. However, further study needs to be conducted to assess the direct relationship between patients' attitudes towards the practice of arts and culture and OPT, and the outcomes of these practices.

\section{Phase II qualitative discussion of the study}

The qualitative phase of the study consisted of interviews with a convenience sample of patients from an integrative clinic in Tokyo, which was one of the 10 clinics from which participants for the primary study were recruited. The mean score for QOL was slightly higher and the perceived stress score was slightly lower among the participants of the qualitative study, compared to the participants of the quantitative study. 


\section{Major findings}

One of the reasons why some people chose to receive OPT was because they had negative attitudes towards or experiences with conventional medicine. Themes such as dissatisfaction with doctors and limits of conventional medicine emerged. Participant 18 described how he decided to seek alternative medicine for his symptoms because his dermatological condition was not improving and his psychological and spiritual needs were unmet. A similar reaction was described by patients suffering from atopic dermatitis and psoriasis in other previous research, and the most decisive factor for trying alternative medicine was dissatisfaction with the effect of physician-prescribed treatment (Jensen, 1990). In another study conducted among patients of a gastroenterology clinic, one of the reasons for compliance with alternative medicine was because of skepticism of conventional medicine. In addition, there was an inverse relationship between use of alternative medicine and patients' perceived health status and satisfaction with clinic physicians (Sutherland \& Verhoef, 1994). In another study, patients receiving conventional therapy were more likely to have good relationships with physicians than were patients receiving both conventional and alternative care. These patients in turn reported better experiences with physicians than did patients who sought alternative treatment exclusively (Cassileth, Lusk, Strouse, \& Bodenheimer, 1984). In other words, as the relationship with doctors in conventional health care deteriorated, the likelihood of patients deciding to pursue alternative medicine increased and vice versa. Patients' dissatisfaction with providers predicts changes in health care provider in general medical practice as well as shifts towards using CAM (Marquis, Davies, \& Ware, 1983). In the interview, Participant 18 described how doctors failed to respectfully listen to what he 
had to say, which seemed to be one of his main complaints about conventional medical care. Similar views were expressed by a number of patients. Participants 15 and 17 described similar experiences of how the way doctors spoke to them felt mechanical and indifferent, and that doctors were too "busy" to show compassion for the patients, which made them worry about their future health prospect.

Dissatisfaction with conventional medicine and limits of conventional medicine were also reported in studies conducted in the U.S. A focus group of older women with arthritis reported that one of the reasons why patients sought CAM was dissatisfaction with conventional medicine. The dissatisfaction consisted of concern for side effects and harmful interaction effects of CAM with prescribed medication, non-holistic approaches of medical prescription, long waiting times, and lack of time during appointments (Cheung, Geisler, \& Sunneberg, 2014). Findings from other studies reported patients' perception of medical doctors being only interested in treating their disease rather than the whole person, which facilitated patients to use CAM (Lengacher et al., 2006). Concerns about side effects from prescription drugs and distrust of the pharmaceutical companies were also reported by CAM users in the U.S. (Kroesen, Baldwin, Brooks, \& Bell, 2002). Patients in the present study and patients in the U.S. seem to be turning to CAM for the same reasons, despite differences in the type of CAM used.

"Three-hour wait, three-minute contact" is a term used to describe the medical consultation process in Japan. Physician shortage in some areas due to mal-distribution of physicians has been a problem. In addition, patients are seeking more than essential advanced medical care, which is usually not available in local primary care clinics, increasing the pressure on hospitals (Matsumoto et al., 2010). Issues of unequal 
distribution of physicians resulting in increased physician workload and deterioration of the patient-physician relationship will only worsen as the aging population of Japan continues to grow rapidly and demand for medical care increases. This may in turn create a significant spillover effect of more demand for CAM. The health care structure of Japan is also what facilitates poor provider-patient relationships. Health care providers are paid for each prescription or medical examination rather than time spent with patients. Both the patient and the physicians are driven towards the direction of more medical examinations and more drugs, facilitating the mechanistic exchange of communication and worsening provider-patient relationships (H. Nomura \& Nakayama, 2005).

In contrast to the dissatisfaction with conventional medicine, positive relationship and satisfaction with doctors and the staff of the clinic was one of the themes that emerged as to why patients continued to receive OPT. Many participants from the interview described how they were comforted by the words from the doctors at the integrative clinic. Participant 8 admitted that he comes to receive OPT because he enjoys talking with the doctor and listening to the advice the doctor gives him. Participant 13 described the difference in the atmosphere of the clinic compared to regular hospitals. $\mathrm{He}$ described how the interaction between the patient and the staff and doctors was different from regular hospitals, and that the atmosphere of the clinic was like home. He further explained how the doctors gave him appropriate advice and that just seeing their faces relaxed him. A study has shown that one of the main values of CAM for customers was the supportive, empathic, and caring attitudes of the CAM practitioners, which resulted in encouraging continuity and treatment compliance (Dodds, Bulmer, \& Murphy, 2014). This is related to the fact that CAM medical patients seek to relieve emotional aspects of 
their problems as well as their physical symptoms, and also come for the counseling aspects of treatment (Vincent \& Furnham, 1996).

Suffering from poorly controlled symptoms was a theme that emerged within the category of what prompted individuals to receive OPT. A previous study confirmed that the most important expectation that patients had of alternative medicine was relief of symptoms. People who suffered chronic illnesses, in particular, received CAM with the hope of curing their illness or gaining relief from their symptoms (Richardson, 2004). Moreover, health problems are major predictive factors for alternative health care use, and experiencing health problems increases the likelihood that one will be a user of alternative medicine (Astin, 1998). The pain and suffering caused by illness motivates patients to seek therapy proactively. Many patients have described their experience of both physical and psychological suffering prior to receiving OPT. Some of the suffering came as adverse effects from taking medication. They wanted to do something about their condition; in most instances, they felt that they had exhausted the potential benefits of conventional medicine, prompting them to go beyond what they had already received as treatment. Some patients stated that they wanted to avoid aggressive treatment for fear of not being able to return to the state they were in before the illness.

Another reason for the use of OPT was the extreme desperation that patients endured. The feelings of desperation that led patients to receive OPT is the same as the "last resort users" of CAM described by Shaw et al. (2006). This theme was constructed based on participants' description of the desperation they felt in receiving OPT. The independent category feelings of extreme desperation, "clutching at a straw," emerged from replies by patients that were similar to those of "last resort users." When asked why 
they decided to start and continue receiving OPT, most participants stated that they were desperate and would try anything to relieve symptoms and recover from the disease. Participants were actively seeking to relieve symptoms, tacitly conveying that they had nothing to lose, since the options in conventional medicine had either proven ineffective or were unacceptable because of side effects. Participants' main focus was on relieving pain and other intractable symptoms and doing something "good" for their health.

Shaw et al. (2006) described how CAM users fall into one of three categories: "committed users," "pragmatic users," or "last resort users." Committed users of CAM are people who hold "alternative" philosophical beliefs about health that often differ from those underpinning conventional medicine. These users ideally prefer alternatives to conventional medicine and have a preference for non-pharmaceutical treatments. The second group consists of pragmatic CAM users. These people seek various treatments and self-help strategies to improve symptoms and related health issues, without a strong philosophical preference for complementary therapies. Finally, the third group are people who use complementary therapies in desperation after trying conventional treatments and finding them to be ineffective for managing their condition or unacceptable for various reasons. These were patients for whom medication had escalated, often with limited benefit for controlling symptoms (Shaw, Thompson, \& Sharp, 2006). The interviewed patients who began to receive OPT after being diagnosed with an illness were either "last resort" users or "pragmatic users." Some participants who were introduced to OPT before becoming ill had an understanding of the philosophy behind OPT use or, if not, seemed to be more motivated in trying to understand the philosophy behind the use of OPT. 


\section{OPT}

Biofield therapy or hands-on healing practices have a long history in various cultures around the world. However, there has not been enough research on this particular field, in part because of limitations in the standardization and scientific characterization of the methods, mechanisms, and effectiveness of these therapies (Anderson \& Taylor, 2012). In addition, no qualitative research studies on OPT have been published to date. This study is the first to attempt to identify the reasons why patients decide to receive this particular biofield therapy. The "pull" factors which attracted participants to adopt and implement OPT for achieving health, and how participants understood OPT, will be discussed below in a review of the themes of perception, understanding of OPT, effects, and the benefits of OPT.

\section{Perception of OPT}

The perceptions of OPT were varied. Participants who had prior experience in other biofield modalities or those who were accustomed to the use of other CAM practices tended to have positive perceptions towards OPT. These participants had an understanding and familiarity with the philosophy and/or favorable attitude towards biofield therapy or other nonconventional therapy methods. Participants generally stated their views as having no awkwardness towards OPT or having a good impression of the therapy. The positive perception of OPT among these participants was attributable to OPT being perceived as relevant to the individual's needs and being consistent with the individual's attitudes and beliefs (Rogers, 2003).

Participants who were not accustomed to biofield therapy or other CAM practices had negative or neutral perceptions of OPT and expressed a range of thoughts and 
attitudes about the practice. Many had doubts about OPT. However, for those who experienced symptom relief, perception of OPT evolved into a positive one. They described OPT as "mysterious" and stated that understanding the practice was difficult at first. The initial negative or neutral perception these participants had was reasonable because of the unlikelihood of these people having a favorable opinion about ideas they had never before encountered.

The third group of participants consisted of persons to whom OPT had been recommended by close family members or friends after they revealed their condition to these relatives or friends. These participants were aware of the existence of OPT or may even have had prior experiences receiving OPT before becoming ill. The diagnosis of a chronic illness pushed these people to receive OPT, and after experiencing the benefits of the therapy, they gradually changed their perception of the therapy. These participants stated that they had doubts and misunderstanding about OPT at first, but their feelings of suspiciousness towards OPT decreased as they became more aware of the practice. These people did not feel the need for OPT and had a reluctant attitude about and negative perception of the practice when they were first introduced through close friends or family members. Initially, there was no need for these people to want to receive OPT, and the practice was not consistent with their attitudes and beliefs. Some expressed that they were not interested in "religion," obviously concerned that OPT resembled "faith healing" or other religious rituals. 
The initial attitude is understandable because people tend to consciously or unconsciously avoid conversations and messages that are in conflict with their existing predispositions, which is termed "selective exposure" (Rogers, 2003). However, after being diagnosed with a chronic illness and as their desperation grew, their need for the practice increased, and they proceeded to try OPT.

The common factors underlying the second and third types of participants were the desire and need to recover from their chronic diseases, which became the impetus to receive OPT. According to Diffusion of Innovations theory, individuals do not expose themselves to messages about an innovation unless they first feel a need for the innovation, and even if individuals are exposed to the innovation messages, the exposure will have little effect unless the innovation is perceived as relevant to the individual's needs (Rogers, 2003). For these people, their need for OPT preceded the awareness and knowledge of OPT. In other words, it was the need for OPT that led them to acknowledge OPT. However, people who had prior experiences with other types of biofield therapy or CAM had beliefs and attitudes consistent with the possibility that OPT was effective in the first place. Hence, these individuals were favorably disposed to receiving OPT before having the need for OPT.

\section{Understanding of how OPT works}

As participants gained experience with OPT, they were able to increase acceptance that OPT worked and reduce uncertainties about the practice. Although some participants stated that they were still in the process of trying to understand the practice, statements such as “don't understand OPT well yet, but want to continue and see how it comes along" were also voiced. Many participants shared some of their current 
understandings of how they believed OPT worked. The common understanding presented by the participants was that OPT is a therapy that takes time, and because it is a nonmanipulative (no contact) "natural" therapy, there are no side effects involved.

Participants also indicated that they did not expect to experience drastic changes within a few sessions. These understandings are believed to be common among different biofield therapies. Reiki is also a therapy for which there are no accurate predictions of how quickly symptoms may respond. In addressing chronic conditions, several sessions of complete treatments are generally recommended before evaluating the benefits of Reiki (Miles \& True, 2003).

Understanding exactly how and why something works is important for the user of a practice when making decisions about whether to begin and/or continue the practice, although it is by no means essential (Rogers, 2003). In public health, for example, supine sleep positions for infants is endorsed based on its association in observational studies with lower risk of sudden infant death, without any clear understanding of the exact mechanism by which it protects against sudden infant death. Participants who indicated that they did not understand the practice continued to receive OPT to test and determine its effects. The understanding that participants gained about the principles of OPT facilitated their ability to judge the effectiveness of OPT. Most of the comments that described the understanding of how OPT worked were related to the functioning principles underlying how OPT is believed or expected to work.

\section{Effects and benefits of OPT}

The understanding of the effects of OPT were reinforced through both physical and psychological benefits experienced by participants. The common effects experienced 
were feelings of warmth or heat and the body feeling lighter, loosened, and relaxed during and after the therapy. The compassion and care given by the therapy practitioners as described by participants also reportedly elicited feelings of mental relaxation and wanting to do something for others. These effects influenced the participants to have favorable attitudes towards OPT. Many participants described experiencing unexpected positive results from receiving OPT during their first encounter with the therapy. In addition, some of the tangible changes in health symptoms after prolonged periods of practice described in the interview were feeling well psychologically, stopping weight loss related to adverse effects, regained appetite, lowered pain, relief of symptoms of illness, slowing cancer spread, softening of stiff shoulders, reduced need for medication allowing its complete suspension, and a decline in hemoglobin A1c levels. Participants described the above changes in their lifestyle and symptoms when asked to talk about changes they had experienced since starting OPT. Several participants stated that they were unsure of what caused the changes in symptoms to occur and that they had experienced something "mysterious. “

As indicated in Chapter Two, beneficial effects from receiving OPT and other forms of biofield therapy have been reported in previous studies. Some of the beneficial effects reported in previous research conducted on OPT were improvement in the severity of physical pain, palpitations, dizziness, and anxiety/depression (K. Suzuki et al., 2012). A small controlled trial conducted in Democratic Republic of Congo sickle cell disease patients comparing daily OPT for a year with a presumably low level of standard care showed that the OPT group had significantly greater improvements in hemoglobin, bilirubin, and renal function tests, and lower hospitalization levels than the patients 
assigned to standard care, suggesting effectiveness of OPT for sickle cell disease treatment (Mikobi \& Suzuki, 2012). In a randomized controlled study conducted by Uchida et al., OPT showed a significant increase in the mean spectral power of alpha waves relative to a placebo treatment (Uchida et al., 2012). Increase in alpha wave activity of the brain is associated with lessened perceived discomfort and pain and reductions in stress and anxiety (T. Nomura et al., 2006; Ossebaard, 2000). The common effects such as relaxation and feeling lighter described by participants of the present study were consistent with these alpha wave findings.

Similar experiences were described in a qualitative case study that explored the experience of therapeutic touch, a biofield therapy. Feelings such as ease of pain, sensations of warmth, and relaxation were described (Green, 1998; Keller \& Bzdek, 1986). Furthermore, reduction of pain and lowering heart rate, blood pressure, and mood disturbances among patients suffering from advanced cancer were reported in another study on therapeutic touch (Post-White et al., 2003). In a descriptive study of Reiki, the most common descriptions on the effects of Reiki reported by patients receiving the practice were relaxation, ease of pain, and improvement in mood and well-being (Richeson, Spross, Lutz, \& Peng, 2010). Recipients of Reiki often sense feelings of heat or coolness, or waves of relaxation throughout their body or in specific areas that may or may not correspond to where the practitioner's hands are placed (Engebretson \& Wardell, 2002). A systematic study confirmed the significant therapeutic effects of Reiki therapy on measurements such as pain, depression, anxiety, and other factors, which was described in several studies assessing the effectiveness of Reiki therapy (Lee, 2008). Despite differences in the philosophical principles and the development of each practice, 
it is interesting to see common effects observed among the different biofield practices as far as therapeutic effects are concerned (Potter, 2003).

The many positive effects reported by participants in the study require exploration of the possible role of placebo effects. Placebo effects may occur in any type of patientpractitioner relationship, both in conventional and non-conventional treatments (Kaptchuk, 2002). There are many factors that contribute to placebo effects. Among them, patients' expectations for the treatment are believed to influence the outcomes of both placebo effect and treatment (Kaptchuk, 2002). Patients who believe the treatment to work may experience some beneficial effects, even with ineffective "sham" treatments. This applies especially to participants who have had positive attitudes and experiences with biofield therapy and other CAM practices. People will have expectations for a positive experience in light of the belief in the therapy to work.

Other potential factors contributing to the reporting of positive effects with treatments that are not truly effective - such as those associated with positive interaction between patient and practitioner or environmental settings - must also be considered. In the present study, people who initially had neutral or negative perceptions of OPT also responded as having felt unexpected effects. Among these participants, the positive interaction between patient and practitioner and environmental setting may have worked positively towards creating a favorable experience for the patients, independent of OPT itself. Particularly for chronically ill patients who have overlays of anxiety, mood disorders, or stress, soothing supportive relationships can themselves be associated with lowered stress; some participants' reports of attending biofield therapy because they liked the therapist suggest such a mechanism played a part in symptom relief. In order to 
examine the true effects of OPT, further studies that isolate the effects of OPT from other potential influences need to be conducted by implementing a rigorous randomized controlled study design, ideally double-blinded, with a credible "sham" therapy control arm. There has only been one randomized controlled study conducted so far (Uchida et al., 2012). Further studies that are better designed to reduce the limitation of these studies need to be conducted in order to strengthen the evidence for efficacy of biofield therapies.

\section{Mixed methods}

The quantitative study was able to provide vital information on the association of each of five lifestyle-related CAM practices with perceived stress and QOL among chronically ill patients. The study showed that OPT was not associated significantly with decreased perceived stress, but a weak statistically significant association existed with increased QOL. In other words, patients who received OPT more often reported a somewhat higher QOL than those who did not. The mixed methods approach enabled the researcher to provide an in-depth analysis of what led patients to decide to receive OPT. The qualitative approach was able to shed light on the context behind choosing to receive OPT, such as frustrations and shortcomings felt by patients towards the methods and outcomes of conventional medical care. There was a range of factors, including an indepth description of the effects and benefits of OPT, reported by participants, associated in part with the relaxing environment of the facility and positive relationships with doctors and staff that facilitated patients to continue receiving OPT. The principal reason that compelled participants to receive OPT seemed to be their desperation with their disease and symptoms. Many patients described experiencing doubts about the effect of 
OPT when they first heard about the practice; however, most of the patients seemed to be benefitting from the practice of OPT. Participants were able to control the symptoms of their disease. For instance, Participant 18 described how he was able to gain a sense of control over his dermatological symptoms. Participants 3 and 23 described the greater mental damage they would have suffered if they did not know OPT, because they had an incurable condition for which there is currently no available treatment. From these responses we can infer that participants' QOL was raised through the practice of OPT, which was also observed in the quantitative results. Consequently, the qualitative informed the quantitative section of the study. Furthermore, the qualitative results were able to offer tentative explanations for why the quantitative results for OPT were weak, as was discussed previously. In general, people who suffer from chronic diseases and are poorly responsive to conventional therapy would be likely to perceive their health status to be poor, score low in measurements of QOL and high in perceived stress, and have an increased likelihood of receiving OPT due to their desire for recovery from the disease and/or symptoms and dissatisfaction with conventional treatment. Feelings of desperation are among the principal reasons for receiving OPT. People who are feeling desperate among those suffering from chronic disease would have severe conditions and would continue to receive OPT frequently. However, their QOL measurements would be low and perceived stress measurements high.

\section{Limitations}

Several limitations need to be taken into account while interpreting the findings for this study. First, the secondary data used for the quantitative study was not a random sample. The sample was collected from 10 different clinics throughout Japan, the 
participants were conveniently sampled, and the ratio of the number of participants sampled from each clinic did not correspond to the population distribution. Thus, generalizability is limited. Second, there was higher participation from females than from males (three-fourths of the participants were female), and the average age of the participants was 60 years, reflecting the distribution of chronic illness treatment in the population but not necessarily reflecting the distribution of need for treatment. Third, the illnesses of the participants varied widely. Therefore, the results and interpretations of this study might differ according to the type and severity of diseases. Fourth, this study was a cross-sectional study in which data were collected at only one time point. Therefore, determining cause-effect relationships with certainty is impossible.

Some of the limitations for the qualitative portion are as follows: First, there were higher proportions of chronic conditions that were severe in the participants of the qualitative study compared to the quantitative study. Second, the process of coding was conducted by a single researcher. Therefore, the process of interpreting the descriptive data into codes and themes may have been different if other researchers' perspectives were reflected. However, the results of the analysis were sent to three non-randomly chosen interview participants to confirm its applicability to their experiences and to maintain credibility. Finally, although participants were assured of their privacy and anonymity, social desirability bias also needs to be taken into account; participants were often talking about practitioners with whom they had formed a close, warm bond. Only one qualitative study participant actually reported not responding to the therapy, suggesting that the study may have underrepresented patients who discontinued biofield therapy because they were dissatisfied with their response. 


\section{Public health implications of CAM}

Lifestyle-based health promotion is gaining popularity as health paradigms shift towards focusing on prevention and health promotion rather than on disease treatment alone. More emphasis is placed on the goal to stop disease before it starts or otherwise minimize the damage from chronic diseases. A further successful shift towards health promotion and disease prevention is crucial. Otherwise, the consistent increase in chronic diseases will further detrimentally impact the economies of both Japan and the United States, as public and private health expenditures continue to rise at unsustainable rates (Redwood, 2010). The change in popular health consciousness due to the increase in the prevalence of chronic diseases has led to more demand for health practices stressing the importance of QOL. At the same time, negative health effects caused by unevaluated dietary foods, "natural" drugs, and supplements have been facilitated by a flood of directto-consumer marketing and claims encouraging health practices without research assurance of their safety and efficacy. In response to these concerns, legislators of the Liberal Democratic Party of Japan (LDP) (the current majority party of both the House of Representatives and the House of Councilors, which constitute the National Diet of Japan) have formed an association of legislators in support of the promotion of integrative medicine. This has led to the inclusion of the statement "promotion of integrative medicine which improves QOL" within the political manifesto announced from the LDP in 2012 (Liberal Democratic Party of Japan, 2012). The government is currently working towards establishing a research institute (like the NCCIH of the NIH) under the Ministry of Labor Health and Welfare for conducting research and releasing information on the safety and effectiveness of various CAM practices. The legislators are 
also working on creating a law provisionally named "The Basic Act on the Promotion of Integrative Medicine" and securing a budget for the implementation of the law (Health Industry Marketing News, 2014). However, there are claims against this movement due to the scarcity of research showing evidence of the effectiveness of CAM practices (Hanyuda, 2014). This study was able to provide an in-depth explanation as to why patients decide to receive OPT, with some concepts being applicable to the reason why chronically diseased patients choose to practice CAM in general. Furthermore, patients seemed to be able to manage symptoms of their disease and increase QOL despite initially being skeptical of achieving any benefits from OPT.

The present study was able to show significant benefits of the practice of arts and cultural activities, and exercise. Although the benefits of exercise to general well-being and health are well known, the benefits of arts and culture or similar practices are not as well understood. Many people inherently understand the positive effects of enjoying beautiful sceneries, aesthetic art, landscapes, and visits to art museums. However, formal recognition of the beneficial effects on health and well-being is uncommon. Many people exercise for the sake of maintaining health or preventing disease; however, it is unusual to hear of people planting flowers for the purpose of maintaining health and well-being. The results of the present study can be applied to and implemented in various settings. For example, the beneficial effects of art towards improving QOL and stress reduction can be applied to community infrastructures and dwellings, possibly impacting the health of residents of the community. Although the effects of one CAM practice may be subtle, if people's lives were supported by many evidence-based health-promotion and diseaseprevention activities and programs, the cumulative effects could be considerable. 


\section{Recommendation for future research}

The benefits of OPT remain unclear. The findings of the quantitative results were weak, and definitive decisions on whether OPT is beneficial to health cannot be confirmed. The purpose of the present study was based on anecdotes from participants of the present research and other previous findings. More research needs to be conducted on this therapy, with studies adopting a rigorous design. The current study was not able to examine the effects of OPT on patients, which isolated the exposure from other lifestylebased CAM practices. OPT is frequently practiced with a combination of arts and cultural activity and consumption of organic, additive-free food. In future research, there needs to be a study that controls and isolates the exposure among these practices in order to examine the pure effects of OPT and the effects of OPT in combination with other therapies. 


\section{REFERENCES}

Adam, T. C., \& Epel, E. S. (2007). Stress, eating and the reward system. Physiology \& Behavior, 91(4), 449-458.

Alavanja, M. M. C. R. (2004). Health effects of chronic pesticide exposure: Cancer and neurotoxicity*. Annual Review of Public Health, 25(1), 155-197.

Amarantos, E., Martinez, A., \& Dwyer, J. (2001). Nutrition and quality of life in older adults. The Journals of Gerontology Series A: Biological Sciences and Medical Sciences, 56, 54-64.

Anita, D. A. (1982). Relationship of daily hassles, uplifts, and major life events to health status. Health Psychology, 1(2), 119-136.

Astin, J. A. (1998). Why patients use alternative medicine: Results of a national study. Jama, 279(19), 1548-1553.

Astin, J. A., Marie, A., Pelletier, K. R., Hansen, E., \& Haskell, W. L. (1998). A review of the incorporation of complementary and alternative medicine by mainstream physicians. Archives of Internal Medicine, 158(21), 2303-2310.

Bailey, S. S. (1997). The arts in spiritual care. Seminars in Oncology Nursing, 13(4), 242247.

Baker, B. B. O. (1966). Weak measurements vs. strong statistics: An empirical critique of S. S. Stevens' proscriptions in statistics. Educational and Psychological Measurement, 26(2), 291-309.

Barnes, P. M., Bloom, B., \& Nahin, R. L. (2008). Complementary and alternative medicine use among adults and children: United States, 2007. National Health Statistics Reports, (12)(12), 1-23.

Barnett, J., Vasileiou, K., Djemil, F., Brooks, L., \& Young, T. (2011). Understanding innovators' experiences of barriers and facilitators in implementation and diffusion of healthcare service innovations: A qualitative study. BMC Health Services Research, 11(1), 1-12.

Baum, A., Herberman, H., \& Cohen, L. (1995). Managing stress and managing illness: Survival and quality of life in chronic disease. Journal of Clinical Psychology in Medical Settings, 2(4), 309-333.

Belloc, N. B. (1973). Relationship of health practices and mortality. Preventive Medicine, 2(1), 67-81. 
Bennett, B. M., Laidlaw, T. M., Dwivedi, P., Naito, A., \& Gruzelier, J. H. (2006). A qualitative study of the experience of self-hypnosis or Johrei in metastatic breast cancer using interpretative phenomenological analysis. Contemporary Hypnosis, 23(3), 127-140.

Bishop, F. L., \& Lewith, G. T. (2010). Who uses CAM? A narrative review of demographic characteristics and health factors associated with CAM use. EvidenceBased Complementary and Alternative Medicine : eCAM, 7(1), 11-28.

Bishop, F. L., Yardley, L., \& Lewith, G. (2005). Developing a measure of treatment beliefs: The complementary and alternative medicine beliefs inventory. Complementary Therapies in Medicine, 13(2), 144-149.

Blair, A., Zahm, S. H., Pearce, N. E., Heineman, E. F., \& Fraumeni Jr, J. F. (1992). Clues to cancer etiology from studies of farmers. Scandinavian Journal of Work, Environment \& Health, 209-215.

Breslow, L., \& Enstrom, J. E. (1980). Persistence of health habits and their relationship to mortality. Preventive Medicine, 9(4), 469-483.

Brooks, A. J., Schwartz, G. E., Reece, K., \& Nangle, G. (2006). The effect of Johrei healing on substance abuse recovery: A pilot study. Journal of Alternative and Complementary Medicine (New York, N.Y.), 12(7), 625-631.

Brown, D. W., Balluz, L. S., Heath, G. W., Moriarty, D. G., Ford, E. S., Giles, W. H., \& Mokdad, A. H. (2003). Associations between recommended levels of physical activity and health-related quality of life findings from the 2001 behavioral risk factor surveillance system (BRFSS) survey. Preventive Medicine, 37(5), 520-528.

Burstein, H. J., Gelber, S., Guadagnoli, E., \& Weeks, J. C. (1999). Use of alternative medicine by women with early-stage breast cancer. The New England Journal of Medicine, 340(22), 1733-1739.

Buzzetti, R. A., Hinojosa-Kurtzberg, M., Shea, T. J., Ibuki, Y., Sirakis, G., \& Parthasarathy, S. (2013). Effect of Johrei therapy on sleep in a murine model. Explore (New York, N.Y.), 9(2), 100-105.

Cantor, K. P., Blair, A., Everett, G., Gibson, R., Burmeister, L. F., Brown, L. M., \& Dick, F. R. (1992). Pesticides and other agricultural risk factors for non-Hodgkin's lymphoma among men in Iowa and Minnesota. Cancer Research, 52(9), 2447-2455.

Carlsson, M., Arman, M., Backman, M., Flatters, U., Hatschek, T., \& Hamrin, E. (2006). A five-year follow-up of quality of life in women with breast cancer in anthroposophic and conventional care. Evidence-Based Complementary and Alternative Medicine: eCAM, 3(4), 523-531. 
Cassileth, B. R., Lusk, E. J., Strouse, T. B., \& Bodenheimer, B. J. (1984). Contemporary unorthodox treatments in cancer medicine. A study of patients, treatments, and practitioners. Annals of Internal Medicine, 101(1), 105-112.

Centers for Disease Control and Prevention. (2009). Chronic diseases: The power to prevent, the call to control: At a glance 2009. Retrieved from http://www.cdc.gov/chronicdisease/resources/publications/aag/chronic.htm

Centers for Medicare and Medicaid Services. (2012). National health expenditure data. Retrieved from http://www.cms.gov/Research-Statistics-Data-andSystems/Statistics-Trends-andReports/NationalHealthExpendData/downloads/tables.Pdf (retrieved April 1, 2014)

Cheung, C., Geisler, C., \& Sunneberg, J. (2014). Complementary/alternative medicine use for arthritis by older women of urban-rural settings. Journal of the American Association of Nurse Practitioners, 26(5), 273-280.

Chryssohoidis, G. M., \& Krystallis, A. (2005). Organic consumers' personal values research: Testing and validating the list of values (LOV) scale and implementing a value-based segmentation task. Food Quality and Preference, 16(7), 585-599.

Clammer, J. (2010). Practical spirituality and engaged Shinto: Ecology, peace and the critique of modernity in reformed Japanese religion. IBA Journal of Management and Leadership, 97.

Clarke, T. C., Black, L. I., Stussman, B. J., Barnes, P. M., \& Nahin, R. L. (2015). Trends in the use of complementary health approaches among adults: United states, 20022012. National Health Statistics Reports, (79)(79), 1-16.

Cohen, S., Janicki-Deverts, D., \& Miller, G. E. (2007). Psychological stress and disease. JAMA: The Journal of the American Medical Association, 298(14), 1685-1687.

Cohen, S., Kamarck, T., \& Mermelstein, R. (1983). A global measure of perceived stress. Journal of Health and Social Behavior, 24(4), 385-396.

Colon-Emeric, C. S., Lekan, D., Utley-Smith, Q., Ammarell, N., Bailey, D., Corazzini, K., $\&$ Anderson, R. A. (2007). Barriers to and facilitators of clinical practice guideline use in nursing homes. Journal of the American Geriatrics Society, 55(9), 1404-1409.

Corbin, J., \& Strauss, A. (2008). Basics of qualitative research 3rd edition (Third Edition ed.). Thousand Oaks, CA: Sage Publications.

Courneya, K. S., \& Friedenreich, C. M. (1999). Physical exercise and quality of life following cancer diagnosis: A literature review. Annals of Behavioral Medicine, 21(2), 171-179. 
Creswell, J. W. (2012). Qualitative inquiry and research design: Choosing among five approaches (Third Edition). Thousand Oaks, CA: Sage.

Creswell, J. W. (2013). Research design: Qualitative, quantitative, and mixed methods approaches (Fourth Edition). Thousand Oaks, CA: Sage.

Crinnion, W. J. (2010). Organic foods contain higher levels of certain nutrients, lower levels of pesticides, and may provide health benefits for the consumer. Alternative Medicine Review: A Journal of Clinical Therapeutic, 15(1), 4-12.

Curl, C. L., Fenske, R. A., \& Elgethun, K. (2003). Organophosphorus pesticide exposure of urban and suburban preschool children with organic and conventional diets. Environmental Health Perspectives, 111(3), 377-382.

Daston, L., \& Vidal, F. (2010). The moral authority of nature. Chicago (pp. 308 330): University of Chicago Press.

Davis, D. R., Epp, M. D., \& Riordan, H. D. (2004). Changes in USDA food composition data for 43 garden crops, 1950 to 1999. Journal of the American College of Nutrition, 23(6), 669-682.

Denzin, N. K., \& Lincoln, Y. S. (1998). The landscape of qualitative research: Theories and issue. Thousand Oaks, CA: Sage.

Denzin, N. K., \& Lincoln, Y. S. (2003). Strategies of qualitative inquiry. Thousand Oaks, CA: Sage.

DiPietro, L. (2001). Physical activity in aging: Changes in patterns and their relationship to health and function. The Journals of Gerontology. Series A, Biological Sciences and Medical Sciences, 56 Spec No 2, 13-22.

Dodds, S., Bulmer, S., \& Murphy, A. (2014). Consumer value in complementary and alternative medicine (CAM) health care services. Australasian Marketing Journal (AMJ), 22(3), 218-229.

Dressen, L. J., \& Singg, S. (1998). Effects of Reiki on pain and selected affective and personality variables of chronically ill patients. Subtle Energies \& Energy Medicine Journal Archives, 9(1)

Edberg, M. C. (2009). Essential readings in health behavior: Theory and practice. Boston, MA. Jones \& Bartlett Learning. 
Eisenberg, D. M., Davis, R. B., Ettner, S. L., Appel, S., Wilkey, S., Van Rompay, M., \& Kessler, R. C. (1998). Trends in alternative medicine use in the United States, 19901997: Results of a follow-up national survey. JAMA: The Journal of the American Medical Association, 280(18), 1569-1575.

Eisenberg, D. M., Kessler, R. C., Foster, C., Norlock, F. E., Calkins, D. R., \& Delbanco, T. L. (1993). Unconventional medicine in the United States. prevalence, costs, and patterns of use. The New England Journal of Medicine, 328(4), 246-252.

Engebretson, J., \& Wardell, D. W. (2002). Experience of a Reiki session. Alternative Therapies in Health and Medicine, 8(2), 48-53.

Epel, E., Jimenez, S., Brownell, K., Stroud, L., Stoney, C., \& Niaura, R. (2004). Are stress eaters at risk for the metabolic syndrome? Annals of the New York Academy of Sciences, 1032, 208-210.

Evans, G. G. W. (2003). Housing and mental health: A review of the evidence and a methodological and conceptual critique. Journal of Social Issues, 59(3), 475; 475$500 ; 500$.

Fasching, P. A., Thiel, F., Nicolaisen-Murmann, K., Rauh, C., Engel, J., Lux, M. P., \& Bani, M. R. (2007). Association of complementary methods with quality of life and life satisfaction in patients with gynecologic and breast malignancies. Supportive Care in Cancer: Official Journal of the Multinational Association of Supportive Care in Cancer, 15(11), 1277-1284.

Ford, E. S., Croft, J. B., Posner, S. F., Goodman, R. A., \& Giles, W. H. (2013). Cooccurrence of leading lifestyle-related chronic conditions among adults in the United States, 2002-2009. Preventing Chronic Disease, 10, E60.

Forman, J., Silverstein, J., Committee on Nutrition, Council on Environmental Health, \& American Academy of Pediatrics. (2012). Organic foods: Health and environmental advantages and disadvantages. Pediatrics, 130(5), e1406-15.

Furnham, A., \& Bhagrath, R. (1993). A comparison of health beliefs and behaviours of clients of orthodox and complementary medicine. British Journal of Clinical Psychology, 32(2), 237-246.

Furnham, A., \& Forey, J. (1994). The attitudes, behaviors and beliefs of patients of conventional vs. complementary (alternative) medicine. Journal of Clinical Psychology, 50(3), 458-469.

Furnham, A., \& Kirkcaldy, B. (1996). The health beliefs and behaviours of orthodox and complementary medicine clients. The British Journal of Clinical Psychology / the British Psychological Society, 35 (Pt 1)(Pt 1), 49-61. 
Furnham, A., \& Smith, C. (1988). Choosing alternative medicine: A comparison of the beliefs of patients visiting a general practitioner and a homoeopath. Social Science \& Medicine (1982), 26(7), 685-689.

Gasiorowska, A., Navarro-Rodriguez, T., Dickman, R., Wendel, C., Moty, B., Powers, J., \& Fass, R. (2009). Clinical trial: The effect of Johrei on symptoms of patients with functional chest pain. Alimentary Pharmacology \& Therapeutics, 29(1), 126-134.

Gigliotti, C. M., \& Jarrott, S. E. (2005). Effects of horticulture therapy on engagement and affect. Canadian Journal on Aging, 24(4), 367-378.

González-Alzaga, B., Lacasaña, M., Aguilar-Garduño, C., Rodríguez-Barranco, M., Ballester, F., Rebagliato, M., \& Hernández, A. F. (2014). A systematic review of neurodevelopmental effects of prenatal and postnatal organophosphate pesticide exposure. Toxicology Letters, 230(2), 104-121.

Grabbe, L., Ball, J., \& Goldstein, A. (2013). Gardening for the mental well-being of homeless women. Journal of Holistic Nursing: Official Journal of the American Holistic Nurses' Association, 31(4), 258-266.

Green, C. A. (1998). Reflection of a therapeutic touch experience: Case study 2. Complementary Therapies in Nursing \& Midwifery, 4(1), 17-21.

Greene, C. (2014). Organic market overview. Retrieved from http://www.ers.usda.gov/topics/natural-resources-environment/organicagriculture/organic-market-overview.aspx (retrieved April 2, 2015)

Greenfield, S. M., Brown, R., Dawlatly, S. L., Reynolds, J. A., Roberts, S., \& Dawlatly, R. J. (2006). Gender differences among medical students in attitudes to learning about complementary and alternative medicine. Complementary Therapies in Medicine, 14(3), 207-212.

Guba, E. G., \& Lincoln, Y. S. (1981). Effective evaluation: Improving the usefulness of evaluation results through responsive and naturalistic approaches. Jossey-Bass.

Guyton, K. Z., Loomis, D., Grosse, Y., El Ghissassi, F., Benbrahim-Tallaa, L., Guha, N., \& International Agency for Research on Cancer Monograph Working Group, IARC, Lyon, France. (2015). Carcinogenicity of tetrachlorvinphos, parathion, malathion, diazinon, and glyphosate. The Lancet Oncology, 16(5), 490-491.

Hammen, C. (2005). Stress and depression. Annual Review of Clinical Psychology, 1, 293-319.

Hammerschlag, R., Marx, B. L., \& Aickin, M. (2014). Nontouch biofield therapy: A systematic review of human randomized controlled trials reporting use of only 
nonphysical contact treatment. Journal of Alternative and Complementary Medicine (New York, N.Y.), 20(12), 881-892.

Hanyuda, S. (2014). Integrative medicine and its issues (in Japanese). Retrieved from http://www.med.or.jp/doctor/member/kiso/d20.html (retrieved May 29, 2015)

Harris, P. E., Cooper, K. L., Relton, C., \& Thomas, K. J. (2012). Prevalence of complementary and alternative medicine (CAM) use by the general population: A systematic review and update. International Journal of Clinical Practice, 66(10), 924-939.

Health Industry Marketing News. (2014). League of legislators of the LDPJ on the promotion of integrative medicine to demand "basic act on promotion of integrative medicine". Retrieved from http://www.him-news.com/news/view/892 (retrieved May 28, 2015)

Henke, N., Kadonaga, S., \& Kanzler, L. (2009). Improving Japan's health care system. The McKinsey Quarterly, Retrieved from http://www.mckinsey.com/insights/health_systems_and_services/improving_japans_ health_care_system (retrieved September 1, 2014)

Honkanen, P., Verplanken, B., \& Olsen, S. O. (2006). Ethical values and motives driving organic food choice. Journal of Consumer Behaviour, 5(5), 420-430.

Hyland, M. E., Lewith, G. T., \& Westoby, C. (2003). Developing a measure of attitudes: The holistic complementary and alternative medicine questionnaire. Complementary Therapies in Medicine, 11(1), 33-38.

Imanishi, J., Watanabe, S., Satoh, M., \& Ozasa, K. (1999). Japanese doctors' attitudes to complementary medicine. Lancet, 354(9191), 1735-1736.

Jain, S., \& Mills, P. J. (2010). Biofield therapies: Helpful or full of hype? A best evidence synthesis. International Journal of Behavioral Medicine, 17(1), 1-16.

Jensen, P. (1990). Alternative therapy for atopic dermatitis and psoriasis: Patient-reported motivation, information source and effect. Acta Dermato-Venereologica, 70(5), 425428.

Jones, R. S. (2009). Health-Care Reform in Japan: Controlling Costs, Improving Quality and Ensuring Equity. Organization for Economic Co-operation and Development. doi: $10.1787 / 220005270870$ 
Jones, R. R., Barone-Adesi, F., Koutros, S., Lerro, C. C., Blair, A., Lubin, J., Heltshe, S., Hoppin, J., Alavanja, M., \& Beane Freeman, L. E. (2015). Incidence of solid tumours among pesticide applicators exposed to the organophosphate insecticide diazinon in the agricultural health study: An updated analysis. Occupational and Environmental Medicine, doi:oemed-2014.

Kaptchuk, T. J. (2002). The placebo effect in alternative medicine: Can the performance of a healing ritual have clinical significance? Annals of Internal Medicine, 136(11), 817-825.

Keller, E., \& Bzdek, V. M. (1986). Effects of therapeutic touch on tension headache pain. Nursing Research, 35(2), 101-106.

Kimura, T., Matsuo, H., Iida, N., Maki, Y., \& Suzuki, K. (2013). Associations between perceived stress, quality of life and complementary health practices in Japanese outpatients: A multicenter observational study. Alternative Medicine Studies, 3(1)

Kimura, T., Suzuki, K., Uchida, S., \& Katamura, H. (2012). Responsiveness and minimally important difference of a generic quality of life measure for complementary health practices. Alternative Medicine Studies, 2(1), e12.

Kimura, T., Yasutami, T., Uchida, S., Iwahashi, S., Eboshida, A., \& Kiyoshi, Y. (2008). Development of the shortened questionnaires for the Japanese version of the perceived stress scale (in Japanese). Research Reports from the MOA Health Science Foundation, (Vol. 12)

Kimura, T., Ogushi, Y., Haruki, Y., \& Okada, Y. (2000). Is interest in art effective in health-related quality of life? Results of a cross-sectional survey on lifestyle and health promotion. The Tokai Journal of Experimental and Clinical Medicine, 25(3), 141-149.

Kimura, T., Uchida, S., Tsuda, Y., \& Eboshida, A. (2005). Computer-assisted measurement of perceived stress: An application for a community-based survey. Hiroshima Journal of Medical Sciences, 54(3), 61-65.

Kroesen, K., Baldwin, C. M., Brooks, A. J., \& Bell, I. R. (2002). US military veterans' perceptions of the conventional medical care system and their use of complementary and alternative medicine. Family Practice, 19(1), 57-64.

Kuo, F. E., \& Taylor, A. F. (2004). A potential natural treatment for attentiondeficit/hyperactivity disorder: Evidence from a national study. American Journal of Public Health, 94(9), 1580-1586. 
Laidlaw, T. M., Kerstein, R., Bennett, B. M., Naito, A., Dwivedi, P., \& Gruzelier, J. (2004). Hypnotizability and immunological response to psychological intervention in HIV. Contemporary Hypnosis, 21(3), 126-135.

Laidlaw, T. M., Naito, A., Dwivedi, P., Enzor, N. A., Brincat, C. E., \& Gruzelier, J. H. (2003). Mood changes after self-hypnosis and Johrei prior to exams. Contemporary Hypnosis, 20(1), 25-39.

Laidlaw, T., Bennett, B. M., Dwivedi, P., Naito, A., \& Gruzelier, J. (2005). Quality of life and mood changes in metastatic breast cancer after training in self-hypnosis or Johrei: A short report. Contemporary Hypnosis, 22(2), 84-93.

Laidlaw, T. M., Naito, A., Dwivedi, P., Hansi, N. K., Henderson, D. C., \& Gruzelier, J. H. (2006). The influence of $10 \mathrm{~min}$ of the Johrei healing method on laboratory stress. Complementary Therapies in Medicine, 14(2), 127-132.

Lairon, D. D. (2010). Nutritional quality and safety of organic food. A review. Agronomy for Sustainable Development, 30(1), 33; 33-41; 41.

Lance, C. E., Butts, M. M., \& Michels, L. C. (2006). The sources of four commonly reported cutoff criteria: What did they really say? Organizational Research Methods, $9(2), 202-220$.

Langhorst, J., Anthonisen, I. B., Steder-Neukamm, U., Luedtke, R., Spahn, G., Michalsen, A., \& Dobos, G. J. (2007). Patterns of complementary and alternative medicine (CAM) use in patients with inflammatory bowel disease: Perceived stress is a potential indicator for CAM use. Complementary Therapies in Medicine, 15(1), 3037.

Leckey, J. (2011). The therapeutic effectiveness of creative activities on mental wellbeing: A systematic review of the literature. Journal of Psychiatric and Mental Health Nursing, 18(6), 501-509.

Leckie, J. (1999). Is organic food production feasible? Nutrition and Health, 13(2), 109119.

Lee, M. M. S. (2008). Effects of Reiki in clinical practice: A systematic review of randomised clinical trials effects of Reiki in clinical practice. International Journal of Clinical Practice (Esher), 62(6), 947; 947-954; 954.

Lemaitre RN, Siscovick DS, Raghunathan TE, Weinmann S, \& Arbogast P,Lin D. (1999). Leisure-time physical activity and the risk of primary cardiac arrest. Archives of Internal Medicine, 159(7), 686-690. 
Lengacher, C. A., Bennett, M. P., Kip, K. E., Gonzalez, L., Jacobsen, P., \& Cox, C. E. (2006). Relief of symptoms, side effects, and psychological distress through use of complementary and alternative medicine in women with breast cancer. Oncology Nursing Forum, 33(1), 97-104.

Leona S. Aiken, Stephen G. West, \& Raymond R. Reno. (1991). Multiple regression: Testing and interpreting interactions. Thousand Oaks, CA: Sage.

Leserman, J., Jackson, E. D., Petitto, J. M., Golden, R. N., Silva, S. G., Perkins, D. O., \& Evans, D. L. (1999). Progression to AIDS: The effects of stress, depressive symptoms, and social support. Psychosomatic Medicine, 61(3), 397-406.

Liberal Democratic Party of Japan. (2012). Policy agenda for the Liberal Democratic Party of Japan (in Japanese). Retrieved from http://jimin.ncss.nifty.com/pdf/j_file2012.pdf (retrieved on May 28, 2015)

Lockie, S., Lyons, K., Lawrence, G., \& Mummery, K. (2002). Eating 'green': Motivations behind organic food consumption in Australia. Sociologia Ruralis, 42(1), 23-40.

Lu, C., Toepel, K., Irish, R., Fenske, R. A., Barr, D. B., \& Bravo, R. (2006). Organic diets significantly lower children's dietary exposure to organophosphorus pesticides. Environmental Health Perspectives, 114(2), 260-263.

Maas, J., Verheij, R. A., de Vries, S., Spreeuwenberg, P., Schellevis, F. G., \& Groenewegen, P. P. (2009). Morbidity is related to a green living environment. Journal of Epidemiology and Community Health, 63(12), 967-973.

Magnusson, M. K., Arvola, A., Hursti, U. K., Åberg, L., \& Sjödén, P. (2003). Choice of organic foods is related to perceived consequences for human health and to environmentally friendly behaviour. Appetite, 40(2), 109-117.

Malchiodi, C. A. (1999). Medical art therapy with adults. London: Jessica Kingsley.

Marquis, M. S., Davies, A. R., \& Ware, J. E., Jr. (1983). Patient satisfaction and change in medical care provider: A longitudinal study. Medical Care, 21(8), 821-829.

Matsumoto, M., Inoue, K., Bowman, R., Noguchi, S., Toyokawa, S., \& Kajii, E. (2010). Geographical distributions of physicians in Japan and US: Impact of healthcare system on physician dispersal pattern. Health Policy, 96(3), 255-261.

McCabe, C., Roche, D., Hegarty, F., \& McCann, S. (2013). 'Open window': A randomized trial of the effect of new media art using a virtual window on quality of life in patients' experiencing stem cell transplantation. Psycho-Oncology, 22(2), 330337. 
McDade, T. W., Chyu, L., Duncan, G. J., Hoyt, L. T., Doane, L. D., \& Adam, E. K. (2011). Adolescents' expectations for the future predict health behaviors in early adulthood. Social Science \& Medicine (1982), 73(3), 391-398.

McEwen, B. S., \& Stellar, E. (1993). Stress and the individual. Mechanisms leading to disease. Archives of Internal Medicine, 153(18), 2093-2101.

McKinlay, J. J. (2008). When there is no doctor: Reasons for the disappearance of primary care physicians in the US during the early 21 st century. Social Science \& Medicine (1982), 67(10), 1481; 1481-1491; 1491.

Mertler, C. A., \& Vannatta, R. A. (2005). Advanced and multivariate statistical methods (Third Edition ed.). Glendale, CA: Pyrczak Publishing.

Michaelidou, N., \& Hassan, L. M. (2008). The role of health consciousness, food safety concern and ethical identity on attitudes and intentions towards organic food. International Journal of Consumer Studies, 32(2), 163-170.

Mikobi, M., \& Suzuki, K. (2012). P02.153. Effectiveness of biofield therapy for patients with sickle cell disease in Africa. BMC Complementary and Alternative Medicine, 12(Suppl 1), P209-6882-12-S1-P209.

Miles, P., \& True, G. (2003). Reiki--review of a biofield therapy history, theory, practice, and research. Alternative Therapies in Health and Medicine, 9(2), 62-72.

Milligan, C., Gatrell, A., \& Bingley, A. (2004). "Cultivating health": Therapeutic landscapes and older people in northern England. Social Science \& Medicine (1982), 58(9), 1781-1793.

Minga, T. M., Koto, F. K., Egboki, H., \& Suzuki, K. (2014). Effectiveness of biofield therapy for individuals with sickle cell disease in Africa. Alternative Therapies in Health and Medicine, 20(1), 20-26.

Motl, R. W., \& Gosney, J. L. (2008). Effect of exercise training on quality of life in multiple sclerosis: A meta-analysis. Multiple Sclerosis (Houndmills, Basingstoke, England), 14(1), 129-135.

Nainis, N., Paice, J. A., Ratner, J., Wirth, J. H., Lai, J., \& Shott, S. (2006). Relieving symptoms in cancer: Innovative use of art therapy. Journal of Pain and Symptom Management, 31(2), 162-169.

Naito, A., Laidlaw, T. M., Henderson, D. C., Farahani, L., Dwivedi, P., \& Gruzelier, J. H. (2003). The impact of self-hypnosis and Johrei on lymphocyte subpopulations at exam time: A controlled study. Brain Research Bulletin, 62(3), 241-253. 
Nakamura, R., \& Fujii, E. (1990). Studies of the characteristics of the electroencephalogram when observing potted plants: Pelargonium Hortorum "Sprinter red" and Begonia Evansiana. Technical Bulletin of the Faculty of Horticulture of Chiba University, 43, 177-183.

Nakamura, R., \& Fujii, E. (1992). A comparative study of the characteristics of the electroencephalogram when observing a hedge and a concrete block fence. Journal of the Japanese Institute of Landscape Architects, 55(5), 139-144.

Nakau, M., Imanishi, J., Imanishi, J., Watanabe, S., Imanishi, A., Baba, T., \& Morimoto, Y. (2013). Spiritual care of cancer patients by integrated medicine in urban green space: A pilot study. Explore (New York, N.Y.), 9(2), 87-90.

Nasreddine, L., \& Parent-Massin, D. (2002). Food contamination by metals and pesticides in the European Union. Should we worry? Toxicology Letters, 127(1-3), $29-41$.

National Cancer Institute. (2012). Categories of CAM therapies. Retrieved from http://cam.cancer.gov/health_categories.html\#energytherapies (retrieved April 23, 2015)

Nguyen-Michel, S. T., Unger, J. B., Hamilton, J., \& Spruijt-Metz, D. (2006).

Associations between physical activity and perceived stress/hassles in college students. Stress and Health, 22(3), 179-188.

Nomura, H., \& Nakayama, T. (2005). The Japanese healthcare system: The issue is to solve the "tragedy of the commons" without making another. BMJ: British Medical Journal, 331(7518), 648-649.

Nomura, T., Higuchi, K., Yu, H., Sasaki, S., Kimura, S., Itoh, H., Taniguchi, M., Arakawa, T., \& Kawai, K. (2006). Slow-wave photic stimulation relieves patient discomfort during esophagogastroduodenoscopy. Journal of Gastroenterology and Hepatology, 21(1 Pt 1), 54-58.

O'Callaghan, F. V., \& Jordan, N. (2003). Postmodern values, attitudes and the use of complementary medicine. Complementary Therapies in Medicine, 11(1), 28-32.

Ossebaard, H. C. (2000). Stress reduction by technology? An experimental study into the effects of brain machines on burnout and state anxiety. Applied Psychophysiology and Biofeedback, 25(2), 93-101.

Pellegrini, G. G. (2009). Organic consumers and new lifestyles: An Italian country survey on consumption patterns. British Food Journal (1966), 111(9), 948; 948-974; 974. 
Perez-Cueto, F. J., Verbeke, W., de Barcellos, M. D., Kehagia, O., Chryssochoidis, G., Scholderer, J., \& Grunert, K. G. (2010). Food-related lifestyles and their association to obesity in five European countries. Appetite, 54(1), 156-162.

Pesatori, A. C., Sontag, J. M., Lubin, J. H., Consonni, D., \& Blair, A. (1994). Cohort mortality and nested case-control study of lung cancer among structural pest control workers in Florida (United States). Cancer Causes \& Control: CCC, 5(4), 310-318.

Post-White, J., Kinney, M. E., Savik, K., Gau, J. B., Wilcox, C., \& Lerner, I. (2003). Therapeutic massage and healing touch improve symptoms in cancer. Integrative Cancer Therapies, 2(4), 332-344.

Potter, P. (2003). What are the distinctions between Reiki and Therapeutic Touch? Clinical Journal of Oncology Nursing, 7(1), 89-91.

Rasheed, S., \& Woods, R. T. (2014). An investigation into the association between nutritional status and quality of life in older people admitted to hospital. Journal of Human Nutrition and Dietetics: The Official Journal of the British Dietetic Association, 27(2), 142-151.

Redwood, D. (2010). Health reform, prevention and health promotion: Milestone moment on a long journey. The Journal of Alternative and Complementary Medicine, 16(5), 521-523.

Reece, K., Schwartz, G. E., Brooks, A. J., \& Nangle, G. (2005). Positive well-being changes associated with giving and receiving Johrei healing. Journal of Alternative and Complementary Medicine (New York, N.Y.), 11(3), 455-457.

Reimer, M. A., \& Flemons, W. W. (2003). Quality of life in sleep disorders. Sleep Medicine Reviews, 7(4), 335-349.

Rembialkowska, E. (2007). Quality of plant products from organic agriculture. Journal of the Science of Food and Agriculture, 87(15), 2757-2762.

Repetto, R., \& Baliga, S. S. (1996). Pesticides and the immune system: The public health risks. Executive summary. Central European Journal of Public Health, 4(4), $263-$ 265.

Richardson, J. (2004). What patients expect from complementary therapy: A qualitative study. American Journal of Public Health, 94(6), 1049-1053.

Richeson, N. E., Spross, J. A., Lutz, K., \& Peng, C. (2010). Effects of Reiki on anxiety, depression, pain, and physiological factors in community-dwelling older adults. Research in Gerontological Nursing, 3(3), 187-199. 
Robinson, C., \& Schumacker, R. E. (2009). Interaction effects: Centering, variance inflation factor, and interpretation issues. Multiple Linear Regression Viewpoints, 35(1), 6-11.

Rogan, W. J., \& Chen, A. (2005). Health risks and benefits of bis(4-chlorophenyl)-1,1,1trichloroethane (DDT). Lancet, 366(9487), 763-773.

Rogers, E. (2003). Diffusion of innovations (Fifth edition ed.). New York: Free Press.

Rozanski, A., Blumenthal, J. A., \& Kaplan, J. (1999). Impact of psychological factors on the pathogenesis of cardiovascular disease and implications for therapy. Circulation, 99(16), 2192-2217.

Saba, A., \& Messina, F. (2003). Attitudes towards organic foods and risk/benefit perception associated with pesticides. Food Quality and Preference, 14(8), 637-645.

Saydah, S. H., \& Eberhardt, M. S. (2006). Use of complementary and alternative medicine among adults with chronic diseases: United States 2002. Journal of Alternative and Complementary Medicine (New York, N.Y.), 12(8), 805-812.

Shavro, S. A., Ezhilarasu, P., Augustine, J., Bechtel, J. J., \& Christopher, D. J. (2012). Correlation of health-related quality of life with other disease severity indices in Indian chronic obstructive pulmonary disease patients. International Journal of Chronic Obstructive Pulmonary Disease, 7, 291-296.

Shaw, A., Thompson, E. A., \& Sharp, D. (2006). Complementary therapy use by patients and parents of children with asthma and the implications for NHS care: A qualitative study. BMC Health Services Research, 6, 76.

Shepherd, R., Magnusson, M., \& Sjoden, P. O. (2005). Determinants of consumer behavior related to organic foods. Ambio, 34(4-5), 352-359.

Siahpush, M. (1999). Postmodern attitudes about health: A population-based exploratory study. Complementary Therapies in Medicine, 7(3), 164-169.

Sierpina, V., Levine, R., Astin, J., \& Tan, A. (2007). Use of mind-body therapies in psychiatry and family medicine faculty and residents: Attitudes, barriers, and gender differences. Explore (New York, N.Y.), 3(2), 129-135.

Sirois, F. M., \& Gick, M. L. (2002). An investigation of the health beliefs and motivations of complementary medicine clients. Social Science \& Medicine, 55(6), 1025-1037. 
Skrove, M., Romundstad, P., \& Indredavik, M. S. (2013). Resilience, lifestyle and symptoms of anxiety and depression in adolescence: the Young-HUNT study. Social Psychiatry and Psychiatric Epidemiology, 48(3), 407-416.

Stone, A. A., \& Brownell, K. D. (1994). The stress-eating paradox: Multiple daily measurements in adult males and females. Psychology and Health, 9(6), 425-436.

Sutherland, L. R., \& Verhoef, M. J. (1994). Why do patients seek a second opinion or alternative medicine? Journal of Clinical Gastroenterology, 19(3), 194-197.

Suzuki, K., Uchida, S., Kimura, T., \& Katamura, H. (2012). A large cross-sectional, descriptive study of self-reports after biofield therapy in Japan: Demography, symptomology, and circumstances of treatment administration. Alternative Therapies in Health and Medicine, 18(4), 38.

Suzuki, N. (2004). Complementary and alternative medicine: A Japanese perspective. Evidence-Based Complementary and Alternative Medicine: eCAM, 1(2), 113-118.

Svensk, A., Öster, I., Thyme, K. E., Magnusson, E., Sjödin, M., Eisemann, Astrom, S., \& Lindh, J. (2009). Art therapy improves experienced quality of life among women undergoing treatment for breast cancer: A randomized controlled study. European Journal of Cancer Care, 18(1), 69-77.

Taft, R., Moore, D., \& Yount, G. (2005). Time-lapse analysis of potential cellular responsiveness to Johrei, a Japanese healing technique. BMC Complementary and Alternative Medicine, 5(1), 2.

Teig, E. E. (2009). Collective efficacy in Denver, Colorado: Strengthening neighborhoods and health through community gardens. Health \& Place, 15(4), 1115; $1115-1122 ; 1122$.

Thorne, S., Paterson, B., Russell, C., \& Schultz, A. (2002). Complementary/alternative medicine in chronic illness as informed self-care decision making. International Journal of Nursing Studies, 39(7), 671-683.

Togo, T., Urata, S., Sawazaki, K., Sakuraba, H., Ishida, T., \& Yokoyama, K. (2011). Demand for CAM practice at hospitals in Japan: A population survey in Mie prefecture. Evidence-Based Complementary and Alternative Medicine: eCAM, 2011, 591868.

U.S. Environmental Protection Agency. (2011). Pesticide news story: EPA releases report containing latest estimates of pesticide use in the United States. Retrieved from http://www.epa.gov/oppfead1/cb/csb_page/updates/2011/sales-usage06-07.html (retrieved April 2, 2015) 
Uchida, S., Iha, T., Yamaoka, K., Nitta, K., \& Sugano, H. (2012). Effect of biofield therapy in the human brain. Journal of Alternative and Complementary Medicine (New York, N.Y.), 18(9), 875-879.

Ulrich, R. S. (1984). View through a window may influence recovery from surgery. Science (New York, N.Y.), 224(4647), 420-421.

Ulrich, R. S. (1991). Effects of interior design on wellness: Theory and recent scientific research. Journal of Health Care Interior Design, 3(1), 97-109.

Ulrich, R. S., Simons, R. F., Losito, B. D., Fiorito, E., Miles, M. A., \& Zelson, M. (1991). Stress recovery during exposure to natural and urban environments. Journal of Environmental Psychology, 11(3), 201-230.

Van den Berg, A.E., \& Custers, M. H. G. (2010). Gardening promotes neuroendocrine and affective restoration from stress. Journal of Health Psychology, 1,3-11.

Vincent, C., \& Furnham, A. (1996). Why do patients turn to complementary medicine? An empirical study. The British Journal of Clinical Psychology / the British Psychological Society, 35 (Pt 1)(Pt 1), 37-48.

Von Essen, E., \& Englander, M. (2013). Organic food as a healthy lifestyle: A phenomenological psychological analysis. International Journal of Qualitative Studies on Health and Well-being, 8, 10.3402/qhw.v8i0.20559.

Wang, D., \& MacMillan, T. (2013). The benefits of gardening for older adults: A systematic review of the literature. Activities, Adaptation \& Aging, 37(2), 153-181.

Weil, A. (2011). Spontaneous happiness. (pp. 171-172,173) Little Brown and Company.

WHOQoL Group. (1998). Development of the world health organization WHOQOLBREF quality of life assessment. Psychological Medicine, 28(03), 551.

Willett, W. C., Koplan, J. P., Nugent, R., Dusenbury, C., Puska, P., \& Gaziano, T. A. (2006). Prevention of chronic disease by means of diet and lifestyle changes. In D. T. Jamison, J. G. Breman, A. R. Measham, G. Alleyne, M. Claeson, D. B. Evans, P. Musgrove (Eds.), Disease control priorities in developing countries (2nd ed.). Washington (DC): The International Bank for Reconstruction and Development/The World Bank Group.

Wilson, M. G., Ellison, G. M., \& Cable, N. T. (2015). Basic science behind the cardiovascular benefits of exercise. Heart (British Cardiac Society), 101(10), 758765 . 
Winter, C. K., \& Davis, S. F. (2006). Organic foods. Journal of Food Science, 71(9), R117-R124.

Worthington, V. (2001). Nutritional quality of organic versus conventional fruits, vegetables, and grains. Journal of Alternative and Complementary Medicine (New York, N.Y.), 7(2), 161-173.

Wright, S. D., \& Wadsworth, A. M. (2014). Gray and green revisited: A multidisciplinary perspective of gardens, gardening, and the aging process. Journal of Aging Research, 2014, 283682.

Yamazaki, S., Fukuhara, S., \& Suzukamo, Y. (2005). Household income is strongly associated with health-related quality of life among Japanese men but not women. Public Health, 119(7), 561-567.

Yang, E. V., \& Glaser, R. (2003). Stress-induced immunomodulation: Implications for tumorigenesis. Brain, Behavior, and Immunity, 17 Suppl 1, S37-40.

Ye, X., Wong, L. Y., Zhou, X., \& Calafat, A. M. (2014). Urinary concentrations of 2,4dichlorophenol and 2,5-dichlorophenol in the U.S. population (National Health and Nutrition Examination Survey, 2003-2010): Trends and predictors. Environmental Health Perspectives, 122(4), 351-355.

Iwahashi, S., Tanaka, Y., Fukushi, S., \& Hongo, M. (2002). Development of the Japanese version of the perceived stress scale. J. Psychosomatic Medicine, 42(7), 459-466.

Kimura, T., Suzuki, K., Morioka, H., Iha, T., Tanaka, C., \& Maki, Y. (2009). Development and validation of the 10-item MOA quality of life questionnaire (MQOL-10) for large-scale health surveys. Research Reports from the MOA Health Science Foundation, 13, 73-84. 


\section{APPENDICES}

Items of the MQL-10

Review your lifestyle during the past one month.

Q01. Are you satisfied with yourself now?

1 Very satisfied; 2 Satisfied; 3 Neither satisfied nor dissatisfied; 4 Dissatisfied; 5 Very dissatisfied

Q02. Do you feel your life is worth living?

1 Definitely yes; 2 Yes; 3 Not sure (Neutral); 4 Practically no; 5 Not at all

Q03. Are you satisfied with your relationships with family, friends, and neighbors?

1 Very satisfied; 2 Satisfied; 3 Neither satisfied nor dissatisfied; 4 Dissatisfied; 5 Very dissatisfied

Q04. Are you satisfied with the environment, public welfare services, and commuting conditions in your neighborhood?

1 Very satisfied; 2 Satisfied; 3 Neither satisfied nor dissatisfied; 4 Dissatisfied; 5 Very dissatisfied

Q05. How is your present health?

1 Very good; 2 Good; 3 So-so (Neutral); 4 Bad; 5 Very bad

Q06. Can you perform daily activities and light exercises, such as taking a walk, going up stairs, cleaning up a room, etc.?

1 Easily possible; 2 Usually possible; 3 Possible to some degree; 4 Hardly possible; 5 Not possible at all

Q07. Does any symptom or feeling interfere with your daily life?

1 Not at all; 2 Rarely; 3 Occasionally; 4 Often; 5 At all times

Q08. Is your life full of energy?

1 Very much so; 2 Yes, almost; 3 Not sure (Neutral); 4 Rather not; 5 Not at all.

Q09. Do you feel anxious, depressed, or irritated?

1 Not at all; 2 Rarely; 3 Occasionally; 4 Often; 5 Very often

Q10. Do you have any concerns or feel stressed?

1 Not at all; 2 Rarely; 3 Occasionally; 4 Often; 5 Very often 


\section{Items of JPSS-10}

Q1. Have you been mentally confused due to some unexpected event?

1 Not at all; 2 Rarely; 3 Occasionally; 4 Often; 5 Very often

Q2. Have you been troubled by not being able to make important decisions?

1 Not at all; 2 Rarely; 3 Occasionally; 4 Often; 5 Very often

Q3. Have you been nervous and felt distressed?

1 Not at all; 2 Rarely; 3 Occasionally; 4 Often; 5 Very often

Q4. Are you able to adjust well to changes in life environment?

1 Not at all; 2 Rarely; 3 Occasionally; 4 Often; 5 Very often

Q5. Are things going well for you?

1 Not at all; 2 Rarely; 3 Occasionally; 4 Often; 5 Very often

Q6. Have you experienced failure in work or relationships with others?

1 Not at all; 2 Rarely; 3 Occasionally; 4 Often; 5 Very often

Q7. Have you experienced irritations that you were not able to withstand?

1 Not at all; 2 Rarely; 3 Occasionally; 4 Often; 5 Very often

Q8. Are your work and relationships going well?

1 Not at all; 2 Rarely; 3 Occasionally; 4 Often; 5 Very often

Q9. Do you have worries and frustration related to your work?

1 Not at all; 2 Rarely; 3 Occasionally; 4 Often; 5 Very often

Q10. Are you often troubled due to troublesome tasks and events?

1 Not at all; 2 Rarely; 3 Occasionally; 4 Often; 5 Very often

The questions were answered utilizing the 5-point Likert scale. Of the 10 questions, 4 items were reverse-scoring questions. Higher score indicates a greater perception of stress. 
Table 23. Characteristics of SES

\begin{tabular}{|c|c|c|}
\hline SES variables & Frequency(n) & Percent(\%) \\
\hline \multicolumn{3}{|l|}{ Age } \\
\hline 20 to 29 & 31 & 2.6 \\
\hline 30 to 39 & 86 & 7.2 \\
\hline 40 to 49 & 138 & 11.6 \\
\hline 50 to 59 & 230 & 19.3 \\
\hline 60 to 69 & 377 & 31.7 \\
\hline 70 to 79 & 242 & 20.3 \\
\hline 80 and over & 86 & 7.2 \\
\hline \multicolumn{3}{|l|}{ Sex } \\
\hline Male & 296 & 24.9 \\
\hline Female & 894 & 75.1 \\
\hline \multicolumn{3}{|l|}{ Occupation } \\
\hline Employed & 414 & 34.8 \\
\hline Self-employed & 82 & 6.9 \\
\hline Housewife & 487 & 40.9 \\
\hline Student & 3 & .3 \\
\hline Unemployed & 200 & 16.8 \\
\hline Missing & 4 & .3 \\
\hline \multicolumn{3}{|l|}{ Annual Income* } \\
\hline Below 2 million yen (US $\$ 16,800$ ) & 334 & 28.1 \\
\hline 2 million to 5 million yen (US $\$ 42,000$ ) & 463 & 38.9 \\
\hline 5 million to 7 million yen (US $\$ 58,800$ ) & 123 & 10.3 \\
\hline 7 million to 10 million yen (US $\$ 84,000$ ) & 56 & 4.7 \\
\hline Above 10 million yen (US $\$ 84,000$ ) & 24 & 2.0 \\
\hline Missing & 190 & 16.0 \\
\hline \multicolumn{3}{|l|}{ Education } \\
\hline Elementary/Junior high school graduate & 194 & 16.3 \\
\hline High school graduate & 640 & 53.8 \\
\hline Junior college graduate & 126 & 10.6 \\
\hline Technical school graduate & 114 & 9.6 \\
\hline College graduate or above & 111 & 9.3 \\
\hline Missing & 5 & .4 \\
\hline \multicolumn{3}{|l|}{ Marital status } \\
\hline Married & 877 & 73.7 \\
\hline
\end{tabular}




\begin{tabular}{lrr} 
Widowed & 152 & 12.8 \\
Divorced & 40 & 3.4 \\
Not married & 118 & 9.9 \\
Missing & 3 & .3 \\
\hline
\end{tabular}

*currency rate $\$ 1=120$ yen

2014 Median household income in Japan 5.370 million yen (US \$43,518)

Poverty threshold 1.27 million yen /one person household (US \$15,113)

Table 24. Results of Simple linear regression of CAM practices and QOL and perceived stress

\begin{tabular}{|c|c|c|}
\hline & Perceived Stress & QOL \\
\hline CAM practice & B & $\beta$ \\
\hline Exercise & $-0.213 * * *$ & $0.247 * * *$ \\
\hline Home gardening & $-0.19 * * *$ & $0.171 * * *$ \\
\hline Arts and Culture & $-0.226 * * *$ & $0.265 * * *$ \\
\hline Food & $-0.153 * * *$ & $0.266 * * *$ \\
\hline OPT & $-0.062 *$ & $0.148 * * *$ \\
\hline Gender & Non-significant & $0.064^{*}$ \\
\hline Age & $-0.363 * * *$ & $0.193 * * *$ \\
\hline Occupation & $-0.177 * * *$ & Non-significant \\
\hline Annual Income & Non-significant & Non-significant \\
\hline Marital Status & $-0.129 * * *$ & $0.090^{*}$ \\
\hline Education & $-0.101 * * *$ & Non-significant \\
\hline Sleep & $-0.254 * * *$ & $0.337 * * *$ \\
\hline Appetite & $-0.232 * * *$ & $0.379 * * *$ \\
\hline $\begin{array}{l}\text { Excretory } \\
\text { Functions }\end{array}$ & $-0.222 * * *$ & $0.309 * * *$ \\
\hline
\end{tabular}




\section{Interview Participant 1}

Interviewer: Please reflect upon the time that you first received OPT and tell me how you felt about it and how you came about knowing this practice.

The first time I received OPT was in Kokubunji, it was something that they organized for health and arts, it was comfortable. I initially like healing so I was able to receive it without any hesitation or awkwardness. You sit on the seat and receive the therapy and I remember it felt very comfortable.

Interviewer: When did this take place?

This was maybe about three years ago I think two years have already past.

Interviewer: What is the reason that you are continuing OPT?

I have studied for the certification of the third level practitioner, to teach my friends about this. I knew from before that energy from the universe is good. My friend became ill and the doctor couldn't do much about it. She told me about this and I decided to join along. I thought it would be good if I can do this to my friends. That's the reason why I started. Another reason is because anyone can practice this therapy. The therapists volunteer to treat patients, right? That felt strange in the beginning. Reiki healing and other types of healing, such as qi-qong, they do it as a business, right? But this was done without any fees paid to the volunteers. This felt strange. There is the clinic and people go there as volunteers and regular people help each other out through healing others. The idea of being able to heal the body back to normal was surprising. I didn't think it could be this easy. I didn't like it that they were practicing OPT without being paid. It's not that I didn't like it, it was strange. Healing and Reiki is pretty expensive, but why was this possible? That's how I felt. I was half in doubt. However during that time I didn't know much about Mokichi Okada. I wanted to help my friend out, and I had some interest in this from the beginning so that's the reason why I started. If I was able to practice this, I would be able to practice this anywhere.

Why I am continuing is because after all I was diagnosed with a disease. The reason why I started was not because I was ill, I always thought I was healthy. However my thyroids had .... And then I studied this practice.

Interviewer: Do you think you want to let your friends know about this? Is there anything that you feel is difficult for you to let others know about this?

I would want to let others know. If there is somebody that is suffering and troubled I would want to let them know about it. It depends on the other person, if they are able to believe in things that can't be seen, they would misunderstand this. That's why I would not let others know from myself that I am receiving this kind of practice. However, I would let them know if they are suffering and troubled, and they come to me to talk to me about it, I may introduce them to this. I wouldn't talk about this from myself. 
Interviewer: Before you were introduced to OPT how did you manage your health condition?

I was careful in what I would eat, for example eat foods free of preservatives. I knew about healing, so whenever my husband was feeling sick I would lay my hands on him and do massage. That's why when my husband died, I just thought if I knew OPT a little earlier things may have been different for our family. But this is all timing.

Interviewer: What do you think are the barriers towards receiving OPT?

Do you mean that when I would no longer be able to receive OPT? Or when I stop receiving this from myself? I don't think there are any barriers.

\section{Interview participant 3}

Interviwer: Please describe to me how you felt when you first received OPT, and how you found out about OPT.

I have started to feel difficulty in walking. I realized that this was not normal. I went to the doctor, but the doctor told me he could not figure out for sure what was going on inside me yet. The doctors were not able to identify what was going on. When I was told this, I felt that maybe it is difficult for conventional medicine to treat me. I had a friend that I meet daily. She asked me if I was interested in receiving OPT. My friend didn't know well about this healing technique at this time, but she asked me if I wanted to go with her, it seemed to be interesting so we went together. The first time I received OPT I was very surprised. My body felt hot. I thought I was a type of person that did not believe in these kinds of things. However, once I actually received it my body started to feel hot. That was the beginning of my experience with OPT.

Interviewer: When was this?

It was two, three years ago.

Interviewer: Once after that did you continue to receive OPT?

At first when I was diagnosed as having this disease, the administrators came over to my house four times a day, I started to receive training to become certified as a practitioner myself. I was able to administer OPT by myself. I think my family members started to realize that they would need to be able to practice this as well, so my husband and my daughter also became members. After this I received it many times. At those times I received OPT every day for at least an hour.

Interviewer: So you were convinced with OPT during your first visit and you continued til now? 
Yes.

Interviewer: Did you do anything particular before getting to know OPT to maintain your health?

Before having the symptoms of having a hard time walking or feeling difficulty in raising my legs, my husband's parents lives in Kyoto, so I was doing long distance nursing. What I mean by long-distance nursing is, from where I live in Tokyo to Koyoto I would take the Shinkansen once every three weeks. After my husband's mother had collapsed, I would go to Koyoto to look after my father-in-law. I did this for about a year, leaving my family behind.

Interviewer: Is this what you did to maintain health?

You mean myself? I would engage in walking. I used to do walking from before. Even after I went to Kyoto, I would do it for three or four times a week. Each time for about thirty minutes. I think I had high conscience towards health. That's why I realized that I was starting to feel difficulties walking. If it wasn't for my daily walks I would not have realized it.

Interviewer: What is the greatest reason that keeps you to continue practicing OPT?

It's because I want to recover from my disease. Doctors tell me that it is difficult with conventional western medicine. That's why I want to take this challenge using eastern medicine.

Interviewer: Have you ever told about OPT to others who do not know about this practice?

Yes, I have.

Interviewer: Would you recommend this to your friends too?

Yes I thought about it.

Interviewer: How would you recommend it to others?

It is difficult for others to understand. That's why I think I have to recover from this disease first for it to be convincing. If I tell my friends that I am practicing this sort of thing, and I show them that I am currently like this, they would tell me "oh are you alright practicing this sort of thing?" I would receive this kind of reaction from say about $80 \%$ of the people. That's why I stopped encouraging others to try out. I plan on telling other people after I become a little bit better. However, my family has become better mentally. For example, OPT practitioners come to visit my house and, they see me change, so my family has understood about it smoothly. My eldest son is away though. 
Interviewer: Why do you feel that it is difficult to let others know?

Because it is not convincing. If I let others know while I am still not recovered, the whole discussion will end by them telling me that you are not recovered. That's why I have feelings of frustration, because it feels good. Not considering whether it will cure my disease or not, it soothes you mentally and I know this, that's why it is a bit frustrating.

Interviewer: What are the benefits of OPT?

It soothes you mentally. The practitioners come to you and they are compassionate, and they will be with you. The members and the people from the network as well, and they are not forcing.

Interviewer: Did you know the people from the network from before?

No I did not. I have been introduced a practitioner who lives closest to where I live, and this person comes to my house.

Interviewer: What do you think are potential barriers to you in receiving OPT in the future?

I don't think there would be any barriers. Maybe when I can no longer be able to talk, or when I can't move anymore. I don't think that would happen, so there are none.

\section{Interview Participant 5}

Interviewer: Please tell me about your first experience with OPT and how you came about knowing this practice.

I had an operation for my lung cancer, I was in a stable condition for a while, but I was told that the cancer spread to the bones. The first lung cancer was in my left lung, I had to remove the upper half of my left lung. So after that I was in a stable condition again. After two, or three years the cancer had spread to my right lung, and the treatment concentrated on this part of the cancer. One day I told my doctor that my lower body, especially my right leg, from the lower back to my right leg felt heavy and dull. We took a CT scan and found out that the cancer had spread to the bones, and my doctor was panicking. That's when we first started to try a chemotherapy called Iressa, which is used to treat lung cancer. That was in December 15 two years ago. Then after using Iressa, due to the adverse drug effects rashes started to appear all over my body. These are some of the scars that you can see. They itch and when I scratch them I get really irritated. I knew MOA from through my wife's sister. She lives in Sapporo, and she has been a member of the Toho-no-hikari. She told me that there is this kind of therapy so she recommended passionately to me to go for a check-up. Then the Ryoin introduced me to $\mathrm{Mr}$. N who took us here today. I have been receiving OPT from Mr. N since last 
November and I made reservations to come here since then. I had a medical check-up here, and since then I am receiving OPT. Mr. N also comes to my place once a week. That is the process of how I got to know about OPT.

\section{Interviewer: What were your thoughts when you first received OPT?}

I didn't have pain or I wasn't suffering. I received OPT for about 1 to 2 hours. While I was receiving it I would go into sleep. After the therapy was done it felt like my whole body was loosened up. I still continue the regular medicine too. To treat for the adverse symptoms from using Iressa, the doctor introduced me to a dermatologist, and I still continue the treatment for the rashes as well. I am continuing both OPT and the regular treatment and they are working together. We don't know which is being effective towards the rashes.

Appetite was gone due to the adverse effect from the medicine, and I started to lose weight. My constant weight was about $60 \mathrm{~kg}$ throughout my adult life. I have never lost more than that or gained more than that for the past 40 to 50 years of my life. However after the cancer had spread from my lung, I am not sure whether it was because I started to take Iressa, but my weight had started to change. When I found that the cancer had spread to my bones, my lower back all the way to my right leg was feeling dull and heavy, but not only that, my weight had slowly began to decrease from $60 \mathrm{~kg}$ to about $57 \mathrm{~kg}$. That was when I contacted the doctor and we were able to detect the cancer spreading out to other parts of my body. After taking Iressa, my appetite had decreased rapidly. My weight had gone down to $53 \mathrm{~kg}$ and almost til $52 \mathrm{~kg}$. The lowering of my bodyweight has somehow stopped recently. My appetite had not been very good, but my wife has since been researching what is good for my body and also things like what to cook. Now I am able to finish eating whatever is prepared before me. When I checked my weight yesterday it was returning back to $54.1 \mathrm{~kg}$, I feel that my weight loss has come to a stop and I am gradually returning back to my normal weight.

\section{Interviewer: Why did you decide to continue receiving OPT?}

As I have told you earlier, we are beginners of OPT, so we are not sure how it is effecting to help my worsened condition to gradually become better, stopping the decline of weight and getting back my appetite etc.

When I receive OPT, for example I have other stories. I had a really bad swell on my instep of my foot. When I took the blood test they told me the level of creatine is rising. So my feet got swollen and when I received OPT the swell had subsided drastically. Something like that had happened, and also as I have told you earlier, my appetite is back to normal, I am able to finish whatever has been prepared as a meal. What my doctor, who has been treating my cancer, says is that, if you continue taking Iressa for this long, the chemotherapies effectiveness towards fighting cancer gradually goes down. It has been more than one and a half years almost about one and eight months since I started Iressa. So usually at this time we are supposed to advance to the next type of chemotherapy, or should be thinking of another treatment type. We are supposed to be at that kind of stage by now, however the cancer seems to not be advancing, the cancer that 
spread to the right lung has not disappeared but it is not advancing. When the doctors checked through the MRI and CT scan, it was not advancing to other parts of the bones nor starting to get hurt. We just had a check up on the brain about 10 days ago through the MRI. The cancer had not spread to the brain at all. The doctors say that the advancement of the cancer cannot be seen for a continued period time. When strangers see me, they won't even notice that I am a cancer patient. I look pretty well, they would ask me what would be wrong with you?

Also when I see friends that I haven't seen in a few years, they know beforehand that I have cancer, but they always question what is wrong with me, I don't look at all like having cancer. My condition has been stable like this. When I experience stuff like the swollen instep of the foot subsiding drastically, I start to think that OPT might have some effectiveness, and that it is working well together with western medicine.

There is nothing that is adversely affecting me from receiving OPT, moreover I am having a stable condition from receiving this, so I don't have any reason to not believe the effect of OPT. There is not harm from receiving this.

I am a beginner so I can't have 100 percent confidence towards this therapy, but there is no sign of it being bad. Instead there are many good signs from receiving this, so that's why I want to continue receiving this and I am counting on this therapy.

\section{Interviewer: How about you Mrs. T?}

Wife: For me, my sister was a member of the $\mathrm{R}$ (religious organization). My husband has never had any relationship with religious organizations, but I have heard and witnessed things about it from before and I disliked them. Whenever my sister used to tell me things I wouldn't respond, I have also had fights with my sister about it. Then when my husband got lung cancer, my sister told me to go and just try it out once, it is not a religion. She used to tell me many times that there is a hospital in Shinagawa with doctors working there, so try it out once. I would try to think of excuses so we won't have to go, I would tell her I will go once the outside temperatures gets warmer, or tell her how difficult it is for us to go all the way to Shinagawa because he is sick. Then she told me about a story of a person who suffered from pancreatic cancer and lost appetite, but regained appetite once after he started to receive OPT. That's why she told me to try out OPT just for the purpose of increasing appetite. However even then I did not fulfill her request. After all that we didn't go, so she made contact with some members of the MOA and asked them to come visit our house. There was a contact from Mr. N and they came. They were from Chigasaki. We live in Hayama, so they found somebody living close to our place. Then their cousins were also contacted and every week two of them came over to our house. I know about qi-qong.

\section{Interviewer: Are you accustomed to those type of energy medicine?}

Wife: I don't practice myself, but I have friends who do. I have heard stories about gastroptosis getting better through qi-qong. That's why I know that qi-qong has some effect. My understanding was that receiving OPT was similar to this. 
My wife didn't have any ailments in her body, I was the one who was mainly receiving from the two people. When they asked my wife whether she had any place that she does not feel well, she is this old, but she does not have so much to be worried about.

Interviewer: Is this the first time for you to receive the medical check-up?

Wife: What I was surprised most was my husband's swell on his instep on his foot. Mr. N and his wife came over and they administered OPT with so much concentration. My husband went to the bathroom for two, or three times, and the swelling was relieved. The swelling wasn't completely removed from that time on, it came back again, but I was very surprised that time. Then Mr. and Mrs. $\mathrm{N}$ would tell me this is nothing to be surprised about, there are many more mysterious things happening.

Interviewer: Mrs. T, what do you think about OPT from receiving the therapy yourself?

Wife: I don't know well, I didn't receive it so many times. When I first received I had a sprained ankle. I had a sprain on my ankle and I wasn't able to walk. So I received it on my ankle for the whole time. Then it didn't get well fast, but now I don't have any remains of it. I heard that pain from sprains are likely to stay for a while, but I don't have any pain anymore. That was my first experience.

Interviewer: Do you think you want to talk to others about OPT? Or have you ever talked about it?

No. We only started it one and half years ago.

Interviewer: Do you think you want to let your children or your family members know?

I think I want to do it to my family, especially my daughter. However she lives away right now. We are not convinced enough to actively encourage our friends to know about this. We are still unsure. We are not at the point to be able to recommend to others.

Interviewer: What do you think are the benefits of OPT?

Accumulated toxins that are inside your body are purged outside of your body, and that's the way the source of the illness is removed. Everything comes from this kind of thinking even for intractable diseases. Okada the founder of OPT has researched and left behind his works on how toxins accumulate on which areas of your body to form what type of diseases. The people that come to administer OPT is studying from the aspect of physiology as well. They have studied so much. They are completely volunteers, they don't ask for any returns. They have sacrificed so much of their time for me and did me many favors, I would want to do something to return them their favors to show my appreciation towards them, but when I try to do something they would absolutely reject it. They told me that they have also been helped from others and from OPT and this is what they do for their own joy and happiness, that's why they have told me to not worry 
about anything. Even today their whole day is used just to take me here. Mr. Okada has mastered human physiology, plus he has also included stuff about philosophy and humanity. He did something like that and now the people have high mentality. This is something we can never be able to imitate. We are not sure what is making them do these things, but we admire their efforts and we are just doing as what we are told.

Wife: My husband has not been related with religions, but I have. When they first came to our house, I told them I dislike religion, then they told me that this is not a religion. My husband has not yet studied so much about this but Mr. Okada didn't start this as a religion at first. He didn't want to make it a religious organization but the surrounding forces did not let him practice unless it was a religion back in those days. However now if you mention anything about religion people would reject it, so I think this is a good thing.

\section{Interview participant: 6}

Interviewer: Please try to go back and remember the first time that you have received $O P T$, and tell me about your experience. Please tell me how you came to receive this practice and your thoughts and reactions.

I sometimes shopped at the organic food store once in a while at this place. I came to know that biofield energy therapy was available at this place for people to experience, and I thought I would like to experience it. After that my husband collapsed from a stroke. This happened right before my husband was hospitalized. After him being discharged, I often felt that it is better not to use medicine, so with the hope of my husband getting better through biofield energy therapy, I asked my husband if he wanted to try it out, and so we come here every week on our day off from work. I am starting a lot of different things at once, for example I have stopped buying ready-made food. This all is happening triggered by my husband's stroke, and we started to receive OPT once a week as a consequence of starting to reflect and looking over many things, so I don't know how this one specific thing is affecting us, but it feels like everything is connected overall. I feel that it is really giving us a synergistic effect. I don't expect for any physical change that you can feel right away after OPT. However, I feel really calm and stable each time I receive it. My husband from past experience dislikes religious entities, but he loves this place. And he is willingly coming. As a matter of fact, I think he really felt good the first time and the second time we came here. He is looking forward to coming again each time, and I can really feel it. Last week my husband had a big wart on his back, I told him to go to the hospital right away to remove it, but if you remove it he would have to go to the hospital every day to disinfect the wound, so he told me he won't be able to do it. That's why he just had a big bandage over it for protection, he did take antibiotics. Last week he told the practitioner about the wart and the practitioner administered OPT toward the wart, and since that day everyday blood and other fluid came out of the wart and the wart became very small. Since last week my husband started to tell me that he feels something when he receives OPT. 
Interviewer: So you just started OPT recently?

Yes, we started from May $26^{\text {th }}$.

Interviewer: You told me it started off from you buying organic produces, were you inclined towards buying organic produces from before?

Yes, I sometimes came over to buy food here.

Interviewer: How did you come to know about the organic food store?

When I visited the tax office I came here for shopping and I knew about this place. There is the Shinagawa tax office across from here, I own a business so I go to the tax office frequently. I also buy fresh vegetables online so that they can be delivered directly from the farms. There is a supermarket at the basement of Gate City which has variety of organic vegetables and I go there too. I used to go to these places from before. I have a condition of atopic dermatitis so, I have very sensitive taste buds too. When I searched for something good to eat I ended up choosing natural and organic foods. It was not for health. It was for the taste. I wanted something tasty and it happened to be something that was close to nature and un-artificial. Then I realized that this store was adjacent to a clinic.

Interviewer: Was this the first time that you experienced biofield energy therapy?

Yes, it was my first time on May 26.

Interviewer: How did you expect it to be like before actually receiving it?

Before receiving it I searched online to see if anybody was saying anything about this therapy and I found some. It did not describe what it looked like, but it said you can receive OPT after you get checked up by the doctor at the clinic. I thought I would go to receive it, and then they told me I can experience it. This was before my husband had a stroke, so I came to receive the therapy wanting to receive it. I have initially been accustomed to spiritual healing. I have been studying undulation for a while, and I have also studied Chinese medicine for about half a year. I have been studying undulation for many years now.

Interviewer: What do you think of OPT compared to undulation and such?

I am sensitive, so when I first received OPT my forehead felt like when you squeeze mayonnaise out of a plastic tube. About twice I felt it like that. I think today was the fourth time. From the previous time it started to feel like my consciousness drifted far away once I start to receive the therapy.

Interviewer: Did you do anything in particular to maintain your health before OPT? 
I was most conscious about food most. Also I do exercise, these two are the base. I easily receive people's thoughts. I know this for myself, so I try to control this consciously. I also try to improve undulation through dowsing.

Interviewer: what do you mean by receiving thoughts.

For example when I go to places that are referred to as power spots (locations thought to be filled with mystical energy), long time ago there was this place called Bunguri ridge in Nagano prefecture. This place became very famous. During that time, about 10 years ago, my husband and I liked this place a lot so we would visit this place every year. I easily feel empathic with other people. In the beginning I didn't know why I would feel so bad after visiting this place. I would start to feel sick whenever I go. This place was visited by people who were sick from all over Japan. I have conversations with empathy and that's how I receive other peoples thoughts. Everything. My husband is blunt just as how he appears. He is very protective so he doesn't talk to strangers so much. So we were talking about why I would get sick after coming here. He told me it's because you talk to strangers so much. I realized this was it. I know now. From that moment on I tried not to have empathy with others who visit and I would only try to say hi. I have these experiences, so I realized that I need to control this daily. I don't like borrowing stuff from people, especially umbrellas. I don't know why but I don't like it. I don't like to borrow from anybody. I have a very sensitive sensor towards these things, however I don't see ghosts so much. However my husband see them regularly. My husband sees them. I think we are on a different wavelength. I am able to catch things very sensitively, and my husband sees restligeist regularly. It's just that he has different senses.

Interviewer: So your husband had a stroke after starting to receive OPT?

Yes, that's right.

Interviewer: Have you ever tried talking to others about OPT?

Yes I have towards other people who have the same kind of sensitivity. People would not understand if they don't have it.

Interviewer: How do you let them know about it?

I tell them that energy comes out from the holding the palm out. I tell them its like qiqong, or qi.

Interviewer: What do you think are the advantages of OPT when compared to other health modalities?

There is nothing artificial involved. I think it's very natural. Biofield energy is energy that is out in the universe. I think it's the best. It's a natural healing technique. People use to say ote-ate (treatment with hand), you lay your hands and you would recover from it. A mother would put her hand on the belly of her child and stroke it. I think it's the same as this. It is the most simple and it has the most effect and there are no adverse effects. I think it is the safest treatment. I think it works very much towards mental aspect. 
By the way I can also feel it. I can feel where there are problems. I would hover my palms over the body and where it feels awkward, where it feels bad, I can feel it that the bad parts of the body are less clear compared to other parts of the body.

Interviewer: What do you think are the barriers towards receiving OPT in future?

Do you mean a barrier within me? I don't think there would be any. Right now our days off are on Mondays every week, that's why I bring my husband and come here once every week. Right now I can't think of any barriers that would stop us from coming. For example if this place is closed we won't be able to come, that's all I can think of. I don't think I would have a hard time creating extra time to come here. I want to come here more often too.

Interviewer: Do you practice at your house too?

I can't practice on my own.

Interviewer: Do you have any changes in the impression of how you view or understand OPT from before?

My impression towards OPT after receiving it? Well for me it's really comfortable. I get to come here each week to maintain my body and spirit. They don't charge lots of money for the service. I have no barriers at all. I feel so grateful for this. If my lifestyle becomes much better after receiving this, I would like to return the favor to the society. That's how I feel.

Last week what was so mysterious was I came back home with my husband after home and opened the door the whole house felt like it was purified.

Why did this happen, I don't think people who don't know what OPT is would understand this at all. The whole house felt refreshing inside. We didn't clean the house or anything, but what was this all about, is there anybody who can answer this. I wonder if when yourself change it changes like that.

The society detest these kind of things but at the same time they desire these kind of things. I think it's a transitional period, or a time of change.

I am ok with these kind of topics from before. I live very subjectively so I don't care how people think of me. Recently I feel that people are trying hard to compensate for the loss of spiritual needs. I feel strongly that people are desiring to fill their spiritual needs. They want to elevate their spirituality. I don't want any material. I would want things that I need to use, if they are broken and need to be replaced. However I don't feel like I want to look better by dressing up and buying new clothes. I think that the society at large is transitioning like this.

\section{Interviewer: They want more of mental and physical health?}

Yes, they want to elevate their spirituality that's why people are heading towards power spots (location thought to be filled with mystical energy) and shrines. I think the world is becoming like this, its surprising really. 


\section{$\underline{\text { Interview participant } 11}$}

Interviewer: Please tell me about your experience of how you came about knowing OPT.

Seven years ago, I had a dizziness which occurred and I wasn't able to get up from my bed for half of my day. I couldn't walk without closing my eyes and I had to go to the restroom crawling down. I went to Touhou Medical University Hospital and had a checkup on my brain and my dizziness. The doctors told me not to worry about it there is nothing that is especially worrisome. Even though they told me that I was not feeling well, my head would feel strange. So I discussed this with my friend who used to be one of my classmates during high school her name was Mrs. H she introduced me to TokyoRyoin.

Interviewer: Were you good friends with Mrs. H?

We were friends since high school. Our daughters are also friends. My daughter married and moved to Gifu, and Mrs. H's daughter also got married and moved to Nagoya but right now she is also in Gifu with her own new house. So I was introduced by Mrs. H, received a check-up from Dr. M. While I was coming here I had arrhythmia. When we measured it for 24 hours using a holder, I had 7800 irregular pulses. I had that kind of irregular pulse about three times a year. Due to this irregular pulse and dizziness I was feeling worried. I was always worried about another irregular pulse attacking. The irregular pulse felt like it would push out my heart from beneath. That's why I started to come here to receive OPT for about five times a week for two and a half months. Each month I came here. During that time I lost 10 kilograms from not being able to sleep and worrying too much. However the doctor told me to walk, and don't worry too much about not being able to sleep. There are no cases of people dying from not being able to sleep so don't worry. Rather think of even trying to stay awake till the morning without sleeping. He wasn't trying to prescribe me medication because of not being able to sleep, I realized that there is a method of self-healing. So I became less worried about not being able to sleep. Just by receiving OPT and not relying on medication I experienced a light dizziness two months ago, but that was the first time happening in three years. I haven't had dizziness occurring for about three years. I recovered gradually from receiving OPT. These days I come to receive three times each month. Then I receive OPT from Mrs. H once or twice per week.

Interviewer: Did you ever experience other CAM methods, or did you have an understanding towards CAM?

No, I didn't have any clue. Even if I had friends who were engaging in CAM we never really talked about it. I was well until then, I never really had to go to the hospital so much too. When I became ill, and I was told that this kind of clinic exists, I was desperate and would have clutched at a straw. That's why I chose to come here. Each time I came here to receive OPT, I heard about the philosophy of Okada from the staff administering the OPT towards me. The stories that I heard were not so foreign to what I thought was 
important within me. I thought each stories I heard was a good thing, and they all sunk inside me. That's why I have been here ever since.

Interviewer: Did you have anything in particular that you were practicing to maintain your health before getting to know OPT?

I was well off then so I didn't really think about it. I like music and flowers, so I would go to a concert once in a while. I like Oboe, so I listened to the Oboe players that I liked. I loved flowers, so I plant them each season. I continue decorating flowers in my house too after starting to come here. Mrs. $\mathrm{H}$ is an instructor of flower arrangement so I used to attend her flower arrangement class for several years when I was in my fifties. Then I stopped for a while, and after going to Ryoin I started to attend again after I was informed about the classes taking place at her house.

Interviewer: Do you feel any changes physically or mentally, or changes in attitudes or way of thinking after receiving OPT?

My family was also affected from my dizziness and arrhythmia. They got really worried when I lost 10 kilograms because of this. They have seen me gradually getting better, so they were not worried about where I was going and what I was doing. They acknowledged that this therapy fits me, and they have shown approval of what I was receiving. My family members, my daughter and younger sister had also become affiliated with MOA and received training to practice OPT toward others. My daughter had been diagnosed with a serious disease two years ago. She had ovarian cancer and she had to remove both her uterus and ovaries. When I was feeling very helpless as a mother when my daughter was suffering from the disease, the staff at the Tokyo Ryoin suggested me to administer OPT towards her. This was the time that I felt really good about knowing OPT. When she had her surgery and when I administered OPT towards her wound the relief becomes fast. When I spoke with Dr. M, he told me that the cancer tends to gather around the wound, so administering OPT around the wound is good. After cancer was diagnosed I have administered OPT towards my daughter every single day. There were several days, about two or three days, in which I was not able to because I was home late. My daughter seems to be glad and she is the type who can feel differences after receiving OPT. That's why I have a sense of satisfaction. I feel so happy right now that I got to know this method, and that I am able to receive it myself and also able to administer towards my daughter.

For me my body feels like it is getting better gradually, it is kind of like removing thin layers from your body each time. It's not like becoming well right after receiving OPT but, when you reflect back in time you feel that you have gotten very well from the point where you started. Compared to the time that I felt really bad I feel very well, thanks to OPT.

When I had diarrhea, I was told that it was part of the purification process within the body. I had lots of changes in body from the effect of OPT. When I receive OPT inside my mouth I become a little bit feverish, and also a blood blister would form. I had these kind of changes inside my body when I received OPT. Usually when you have a blood 
blister inside your mouth, you would want to go to the otorhinolaryngologist, or go to the hospital. I have a piece of mind after getting to know that these are also part of the purification process.

Interviewer: You told me in the long run you seem to be doing much better after receiving OPT, but when you first introduced to OPT why were you convinced to come here the second and third time?

I think because I wanted to become better. I wanted to empower my self-healing power within me. When I was given this explanation, I didn't come to a decision to stop receiving this after a certain point in time. I thought of continuing this throughout.

Interviewer: What I meant was why did you know that you would become better after continuing this for a certain period of time in the first place? Why were you able to arrive at the place you are now, when you think about this?

All the explanations I heard from the staff at Ryoin was not so surprising to me. I was able to accept it genuinely. When I was here at first we were able to choose our own staff to administer the OPT and that time I told the staff about everything that was going around in my family and life. She listened to me really well.

Interviewer: So you were satisfied with the relationship of the staff?

Yes we had trust and a good relationship. That was what made me keep going. I think that things that give you a drastic effect like that of drugs or medicine would not be so good to your health. I am feeling better gradually without the help of medication. Plus Dr. M's explanation really sinks in you. He told me I would most likely still have dizziness, but the frequency will lower, and the amount of pain would also lower, that's what he explained to me. When the dizziness did start to come again I knew what was happening and was able to accept it. He told me to walk a lot. He told me to hold my back with my hands and walk a lot. He told me if you use your legs a lot to walk you should also use your hands too. He gave me small numerous advices. So I would be like "oh today I walked a lot and used my legs a lot so I need to move my hands too" etc. All the advices that was given sunk into me well.

\section{Interview participant: 15}

Interviewer: Please describe to me how you came to know about OPT and the reason behind it.

The first time I heard about it was through my sister-in-law. I remember now. My brother was getting married so my sister-in-law started to visit our house. That was 47 or 48 years ago. I think I have been receiving from that point in time. These kind of things. 
Interviewer: Was that when you first learned about it?

Yes that was the time that I first learned about it.

\section{Interviewer: What is the story behind coming to Ryoin and receiving OPT?}

Well, I met with my sister-in-law many times. I don't remember, but I think she touched somewhere and I think it was stiff. So then I wanted to come so I decided to come here. There was only this place at that time, the other building was still new during then. There was only this place. That time the staff asked me if I can come here for three days, and after that I stopped coming and I had not come into contact with Ryoin. However whenever I met with my sister-in-law she would tell me this place is stiff, this place is stiff, and I would receive OPT from her. I wasn't able to absorb all of it back then like the way I am able to now. I didn't have that much knowledge either. So this time I started to come here since last November, because of the disease that I found.

That's why I started to receive OPT. I had multiple experiences with OPT of which felt mysterious. Right now I am at the stage of why your hands would be able to... Why would there be many things from the palm of your hand, things are continuing but why. This is what I am feeling right now.

\section{Interviewer: Why have you decided to receive OPT from since last November?}

It's because I am desperate, I would clutch at a straw. The place that I had my operation was... I am living in Tsurumi. There is a big hospital which was constructed recently by the Benevolent Society. A hospital called the Togo-hospital was built recently. That's where I went directly. Nowadays if you go to a big hospital directly they would not accept you. I didn't know about this. The doctor didn't say anything, and he just told me I can go home. That kind of thing happened. I was feeling so much pain and suffering I couldn't handle it. It was the feeling of my intestines clogging up. I was feeling multiple symptoms of intestinal blockage. Day by day the condition worsened. So I went to a small clinic, because I needed a recommendation from a small clinic. I rushed to a small hospital nearby that I have never been to. Then the doctor knew from the symptoms that were appearing that it was colorectal cancer. I had clear symptoms of it, so even before checking my condition he told me he will refer me to a hospital, he introduced me to a few of which I can choose one. I live in Tsurumi which was close to Kawasaki, so he gave me two choices, either a private hospital or one other hospital. I lived closer to the private hospital so I was referred and rushed to the private one. Then I was hospitalized in an instance. I went to the internal department, but I was placed under the surgical department. I was able to hear the doctors panicking that I needed surgery, even though I was suffering from the pain. For three weeks or one month, all the waste in my body had to be removed so I had to go through many things. I had my body punctured all over, many things they were doing to my body. I couldn't eat anything. I had surgery, it lasted for 8 hours. However mentally I didn't feel scared at all. I really just wanted to be freed from the pain I was suffering. So the operation ended without any pain. I was not prepared to die. I think the doctors thought about it. They even asked my family to sign 
documents that said that they would accept my death if it did not go well. I didn't know this had happened at that time.

That was the condition as to which I received life. However, I felt that the methods of western medicine nowadays don't have feelings of compassion. They would look at the screen and not even look at the face of the patients. They would not even ask how my symptoms were. They would just look at the data, and I didn't know whether they were listening to what I had to say, and they just gave me a lot of medicine. They gave me medication for one whole year. That's when I started to feel worried. I was given my life, but I was worried if I would be able to survive. They wouldn't even listen to me. Then I had spoken about this to my sister-in-law and she immediately recommended me to come here. I felt like I was saved. Everybody here is so nice you don't meet a lot of nice people in the city, right?

People in the city don't open up so much. This place everybody is so nice.

OPT is effective towards your spirit and mind rather than towards aspects of western medicine. So I moved on and stepped up mentally and spiritually. Right now being able to live is so important to me.

Just three, four days ago I received the second results of the medical examination at the hospital in Kawasaki. Doctor told me like this. He didn't say no, but he told me this time I was fine. That's when I felt that the 10 months coming here was not useless. That's how I am feeling right now. Only three or four days have passed since I received the results of the examination. The examination consists of checking with the endoscope, and then you wait for one week, then you take the computerized tomography and wait another week, then after three weeks you receive your results. While I wait for the results I feel so worried, each time.

I am not sensitive to many things, but even then, when it is one day before the results I am so worried about what the doctor says. I was hospitalized on the second year, and had an operation. This time was the third time, it has been two years since I had the operation. When the doctor told me that this time was ok, and he didn't see any spread of the disease, I was so relieved. That's what my condition is right now. That's what my story is about.

The hospital in Kawasaki where I had the operation was like how I described, but I guess it was one of the better ones.

Interviewer: Before when you had first met your sister-in-law, that time was it more of like a religious practice rather than a CAM?

Right now it is bio-field energy medicine within CAM.

Yes, yesterday my sister-in-law was telling me that when she was a child there was only religion. That's why she has so many knowledge about the religion. She reads a lot of the philosophical books too. Sometimes she tells me things that are hard for me to understand. However we have become siblings so she tells me straight forwardly to study harder. She has told me several times. I was shocked that time. I am still told whenever I meet her. She tells me to study more and read more.

Interviewer: Were you familiar with other CAM practices? 
You mean this OPT?

Interviewer: I mean biofield energy medicine in specific.

I think I am a person that believes in stuff easily.

Interviewer: Have you had previous experience of receiving energy therapy other than OPT?

I don't think I have received a biofield energy, however I have had an experience with a bodywork therapist. My daughter's friend only had 15 years of experience but he was specializing in electrotherapy. You have half of your body pinched with electricity. It lasts for about two hours in Omori. I went to receive it for about half a year. This person was my daughter's friend's husband so he was really friendly to me. He did the therapy towards me for half a year and I was not worried. One time he told me that he was going to relieve the pain that I have by receiving the pain into his body. I became afraid, and also felt sorry for this person. If he had many patients his body would not be able endure. That's why I became afraid. When I was doing this therapy that's when my sister-in-law told me she can introduce me to Ryoin. Dr. M saw my conditions. That's why I quit the electro therapy after half a year. I was not able to withstand that kind of worry. So I started to come here last year October.

Interviewer: You told me that you didn't like how the doctors at the regular hospital were just looking at the data on the computer screens and couldn't really tell whether they were listening to you or not, do you mean that you were worried about your relationship with your doctors??

Yes I was. When I came here, I was really relieved with the conversation I was able to have with Dr. M I was feeling relieved and my worries were becoming less, that was a great feeling for me. Other than that I was receiving OPT continuously during last November. 15 years ago when I first came here I left this place after receiving only once.

Interviewer: So the reason why you started to come here again last November was because of your illness?

Yes of course. I had a desire to live more. I think it was about me wanting to live more, that's the biggest reason for me to continue this therapy.

At that time my mother had passed away at the age of 96 . My older sister was the one taking caring of her. The last four years of her life she was put into a nursery home, I was observing how her life was slowly ending. Then when I was diagnosed with the illness all of a sudden, I thought to myself, my mother's life span was 96 and mine is 70 . When I thought about this I didn't have any feelings of wanting to live more or feelings of anxiety. When I think about it right now it feels so strange. I was able to accept that this was my life span. I was not sad and I wasn't crying. It was a very calm feeling. However, when you realize that there is someone out there to help you out, you realize you can live 
longer. If you live longer there are going to be more enjoyable moments, that's why I think I've become a little greedy.

I want to enjoy one more year at least until the next medical examination that will be coming up again next year. I never had the feeling of trying to live my life appreciating each moment. Until I had this illness. I feel so grateful for it.

Another story, I don't want to brag about myself. The hospital I was in was a hospital in Kawasaki, which was under control from the local city. It's a big hospital. There is a policy in which you are not allowed to give any gifts or favors to the hospital for their care and service. The following day after the operation, the doctor would come into my room and tell me to walk, he was a really young doctor. People are walking along the hallways with their intravenous injection stand on their hands. When I was walking I came across something like those flowers you see over there. You are not allowed to bring that kind of thing so the hallway is usually stark. Then one day there was a big vase full of flowers. It was during June so the flowers were spring flowers. When I saw the flowers I don't know but I was very moved emotionally. I realized how beautiful flowers were again. Then when I was about to be discharged from the hospital, I had the operation at the end of May and left the hospital at the end of June. After I was discharged from the hospital, when I revisited the hospital as an outpatient I went to the flower shop and bought a lot of flowers. I was prepared to have them rejected and went to the building of which I was hospitalized. I noticed how they looked troubled. So I talked with the head nurse so that they would be able to accept my flowers. Later on the head nurse sent me a letter telling me that patients and families frequently stopped in front of the flowers, and how the flowers made everybody feel better. I was feeling happy for doing what I did, and then you see flowers here too. Flowers make everybody feel better, they have a healing effect. That's why whenever I come here I buy many flowers and put them all around my rooms and enjoy them. I have feelings that I didn't have before so I am enjoying myself even while I am home. That's why I feel that I have changed from before. Thanks to everybody.

\section{Interviewer: Did you have changes in attitude or the way you think after receiving OPT?}

My attitude? I think I am able to maintain a better relationship with my neighbors than when I did before. I live in a high-end region in Tsurumi. I am originally from Meguro which is the low-lying area of Tokyo, the people from there are very friendly and they try to keep close to one another. I am not really good at keeping tight relations similar to that of families towards neighbors. I always had a line drawn across in between my neighbors and myself. When I was married and moved into where I live now, my neighbor would use to be unkind to me because I didn't fit into the community. However after I came in as an inpatient here and came out I was able to open myself up more. I think I have changed. I feel better now. Living is more easier for me. Its more mentally effective, physically I have appetite, I can sleep well, I am enjoying myself, and I can feel that I am recovering. These things are what I think have changed after coming to Ryoin. I don't think I would be this well if I was only staying at the hospital in Kawasaki. 


\section{Interview participant: 16}

Interviewer: What kind of disease are you diagnosed with?

When I was a child I had an accident and my spine had broken into small little pieces these broken pieces grew back together again distorted as I became fully grown. My symptoms became very bad at around 60 years old. The right side of my body hurt from numbness. That's what my condition is like. I have trouble even walking. Now the symptoms are getting much better.

Interviewer: When was the first time that you received OPT? Can you tell me how you came about learning about this method?

One of my friends knew about this, the reason why I started was because I needed an operation on my left eye. I eventually did have the operation. I have a serious illness on my left eye. I emailed my friend that I needed to have an operation, she asked me why I needed to have the operation, and she introduced me how there is another alternative method to getting it better. So I came here with the hope of recovering. The time that she told me was when I went to her place on June $15^{\text {th }}$. That was the first time that I have engaged to this therapy. My eyes will not get better. Needless to say, I had to go through with the operation. However my chronic pain from my spines did feel really better from this time. That's why she introduced me here. I came here at the end of June, and I immediately came back again as an impatient. It took place very recently. My pain from the spine is doing pretty good.

\section{Interviewer: Is your friend a member of the MOA?}

Yes she is, she knew about this from before, but she told me told me about this when I told her I had to have the operation on my eye.

\section{Interviewer: Why did you decide to continue OPT?}

I just wanted to continue doing what is beneficial for my health. I still don't understand this. The places that are hurting me actually feels better and the shrunken parts because of the injury are elongated. To tell you the truth I will try this out for about a year and if there are no positive changes I will probably quit. The price is not expensive, but I live very far from here so I have to stay overnight as an inpatient. While I am here my house does get very messy, however I don't have any jobs now. So I just want to focus on getting my condition better. The reason why I come here a lot recently is when I had the operation on my eye there were many medication involved. This place has a philosophy that medicine is not good for you. I think that eye drop medication is probably not good for you. They tell me I need to get this out of my body through purification of the body, and I agree to this idea.

Interviewer: Did you have that sort of understanding from before? 
I think medicine is not good for you it puts too much strain on the kidneys.

Interviewer: Before coming to know about OPT how did you cope with your condition? I have tried many different home remedies, nothing ever worked on me. There was an excellent physical therapist at an orthopedics hospital. So I went over to him from about three years ago and my symptoms improved a lot. I've learned everything he has to offer me. This person taught me how to exercise rather than remedies or chiropractic treatment. So its kind of like an exercise therapy. I can't fix distorted bone that already have stuck together and grew. So I need to cope with this problem through managing the pain from this. He told me how to do that. He told me almost everything that there needs to know. I thought I need to do something further on my own, but I didn't really think about this kind of thing. Before, I used to swim every day. After my legs became bad, I went swimming but I couldn't swim. I tried to look into the water and watch my legs but it wasn't moving. My muscles have weakened, not weakened but it has become very tight, I was using only my arms to swim so my heart beat became so fast. So I couldn't continue. So I would be able to return back to swimming once my symptoms have become as well as right now, that's when I heard about this. I just had an operation on my eye so I am afraid to swim right now. That's why I am doing this for now.

Interviewer: What were your impression when you first received the OPT?

I don't know, I don't know but somehow I feel well.I haven't studied about this a lot. Especially I can't see with my eyes so well, so I won't be able to read even if I buy books.

Interviewer: Did you experience any differences in feelings after receiving OPT?

Well, if your pain is relieved and lowers down your feelings become well too. I think that is it.

Interviewer: Have you had any differences on how you think?

I don't think my interview fits your research. Before I was introduced to this, I used to sing a lot. I had my first recital on May $31^{\text {st }}$. After less than one week I was diagnosed with this disease. It's my eyes and I am a soprano so I can't sing out loud. I can't sing out loud. Even my teacher got ill. I introduced her here, and she is also coming. She is the instructor for my singing, so two of us are no longer able to sing. My life has changed completely. So I don't care what is good and what is not good, I'm just trying to handle my health condition. I don't think I can be helpful to your research. I don't think my experience is typical. I want to make this clear, but not being able to sing is hard for me. My previous job I had, I had to quit because of my chronic pain. Singing was my purpose in life. It wasn't just my hobby. I was trying to restart my life. For example if I have a fight with my husband right now I won't even be able to scream. That's why I am taking care of my body cautiously right now. So I am sorry, but I don't have anything that is changing mentally due to this therapy. 
Interviewer: Thank you for your honest opinion. How did you introduce OPT to your instructor?

My instructor? She was feeling very ill, she told me she had a gynecological exam and her uterus was scarred. I introduced her to my gynecologist and she went to check it up, but the doctor told her there was no scar. I thought this would fit her because her symptoms were severe. Then she told me this fits her, so that's why she comes here.

Interviewer: Do you two come together as an inpatient?

No, my instructor lives in Tokyo, so I go to her place to take lessons.

\section{Interview participant: 17}

I was diagnosed with pancreatic cancer 4 years ago. I was introduced to Mrs. $\mathrm{N}$ in Higashikurume. I had received OPT once. I received it for about an hour, the feeling of warmth was behind my back while receiving the OPT. I felt the pain relieve a little bit. So Mrs. N introduced me to Tokyo Ryoin, and she took me there with me. I had a checkup done by Dr. M, and I received two sets of OPT for a week each. I also became an inpatient and received OPT. My body got very well.

Then one of my friends introduced me to a ceramic panel sauna. So I received OPT and went to the ceramic panel sauna concurrently and my cancer disappeared after one and a half year. I was really surprised and I felt I was the only one that was getting better among my friends so I wanted to do something that would benefit others too. So I explained about the practice of OPT to my friends. I had the occasion to talk with Mr. T (the staff of MOA), and I was able to administer OPT towards my friend. Then my friend told me that her back felt warm after receiving OPT, while she had pain in the back it was relieved. My friend told me the pain was gone for about three days after receiving OPT and I was surprised. So I asked my friend if she would like to continue this for a much longer duration, and she agreed. I invited my friend to Tokorozawa, everyone was friendly there. My friend is listening to many other different people and is getting better day by day. I heard that the pain in the pancreas has eased off and I am glad to hear this news.

Interviewer: So this Mrs. I is your friend?? Who is Mrs. N?

Mrs. $\mathrm{N}$ is a friend of my friend's friend.

Interviewer: So Mrs. N introduced you to OPT?

Yes, Mrs. $\mathrm{N}$ is a member of the MOA and she has been for a long time. She is also a good friend with Mr. T (staff of MOA). She lives in Higashikurume. She has come over to my house a couple of times. I was introduced to her in Tokyo Ryoin too.

Interviewer: So how did you become friends with Mrs. N? 
The first time that I met with Mrs. $\mathrm{N}$ was through my friend living in Kawasaki. Mrs. N is a friend of her. So she told me that there is a person called Mrs. N, and asked me if I wanted to try it out?

Interviewer: What were your reactions when you first heard about it?

When I first heard about it I was surprised. However I have interest in many things so I decided to try it out and at first I went to my friend's house to receive it and Mrs. $\mathrm{N}$ was also there at that time.

My body felt so light afterwards. Every time she administered the OPT around my pancreas from behind it was hurting. The pain was relieved afterwards so I thought this therapy was really great. After listening to many things she told me if I become a member of the MOA there is a course to train me how to do this, so she recommended it to me.

Interviewer: So all this happened while you were there?

No not while I was there at the first time, after continuing for a while.

I was introduced to Tokyo Ryoin through Mrs. N, and I received OPT for a week twice. I also received it as an inpatient at the clinic. I felt my body feeling better as I continued so I thought this was really good.

Interviewer: So you went Tokyo Ryoin and also to Tokorozawa?

Mr. T introduced me to Tokorozawa I went there and I received my training for my certification there too, and started to volunteer as an administrator. I received my training from Mr. T, for about a year. Then there was the examination for the third level certification and I was able to pass and I received the certificate.

Interviewer: Your pancreatic cancer had disappeared after how long?

One and a half year.

Interviewer: How often did you receive OPT?

I received it about three times a week. I went to the ceramic panel sauna every day. I went to it every single day even if it rained and I would lie on it for about an hour.

Interviewer: What is the ceramic panel sauna?

Well the ceramic panel sauna was developed by the CEO who first discovered an enzyme called ecoparadise in Hokkaido, he became the CEO for the ceramic panel sauna. After listening to what he told me, the enzymes were coated onto the ceramic panels, and the panels are laid beneath the stone sauna. You heat your back from this, the spine. Then what happens is that the metabolism improves, immunity goes up, and cancer cells disappear. This was the explanation which I received and I have been going there every 
single day. I went here and I went to receive OPT which made the cancer disappear in one and a half year. I also had breast cancer 20 years ago. That time I never received chemotherapy also, I cured that cancer through food therapy. I ate only organic and natural grown vegetables I completely abstained from eating meat and dairy products.

Interviewer: So you didn't know about MOA while you had the breast cancer?

No, I didn't know. I knew about Organic and natural farming. I go to yoga class in Yokohama. That place is called Best Culture and they give you information on everything about health. I take yoga lessons there too. I am doing yoga for more than 20 years now. I have studied a lot about food there, so when I was diagnosed with cancer I thought of implementing a strict food therapy. So I have been eating organic and natural food before I had pancreatic cancer.

\section{Interviewer: What made you interested in all these things?}

Before becoming sick and having breast cancer I was extra careful about my health. My parents died young, that's why I had to take care of my whole family. I had the consciousness that I needed to be healthy. For myself to be healthy I changed the contents of everything that I eat. After being diagnosed with breast cancer I realized about health foods and since then I have continued.

I do food, ceramic panel sauna, and OPT those are the three. Also I do flower arrangement classes. I come here receive OPT and after that Mrs. Y introduced me to the flower arrangement class and I go there, this is my second year now for the flower arranging class.

Interviewer: Why did you decide to continue receiving OPT?

At first I didn't know what OPT was about at all, but my body felt better as I continued to receive it. I thought it would be good for me to continue. I thought it would be good if I can do this to others too. That's why I thought of continuing OPT and also studying for the third level certification. The greatest reason is because of my body feeling better.

\section{Interviewer: Have you felt any difference between regular hospitals or conventional} medicine?

Regular hospitals prescribe lots of medicine. They give so many medicines implying that if the medicine is not taken the disease will not be recovered. Then I had adverse side effects from taking too much medication. I sometimes take medicine to treat my asthma. The medicine is steroids. I have continued to take this for about 7 to 8 years. Then my kidney began to have problems. My face got swollen, the doctors told me that my kidney has problems. That's why I stopped taking medicine. So I gradually stopped taking medicine even while having an asthma attack. It becomes painful but I try not to take medication, symptoms eventually become better without the use of medication. I have learned abdominal breathing, and I stopped taking medication for most of the time. 


\section{Interviewer: Recently as well?}

Yes this is how I am now too. Recently I try not to take medicine so much, about once a week, because my asthma is getting better. This is because I receive OPT many times and I also go to the ceramic panel sauna. I am thinking that this should make me well for now.

Interviewer: Do you feel any psychological changes after receiving OPT?

I think when your body gets better you have more energy. I was mentally depressed from the disease but now it feels like it blew away. After staying in Tokyo Ryoin as an inpatient for 3 nights and 4 days and when I came back home, my body felt really well and that moment on I became better mentally. I have always been a cheerful person, but I was really negative for a period of time. I was thinking about many things. When I came back from Tokyo Ryoin I was back to being positive and cheerful, due to my body feeling better. I think that I am returning back gradually. I think this is part of psychological change I have experienced. I am originally a person like this, people used to always tell me that I am cheerful, I don't worry things about relationship with other people too. I can be friendly and talk with any stranger. So my way of thinking has changed, I think things positively now.

I think my attitude has changed as well. I think I am more positive. I am active, I go out to many different places. I am really active, I go to see so many different things. I go out with my friends to eat and drink too. I do these things nowadays. Whenever I get a phone call from my friends I would go out.

Interview participant: 18

About six years ago when I was still working, something I had never experienced has happened suddenly. I started to have rashes all around my arms and legs, which eventually spread throughout my whole body. It was all red and I couldn't do anything about it. So I went to my primary health care clinic, dermatologist, and received a pretty strong medicine, and it was under control. After it was over, the rashes came back over and over again. So I decided to go to a clinic with greater and different level of dermatologists. However it was all the same procedures. I received medicine, which were steroids. They made me put them on. Everything was the same procedure over and over again, experiencing the same painful condition. The next thing I considered was going to an even greater hospital, so I went to the Juntendo University hospital. They immediately hospitalized me, they were telling me that this is a serious condition. However they did not know why this was happening. They just told me that they did not know, the fact was that I was still suffering from pain. This hospitalization occurred about four to five years ago, it was helpless. After that, each year I would have heavy symptoms of rashes appearing all over my body about twice or three times each year, the severity was different each time. Then last year... no last year august was the last time that I had the sudden rashes spreading on my body. So if this was going to continue, not only my body, 
but psychologically I would not be able to handle it any longer, I would get so confused and didn't know what was going on. If this was continuing and I was receiving the same kind of care each time I would not be able to stand it. The common things that I experienced and want to say about going to the doctors is that, the doctors won't listen to what I was saying. It's not that they don't want to listen I think they are too busy, dermatologists. There are so many kids that come for treatment with atopic dermatitis. Even when I had a very severe condition they would just prescribe me medication and say goodbye. This was the cycle which was repeated continuously.

So eventually I came to a solution that I need to look for a better place for my condition. First, I wanted a doctor that would listen to what I have to say. That's when Mr. T's face popped in my mind, he was from MOA. I knew Mr. T from about 10 years ago. I remembered how he told me that MOA was something about natural healing. So I decided to call Mr. T, and he introduced me to the doctor at the Ryoin Clinic.

\section{Interviewer: What were you diagnosed as?}

The name of the illness, I don't think there was a specific name for this illness, they told me it was like multiple eczematosis or something like that which just described the phenomenon of the disease.

\section{Interviewer: So you decided to go to Ryoin to receive treatment as an outpatient?}

Yes, may I talk about it? The story about Tokyo Ryoin. So I was introduced to Dr. M at Tokyo Ryoin. I told the doctor everything I wanted to say to him, I wanted him to listen to me that's why. Well Dr. M listened to me for about one and a half hour. I been to many dermatologists they would only meet with me for a few minutes. They would say good bye. I was very worried so I had him listen to what I had to say. I don't know whether it was accurate, but he told me maybe it was this, or maybe you should do something like this, and etc. He asked me a lot about my lifestyle, for about one and a half hours. So after that I received OPT for about an hour upstairs and left the place. During the session I was really surprised, I have very stiff shoulders. The stiff shoulders felt so well as soon as I received OPT. Nobody would understand me when I told this, even my wife. So I told Mr. T about this, and I asked him if I can continue receiving OPT. Mr. T happily accepted and he came over to my house, and ever since, I have been receiving OPT at my house from Mr. T. After continuing to receive OPT my stiff shoulders became so well. Another thing is that the last time the rashes stopped appearing was around the beginning of October last year. That's when the phenomenon stopped. The time that I went to Tokyo Ryoin was November $3^{\text {rd }}$. Until now what used to be appearing every once in two to three months has stopped appearing, not even once. However, it is not appearing but it's not that it has completely disappeared. Right now you can still see a few spots. Before, when I had one spot, this would spread all around my body. However, right now, one spot appears and that is it. So currently, even if one spot appeared it would stop right there.

What Dr. M had told me was that, he can't guarantee that the rashes would not appear again. However the frequency of the rashes appearing may decrease, and also even if it 
appears there is a chance that it will stop and not spread. He told me to think of it that way. Now I am like this. I still have worries. I constantly fear about the rashes appearing anytime. Right now I imitate Mr. T on how to administer OPT towards myself. Even when I am suffering, I started to gain confidence mentally that it would not be spreading more than this. It might be more of a feeling of relief than confidence, that it would not be spreading like it used to, that's how I am feeling right now. Before, every minute of each day I was not able to forget about it. I was worried about when it will start to appear, do I have to go through the same pain again once it appears, I always had that worry in myself all the time.

Interviewer: So the first time the rashes appeared was about six years ago?

Yes.

Interviewer: So after going to Tokyo Ryoin did you still continue your prescribed medication?

I stopped completely. In the beginning when I saw a few spots, I had a weak mindset towards resisting to use them. It's because I have a lot of them. Each time I changed doctors they would give me large amounts of medication. I have steroids too. I would use to have a hard time making up my mind on whether to use them or not, but I have not yet used them even once. I don't care if they appeared, that's how my mindset has changed. After listening to the doctor at Tokyo Ryoin and Mr. T, that's how I feel now. In another words even if it appeared the severity has decreased to that extent.

Interviewer: Have you ever experienced other CAM modalities before receiving OPT?

No I haven't. At the beginning when I first met Mr. T, he told me about OPT. I think most of the people would have the same kind of reaction, but I wasn't worried about anything that time, so I thought OPT was a joke. I would tell him, it's ok let's stop with what you have to say about this topic. I was like that. Somehow I remembered about it.

Interviewer: A lot of previous interviewees told me how desperate they were.

You are absolutely right. Each time I went to a different place everything was the same. I thought maybe there is nothing available for me anymore and I lost confidence.

Interviewer: The reason you are continuing to receive OPT from November is because your symptoms are becoming better?

Yes you are right. However, I don't have a very strong feeling towards continuing to receive OPT. I received it back then. It's because I can do it myself, even though I am not sure whether I am doing it the right way. I administer OPT towards myself every night, trying to remember how it should be done. I do it whenever I have nothing to do, even when I watch television. This is the way I intend to continue. 
That's why I've only met with Dr. M twice. Then he told me I don't have to come here any longer. He told me to talk with Mr. T. If I go now maybe I'll be a burden to him, he is a busy person. A little while ago, it's been only half a year since I became member of MOA, so there was this orientation meeting. I came to Tokyo Ryoin and listened to the talks. I also spoke with the doctor too. The doctor told me, "you seem to be putting a lot of effort on OPT, you should apply for the certification courses." "If you become certified that means you will be able to gain knowledge that is equivalent to the level of being able to administer towards others." He told me that I'll be able to learn more precisely the way of administering OPT, so he recommended me to take the third level courses.

\section{Interviewer: Have you ever spoken to others about your experience with OPT?}

Well, I don't think I have ever spoken about it towards others. However I have it set up in my mind like this. If I come to realize that there is somebody that has the same kind of worries that I have, or if they ask me for advice I would let them know.

It is like that usually, you don't hear people recommending stuff without regards to other people's condition of health. Once when I was drinking with my relatives, I would never say such thing, but my wife is really happy about it. Because she saw me how much I had been suffering. Whenever she drinks alcohol she talks about my experience towards our siblings. She describes how I was getting better through these things, but most of the time they made fun. That's why I tell my wife not to tell them. Most of the time, I understand their feeling because I felt the same way seven or eight years ago. I been through this and I know that the other people would be shocked to hear this, not shocked but they would not accept it. However if they come to me and ask me what happened to your condition, I would let them know clearly, of course.

Interviewer: Did you have any physical and/or psychological changes you experienced?

Mentally, I have become much better. I was always worried and afraid, but now I don't have that anymore.

\section{Interviewer: Do you feel any changes in attitudes?}

Do you mean attitudes by attitudes towards lifestyle? I think everybody is the same but, you have worries about your condition, so I would not be able to behave energetically, so I refrained from doing things actively. I was always worried what I should do if the rashes started to come out. I would not do things that would tire me out. Meeting people is not really stressful for me but you do feel stress from meeting others. That's why I

didn't go out as much, I think I was like that for a period of time. Everything in my mind was based on my health condition. Now I don't have that at all. I can live with confidence.

I believe that integrative medicine is very rational. It is more of a medicine than what western medicine is, it is eastern medicine right? Taking care of the psychological and spiritual part of a person. Or Disease prevention. I think both are important. I have been 
feeling this way from a long time ago. I was really surprised when I actually saw OPT, however as for my perception, I think this is right. You say illness and health start from the mind. I think it is a very important element.

Interviewer: Previous interviewees told me that they were surprised at first however what the doctors and the staff tell you at the clinic make sense and a lot of things they heard were convincing. That's why they started receiving OPT without feeling uncertain.

I can understand that. But one step before that, I was not a kind of person that would get involved with the doctors so much. I have met a lot of doctors in dermatology, each doctors specialized in western medicine. I didn't think they were doctors, I didn't want to approve that they were. The reason is because they won't try to understand the suffering that the patients are going through, they would not try to listen. If I were to describe them, they are only robots. Making decisions based on phenomenon. Medicine is supposed to be a healing act or benevolence, they are supposed to respond to psychological and spiritual needs, being able to listen, after those needs are met the physical aspect of the body becomes better. If doctors lack those elements, then they are not, I don't know doctors from other specializations but I thought the doctors specializing in dermatology were the lowest. However they are doctors, I feel that for people with problems with skin, many of the reason behind the symptoms comes from mental and psychological things. Most of the doctors were like that, they were awful. I can understand that they are busy. There were no doctors that would show me a way to try to approach my illness from that kind of aspect. That's why if I come across anybody that has problem with their skin I would like to let them know about OPT.

Interview participant: 22

\section{Interviewer: How did you come to know about OPT?}

My son did not feel well. He became member of MOA.

He had atopic dermatitis, he would have been good if he never went to the doctors. His dermatitis worsened from using steroids, he had steroid dermatitis. This was when he was in high school, once he stopped using steroids, there was a huge backfire, but he couldn't go back to using steroids because he knew now the danger of using it. We went to the Kusatsu hot springs. He felt good while we were there, because the air and water quality is good, he was able to sleep well during the night too. After several years the symptoms build up and started to worsen. He had to repeat two years of high school, but he still managed to go to college, but he didn't feel well. His face didn't have so many symptoms at first, but eventually it spread to his face, he was no longer able to go to college. He was not able to make a lot of friends too. At that time there were cafés where you saw a lot of kittens. He asked me to come with him to one of the cafes with kittens. I felt pitiful for him but I went with him. When I saw him hug the kittens and seeing him relaxed, I felt like I had to do something about it. When my son was in kindergarten his friend's grandfather used to be in this religion, he was in this religion from when he was 17 years 
old. I heard that his lungs were bad after building airplanes during WWII, and his condition was cured. From receiving Johrei. Then he had a lot of influence and I heard that a baby with dermatitis all around the body was cured in one month, or a terminal tuberculosis patient was cured. I heard about these stories so, I thought seeking for help towards religion was our only way. The name of this person was Ms. S, I asked Ms. S for help, and so she introduced me to another person named Ms. T. I heard then that MOA was not a religion, I heard that there is this organization called MOA. So I thought it would be nice if my son gets in to this organization. He became a member. This was four or five years ago. So my son went to receive OPT during the spring break, and then spring break was almost getting to be over so he asked me to become a member so that I can learn how to practice OPT towards him. So I joined, and administered OPT to my son every day. I received a manual on how to administer so I think it is written inside. My son has dermatitis so I don't want to touch his body so much. There are places where he looks hurt, and you can't really tell over his clothes. He has so many scabs around his body, that's why I used to do it with my eyes closed. My son would tell me to open my eyes and do it, but closing my eyes became my habit. So I was practicing OPT on my son for about two to three years, after that I became certified as a third level practitioner, but I am still not confident. What I felt was very mysterious was when I was administering OPT to my son and when my hands somehow felt like it was hitting the spot, my son would use to burp, he was facing the other direction so he was not able to see, so I thought this actually might be working. At first my son was probably full of toxins, once I started administering OPT towards him I soon felt dull and sleepy.

Another thing that was mysterious was when I was certified, and after three or four days, my neighbor, she knew about MOA while she was living in Kyushu, she had a sprained ankle and her friend healed it through OPT. So I heard about these stories, and I told my neighbor that I am also certified so I can administer OPT. This person has recently fallen in her house and hit her back. So I went to her house, we were very close. I was not sure which part of the body to administer, but I thought maybe the lower back, so I administered OPT towards the lower back. I was just doing it abstractly. This person fell asleep, so I thought well people can fall asleep if they are lying down. When I told her later, she told me she would not sleep so easily. But she still fell asleep, so I was at this person's house and the owner has fallen asleep, I was feeling troubled. I didn't want to wake her up too. Then the next day she came to me and told me that her pain was gone and she had recovered. She then told me that there is just one remaining place, that's where I didn't administer the OPT. So I thought again that maybe this OPT works. That's how it was.

So I was practicing OPT on my son almost every day, and my son would return me the favor only sometimes. He does it to me a lot recently though. Two years ago I became very sick. So I went to the Tokyo Ryoin clinic, they told me maybe you became sick from the hot summer weather. I didn't have a medical check-up for a while so the doctors advised me to have a comprehensive medical check-up. We did blood sample test, urine sample test, x-ray and the electrocardiogram. My mother had diabetes, but when I had a blood sample test four years ago I didn't have diabetes. That's why I was not worried about it. Then the doctor from the clinic called me the next day and told me on the answering machine that he needed to tell me something very important about the results 
of the medical test. I was really surprised and called and he told me I had serious case of diabetes. I had a friend who told me that diabetes will not be cured from OPT. My son's condition became like that because of the hospitals and doctors. So I distrusted them, and I didn't want to rely on them by all means. I also didn't want to rely on medicine. I felt like I don't mind if I die from this anyways. But when I received OPT once a week my body feels well. What were we talking about??

Interviewer: I was listening to how you came about receiving OPT.

So the reason was because my son told me to join, and I was like, ok. So is this ok?? Is the interview over??

Interviewer: Before being introduced to OPT did you do anything in particular for maintaining health?

I was weak from when I was little. So I feel like this is how it always is. But I feel that if you practice OPT to others all the time you will feel tired. So I thought I should be receiving this too. I was doing this every day to my son.

Also the reason why I am having diabetes is because of the tremendous stress I received from the earthquake. Because of the earthquake I was really worried about the nuclear power plant. I thought that Japan was coming to an end, probably. After that I try not to worry about it too much when I hear something on the news about it. Nothing will change whether I keep worrying about it or not.

Interviewer: So do you go to the doctors to receive medication?

I want to go to the hospital just to see the level of A1c of hemoglobin, that's what I am feeling. If I go to the hospital I think my levels are very high, and I would be put into a specialized place. If I do go to the specialized place I know that I will be soaked with medication. I am eventually going to die anyways if so I thought the earlier the better because I don't want other people to have the burden of caring for me.

I do feel like I want to let other people know about OPT. However with the condition I am in now, it is not really convincing. My husband when he tells me that his heel hurt or when his heart hurt I do OPT on him and he gets well. But when it comes to healing myself I feel like it might be difficult.

Interviewer: Do you feel any psychological changes from receiving this therapy? Well mentally, I feel like I am being protected. I try not to push too hard nowadays. When I went over to my friend's house there was a cat there. It's a cat with an interesting history, the cat usually goes away when someone else is here. My friends name is called Ayachan, several years ago when she was cleaning up garbage she found a dead cat. She felt bad for the cat so she took it home and buried it in her backyard. The cat that she has now was brought over by a golden retriever that lives in the neighborhood. I think the dog was brought it over by holding it in his mouth. She is telling me that the cat is probably a reincarnation of the dead cat, because the cat looks so similar. She started to keep it as a pet at her house, the cat has eyes which conveys strong emotion, its that kind 
of cat. I went to Ayachan's house and we talked for about one or two hours. Until then the cat was next to us we weren't able to see it though. I explained to her about OPT and offered to do it to her, and she agreed and wanted me to do it. As soon as I started OPT the cat was so quiet before then but it started to cry out a lot. The cat was crying for the whole time. Then when it became quiet it went outside. I think the cat was able to sense something. These kinds of things happened, that's why whenever I administer OPT I feel that Okada is helping me out. I once administered OPT towards a stray cat once from behind. Then the cat became round. That's why I knew it was working. That's why I think Okada is helping me. 
VITA

\section{HIDEAKI TANAKA}

Born, Shizuoka, Japan

2002-2006

B.A., English Language and Studies

Sophia University

Tokyo, Japan

2007-2009

MPIA, Human Security

University of Pittsburgh GSPIA

Pittsburgh, Pennsylvania

2010-2015

Doctoral Candidate

Florida International University

Miami, Florida

\section{PRESENTATIONS}

Tanaka, H., Kimura, T., (2013). Predictors of Quality of Life and Perceived Stress Among People with Chronic Illness. Poster presented at the annual conference of International Society for Quality of Life Research, Miami, Florida. 